Portland State University

PDXScholar

Spring 5-20-2013

\title{
Neighboring in Strip City: A Situational Analysis of \\ Strip Clubs, Land Use Conflict, and Occupational \\ Health in Portland, Oregon
}

Moriah McSharry McGrath

Portland State University

Follow this and additional works at: https://pdxscholar.library.pdx.edu/open_access_etds

Part of the Gender and Sexuality Commons, and the Urban Studies and Planning Commons Let us know how access to this document benefits you.

Recommended Citation

McGrath, Moriah McSharry, "Neighboring in Strip City: A Situational Analysis of Strip Clubs, Land Use Conflict, and Occupational Health in Portland, Oregon" (2013). Dissertations and Theses. Paper 1046. https://doi.org/10.15760/etd.1046

This Dissertation is brought to you for free and open access. It has been accepted for inclusion in Dissertations and Theses by an authorized administrator of PDXScholar. Please contact us if we can make this document more accessible: pdxscholar@pdx.edu. 
Neighboring in Strip City:

A Situational Analysis of Strip Clubs, Land Use Conflict, and Occupational Health in Portland, Oregon

by

Moriah McSharry McGrath

A dissertation submitted in partial fulfillment of the requirements for the degree of

Doctor of Philosophy

in

Urban Studies

Dissertation Committee:

Sy Adler, Chair

Carl Abbott

Lisa K. Bates

Paula Carder

Margaret Everett

Portland State University

2013 
(C) 2013 Moriah McSharry McGrath 


\begin{abstract}
A lack of land use controls on sexually oriented businesses contributes to the unique configuration of Portland, Oregon's strip clubs: nearly fifty clubs are distributed throughout the city's neighborhoods. Considered a locally unwanted land use (LULU) by many, these strip clubs are regulated by a variety of formal and informal social processes in the absence of zoning. This qualitative study explores drivers and constraints shaping the spatial configuration of Portland's strip club industry as well as influences on land use conflict at strip club sites and working conditions for women who work as exotic dancers in the clubs. Data collection entailed review of documents (newspaper articles, legal and administrative decisions and records, and ballot measure pro/con statements); site observations; and in-person interviews with exotic dancers, strip club owners and managers, public employees who deal with strip clubs in their line of work, and people who live and work near strip clubs (n=43). Analysis follows Clarke's (2005) situational analysis methods. The study finds that strip clubs are not necessarily incompatible with residential locations and that such locations can confer benefits to dancers. The normalization of strip clubs in Portland decreases the place stigma associated with strip clubs but has a lesser impact on the person stigma of being an exotic dancer. With regard to land use conflict, the study finds that tolerance of sexual commerce is associated with urbanicity and that neighborhood socioeconomic status has a more complex relationship to community response than is suggested by
\end{abstract}


the literature on land use conflict. Based on these findings, the dissertation argues that conflict resolution programs may be more effective than zoning at managing potential negative effects of sexually oriented businesses, and that improving working conditions for exotic dancers is a complex challenge. It proposes broader adoption of the sex work discourse, including the integration of labor issues in sex industry to advocacy efforts on behalf of other freelance and service sector workers. 


\section{Acknowledgments}

I am deeply appreciative of the time and assistance of the participants in my study, who shared their experiences to help me answer my questions about our community.

I am also indebted to the people and programs that nudged me along the path to completing this dissertation. I am especially grateful to have received this support from my dissertation committee. My chair Sy Adler has been patient, pragmatic, and deeply generous with his time and wisdom. The rest of the bunchCarl Abbott, Lisa K. Bates, Paula Carder, Margaret Everett, and Stéphanie Wahabhave shared myriad gifts, including but not limited to curiosity, creativity, humor, collegiality, and problem-solving acumen. Perhaps most valuable has been everyone's relentless positivity, which enabled me to drag myself into their offices for help when I was feeling less than sparkling about my work. I am also appreciative of the rest of the faculty and staff of the School of Urban Studies and Planning and the School of Community Health, including my field exam committee members Ellen Bassett and Karen Gibson, whose approachability and commitment to student learning have made it easier to see myself as a scholar.

And a million thank-you's to the rest of my honor roll ...

Conduct field observations Callahan, for going above and beyond the call of duty to transcribe, proofread, tolerate kvetching, and wait endlessly.

Smart girls Lauren Larin and Nicole Iroz-Elardo, for support, camaraderie, ingenuity, volunteer transcription, and opportunities to grow together. And the 
smart women we're trailing after, for being real and fun people to follow: Loulie Brown, Maria Gilson deValpine, Meg Merrick, and Andrée Tremoulet.

The Community Research Group and the Urban Studies Writing Interest Group, my communities of scholars and cheerleaders.

Claire Smith, for volunteer transcription.

The hired hands whose professional talents helped keep me moving when momentum waned: Mary Ann Cincotta, Stacey Kirk, and Katie Van Heest.

The various employers and underwriters who have enabled my long tenure at the university: the American Public Health Association Environment Section; the Association of American Geographers Urban Geography Specialty Group; Anne, Jack, Margaret, Mary Ann Spellman, and W. Patrick McGrath; the Multnomah County Health Department; the CDRC and HIV programs at Oregon Health and Science University; the Academically-controlled Auxiliary Activities Fund, Artisan Economy Project, Center for Academic Excellence, Feedback Between Urban Studies and the Environment project, Marie Brown Travel Fund, Oregon Laurels Scholarship Program, Oregon Sports Lottery Scholarship, Portland Edge Scholarship, Population Research Center, School of Community Health, School of Urban Studies and Planning, and University Studies Program at Portland State University; Stephanie Rosselli; and the USDA Supplemental Nutrition Assistance Program. 


\section{Table of Contents}

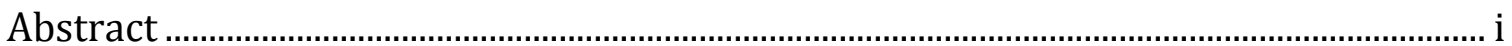

Acknowledgments ...............................................................................................................

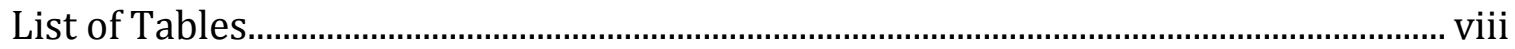

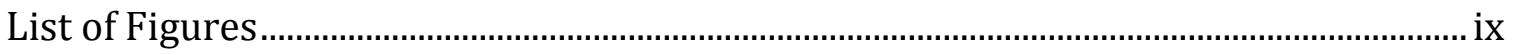

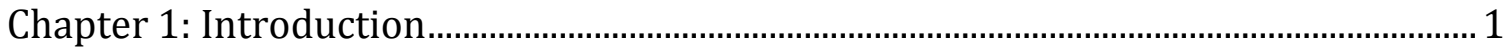

Background and Problem Statement ........................................................................ 2

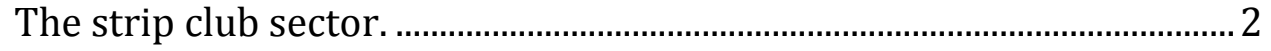

Strip clubs in the community setting............................................................. 7

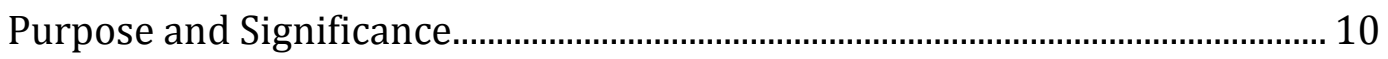

Conceptual Framework......................................................................................... 11

Research Questions and Sensitizing Concepts.......................................................... 13

Overview of Methodology ..................................................................................... 14

Organization of the Dissertation ............................................................................. 16

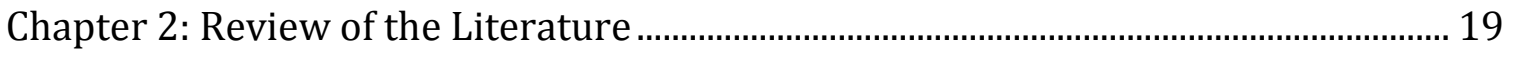

Sexual Commerce in the City.................................................................................. 20

Response to Sexual Commerce................................................................................ 24

Local resistance to sexually oriented businesses. ................................... 25

Spatial stigma and social distancing. …....................................................... 28

Scholarly Understandings of Exotic Dance............................................................. 31

The exploitation question.......................................................................... 32

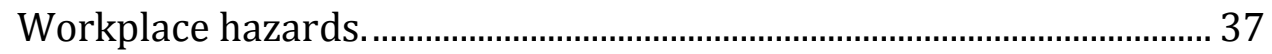

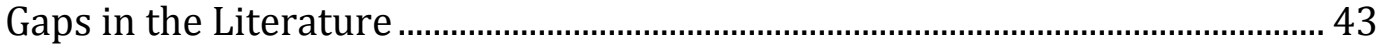

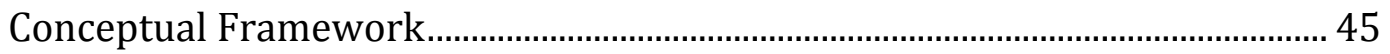

Summary of Literature Review ............................................................................. 48

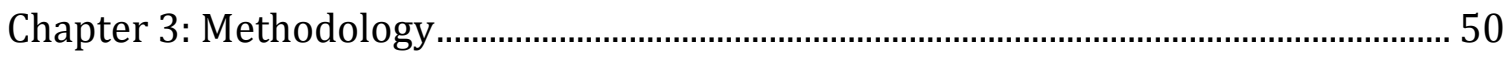

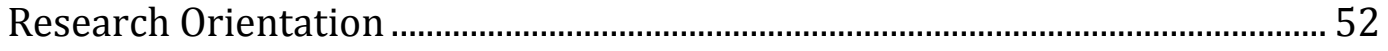

The qualitative tradition............................................................................ 53

Situational analysis............................................................................... 55

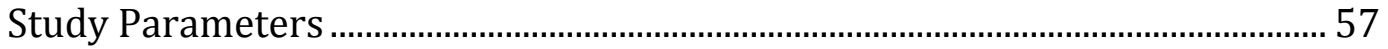

Research Sample and Data Sources........................................................................ 59

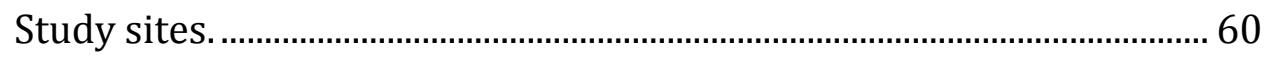

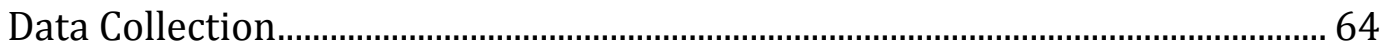


vi

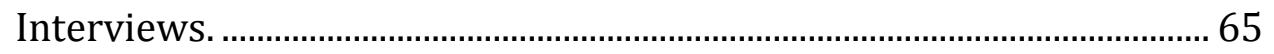

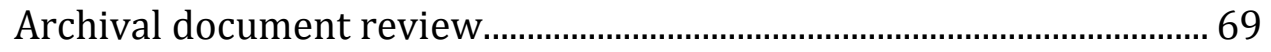

Field observations and GIS. ..................................................................... 71

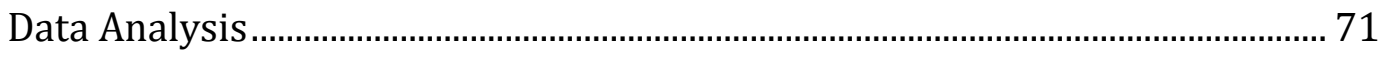

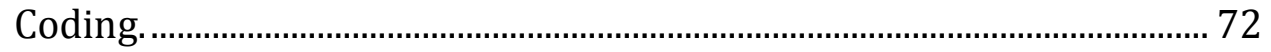

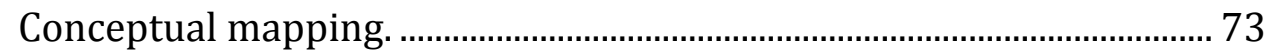

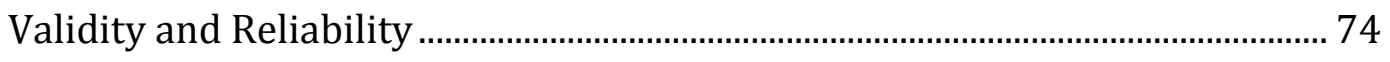

Role of the Researcher............................................................................................ 76

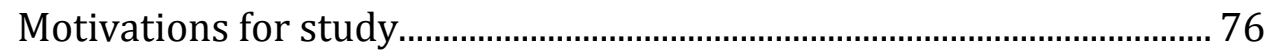

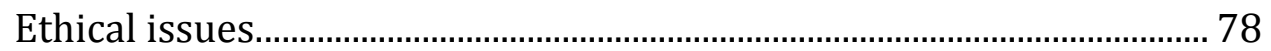

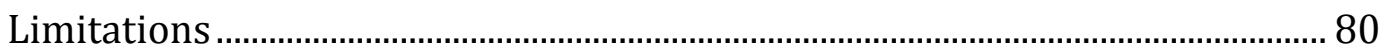

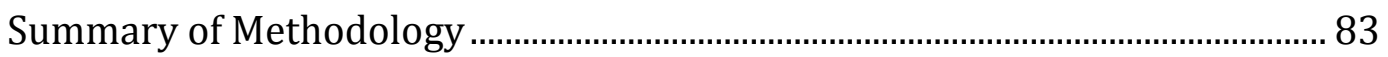

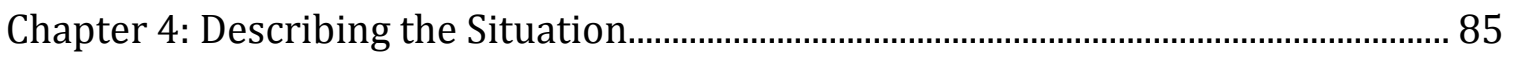

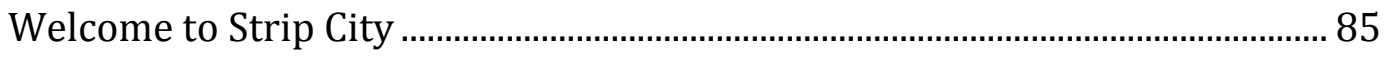

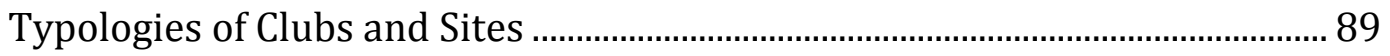

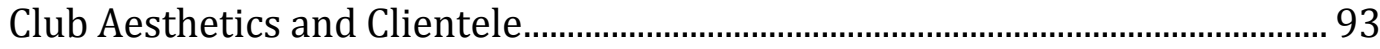

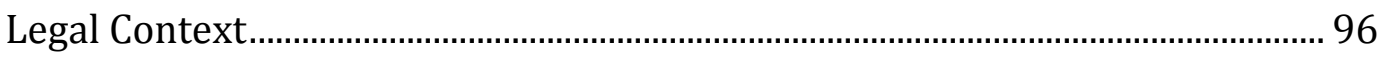

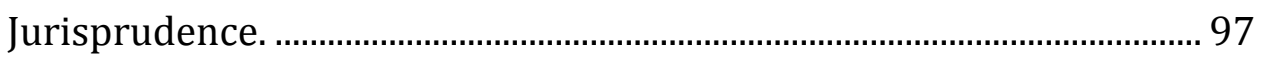

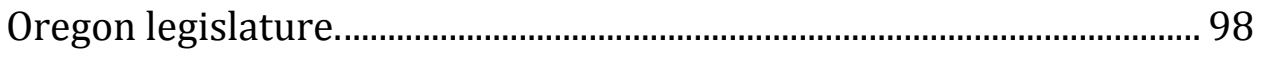

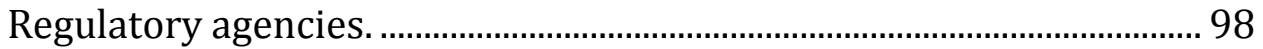

Municipal ordinances. ............................................................................ 99

The ballot box. ............................................................................................. 100

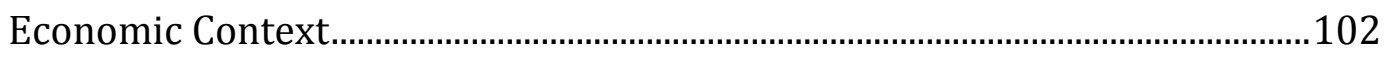

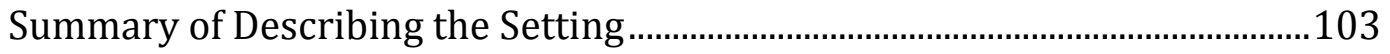

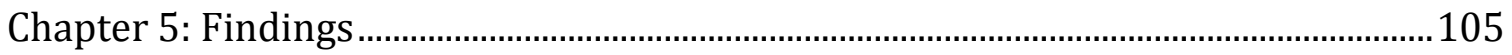

Research Question 1: Local Context...................................................................106

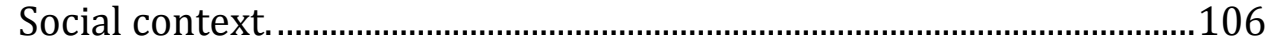

Research Question 2: Land Use Conflict .................................................................113

Conflict and coexistence........................................................................114

Embrace.....................................................................................114

Indifference. ................................................................................ 115

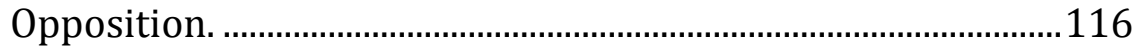

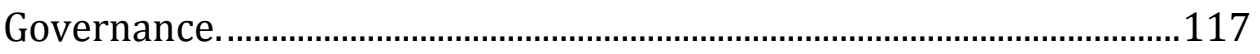

State level.................................................................................. 118

City level ........................................................................................ 124

Neighborhood characteristics.................................................................136 


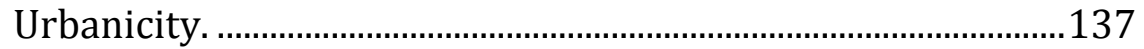

Socioeconomic status (SES).....................................................143

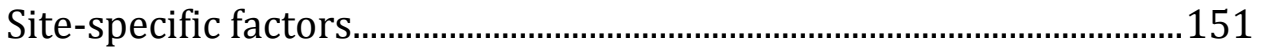

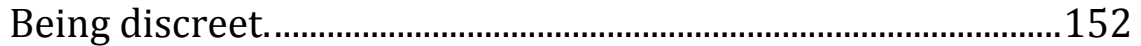

Cultivating relationships.............................................................156

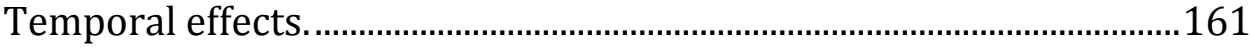

Research Question 3: Dancer Experience ..............................................................162

Working conditions...................................................................................... 163

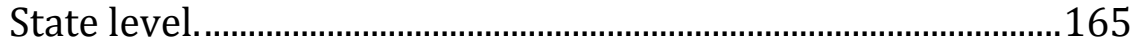

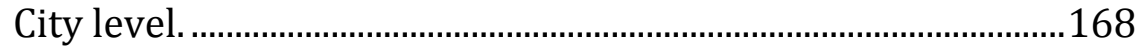

Neighborhood level....................................................................171

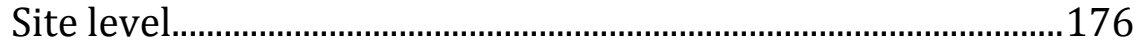

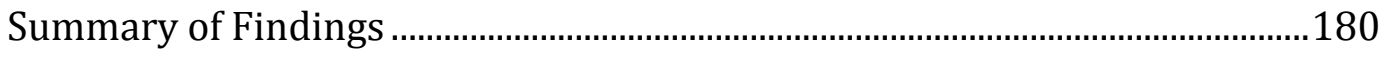

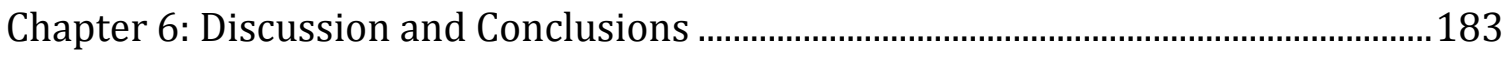

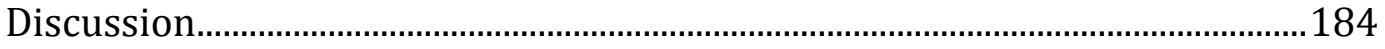

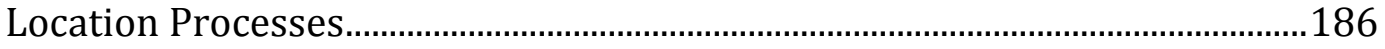

Neighbor Response ..........................................................................................195

Dancer Experience ...............................................................................................199

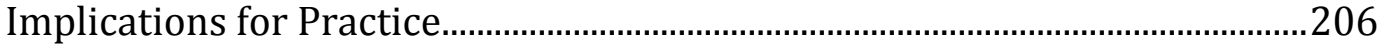

Urban planning practice.......................................................................207

Public health practice.............................................................................210

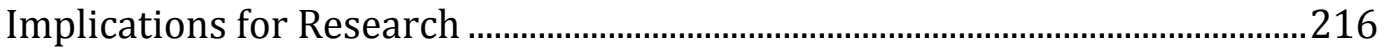

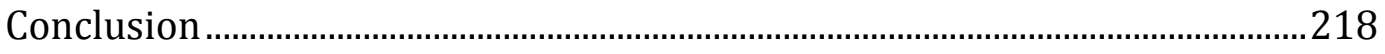

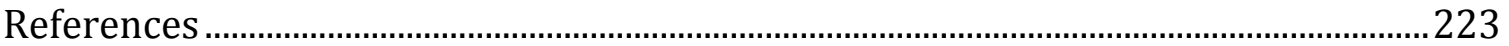

Appendix A: Human Subjects Research Review Committee Application ....................254

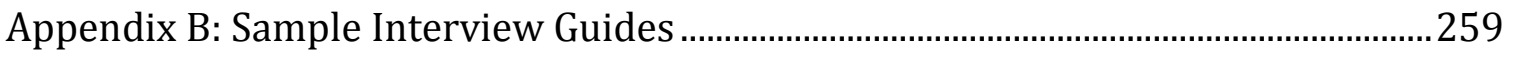

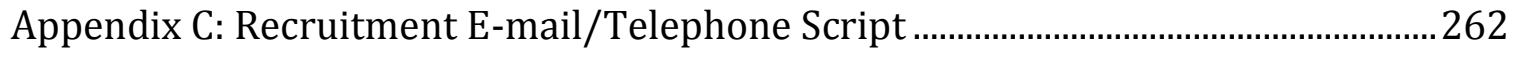

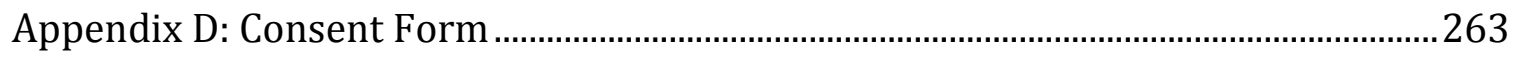

Appendix E: Categories by Analytical Axis and Spatial Scale .....................................266

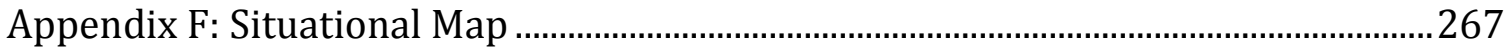

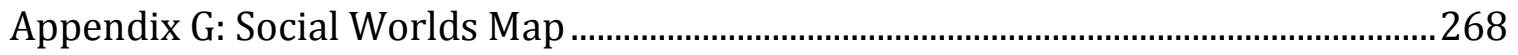

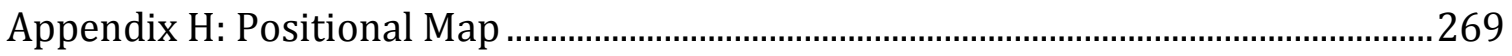




\section{List of Tables}

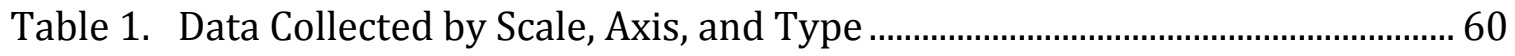

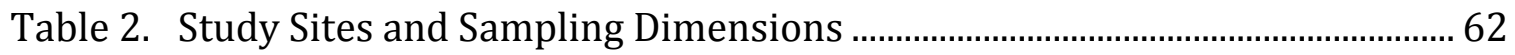

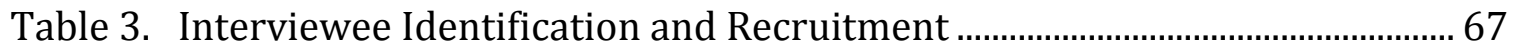

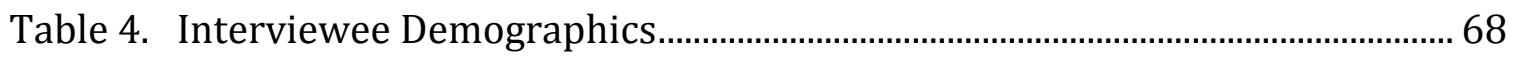

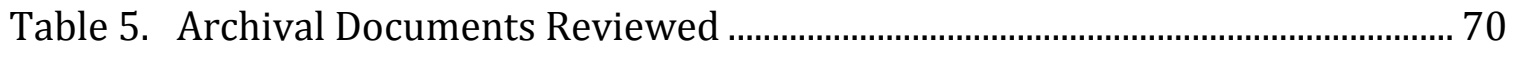

Table 6. Documents Produced During Data Analysis ........................................................ 72

Table 7. Votes on Referenda Proposing Increased Restrictions on Sexually Oriented

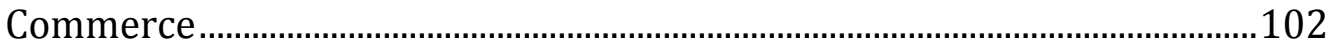




\section{List of Figures}

Figure 1. Estimates of count of strip clubs in the U.S..................................................... 5

Figure 2. Estimates of count of exotic dancers in the U.S.................................................. 5

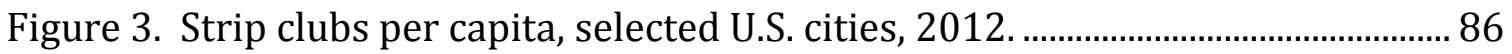

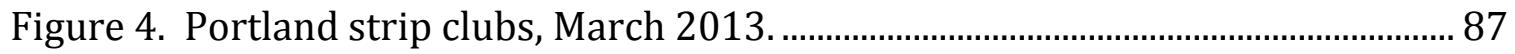

Figure 5. Portland strip clubs and land use designation, 2013.................................... 91

Figure 6. Portland strip clubs and population density, 2010 population, 2013 strip

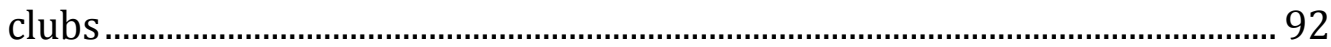

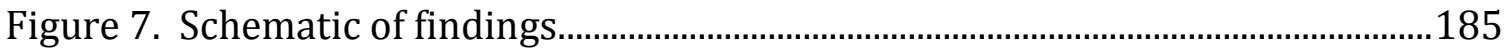




\section{Chapter 1: Introduction}

This dissertation explores the influence of place on strip clubs-bars where exotic dancers perform nude-in Portland, Oregon, focusing on three key issues: where strip clubs are located throughout the city, how residential and commercial neighbors respond to living and working near strip clubs, and the work experience of female exotic dancers who perform at the clubs. These issues were studied by employing situational analysis methods (Clarke, 2003), defining strip clubs in the city of Portland as the situation of interest. This inquiry was inspired by my own surprise, curiosity, and concern about the high visibility of strip clubs in the city. I was surprised by the quantity of strip clubs, their proximity to residential and community facility land uses, and the seemingly high level of acceptance of these historically stigmatized establishments. Living and working in "Strip City," as Portland is sometimes called, I was curious about what determined where strip clubs located, how people felt about living and working near strip clubs, and how working in this environment affected the experience of women working as exotic dancers. Having read extensively about poor working conditions in strip clubs prior to beginning the study, my concern lay in the potential that thousands of Portland women might be exposed to poor conditions in the city's clubs-though I was also hopeful that the apparent local tolerance of strip clubs might confer benefits to dancers. 


\section{Background and Problem Statement}

Strip clubs are one facet of a vast "adult entertainment" industry that includes legal, quasi-legal, and illegal sexually oriented commerce. Among strip clubs, there is great diversity in terms of aesthetic, price point, and conduct occurring on the premises. Exotic dancers, or "strippers," are sex workers, service workers, and contingent workers-experiencing both the benefits and disadvantages of each of these types of work.

This dissertation addresses two problems related to strip clubs in Portland, Oregon: land use conflict and health hazards. While these problems can occur in any setting, the potential for conflict related to strip clubs may be elevated in Portland due to an atypical regulatory environment and the propinquity of strip clubs to a wide variety of land uses. The challenges of land use conflict and poor working conditions in strip clubs are notable on their own, but become particularly salient in the context of the rapid expansion and reconfiguration of the sex industry. A better understanding of the dynamics of these problems is important at this historical moment because the industry's growth is likely to introduce these problems to many communities and could potentially exacerbate them in places where the industry is already present.

\section{The strip club sector.}

In most American strip clubs today, women perform for a predominantly male audience. These exotic dancers arrive on stage in skimpy costumes and remove items of clothing over the course of a dance routine performed to recorded music, usually for the duration of two or three songs. In many cases, the stage 
includes a floor-to-ceiling metal pole that the dancer may incorporate into her routine. While dancers perform, customers tip them by placing money or scrip on the stage or into the dancer's garter belt. Dancers earn these tips in lieu of a wage, and often pay the club management a stage fee for each shift they work. After completing her stage set, a dancer may go backstage or circulate on the floor of the club. On the club floor, dancers may earn money by performing private dances for individual customers. Dancers may keep some or all of the money customers pay for these private dances and may earn a commission on drinks purchased by customers in their company. Not all clubs offer private dances and those that do may also provide private rooms where dances are performed for an additional fee. Clubs vary in how much time their performers spend on stage versus working the crowd and in whether private dances-either on the club floor or in VIP rooms-are offered.

While strip clubs may be perceived as marginal places, they are not a trivial part of the U.S. economy or culture. A 1991 study found that 11 percent of Americans had been to a topless nightclub in the past year (Weitzer, 2000a) , which accords with another analysis of the National Health and Social Life Survey that estimated that 17 million Americans made 67 million visits to strip clubs in 1992 (T. J. Brooks, 2008). These figures are probably even higher today, since the number of strip clubs has likely increased more than two-fold in the intervening years (LiepeLevinson, 2002, estimates that the number of clubs doubled between 1987 and 2002). There are likely at least 3,600 strip clubs in the U.S. today (Bradley, 2008) with an estimated 300,000 people working as exotic dancers (Jeffreys, 2008)—a 
sharp increase over an estimated 68,000 dancers in 1997 and just 8,000 in 1960 (C. J. Forsyth \& Deshotels, 1997). By contrast, the fields of professional dance and choreography combined accounted for only 25,600 jobs in 2012 (Bureau of Labor Statistics, 2013).

However, because there is no consistent tracking of the number of strip clubs or people working in them, estimates for these numbers vary widely. A leading market research firm suggests just below 5\% growth for the industry between 1997-2012 and 2012-2017 (McBee, 2012). Figures 1 and 2 below chart estimates of the number of clubs and dancers, respectively, cited in scholarly literature and major media sources to illustrate the rapid expansion of the strip club industry in the U.S. There is no single consensus on the reasons behind the expansion of the U.S. strip club industry, but theories include a rapid sexualization of popular culture facilitated by evolving information and communication technologies (Levy, 2005; McNair, 2002) and new "postfeminist" expressions of women's sexuality (Evans, Riley, \& Shankar, 2010a; Nally, 2009). 


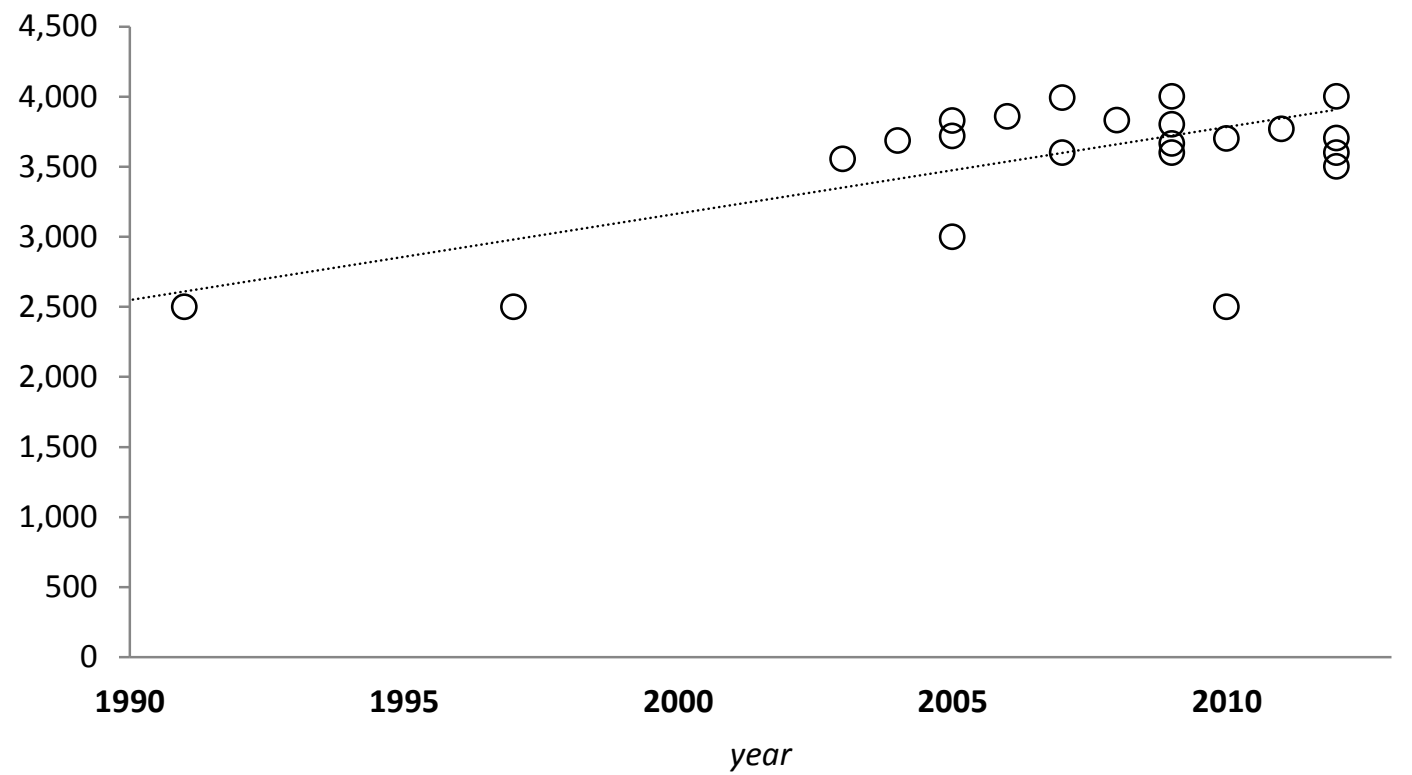

Note. Estimates drawn from (Bradley, 2008; Brents \& Hausbeck, 2010; C. J. Forsyth \& Deshotels, 1997; Hanna, 2005; Liepe-Levinson, 2002; McBee, 2012; Rick's Cabaret International Inc., 2009, 2012; The Ultimate Strip Club List, 2013; VCG Holding Corp., 2009, 2012).

Figure 1. Estimates of count of strip clubs in the U.S.

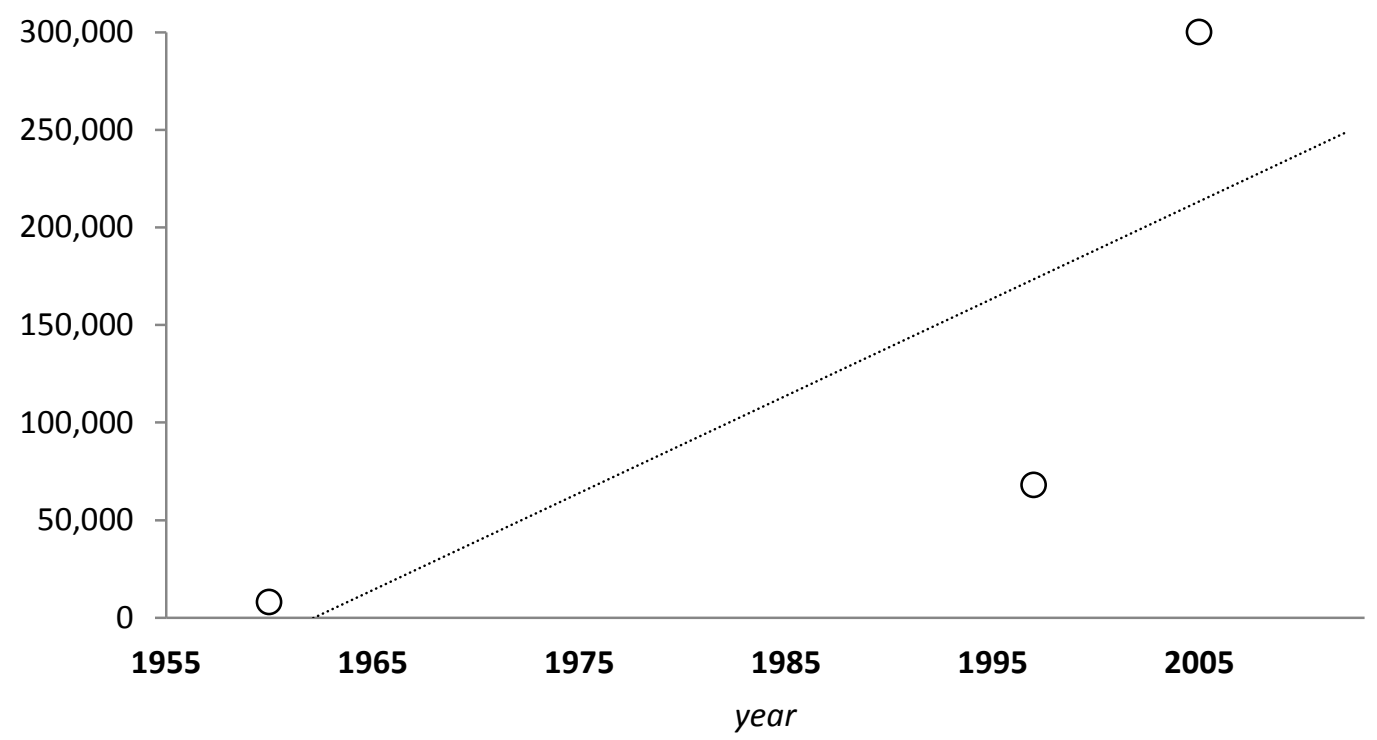

Note. Estimates drawn from (C. J. Forsyth \& Deshotels, 1997; Jeffreys, 2008).

Figure 2. Estimates of count of exotic dancers in the U.S. 
Strip clubs are not only numerous, but are also big business. By 1997, Americans spent "more money at strip clubs than at Broadway, off-Broadway, regional and non-profit theaters; at the opera, the ballet and jazz and classical music performances-combined" (Schlosser, 1997, p. 44). Media and industry estimates may exaggerate the size of the sector (Ackman, 2001), offering figures as high as $\$ 15$ billion for annual spending at U.S. strip clubs-as compared to $\$ 4$ billion on the "national pastime" of baseball (Jeffreys, 2008). A leading market research firm puts the statistic at $\$ 7.4$ billion in 2012 (McBee, 2012). Tax filings by publicly traded strip club companies suggest high profit margins, for example, an individual club netting $\$ 300,000$ a month (W. Sherman, 2007). West and Orr (2007) report that high-end clubs in large urban areas may gross up to $\$ 20$ million annually, indicating that clubs are integrated with many other aspects of the economy through wholesale purchases of food, alcohol, and furnishings as well as payroll for workers who do receive a wage (such as bartenders and bouncers).

This growth in strip clubs comes in the context of a larger sex industry that is changing in size and structure. Schlosser (1997) has documented both the broad consumption of sexually explicit materials by Americans and the entry into the sex industry by mainstream firms like hotel and telecommunications conglomerates lured by the desire to share in the profits. Drawing on Sangera (1997), MatickaTyndale, Lewis, and Street (2005) contend that the sex industry has expanded beyond the traditional "first tier" in which women migrated to sell services in areas with concentrations of single men to include a "second tier" that is spatially diffuse 
and serves as entertainment for the middle class. The burgeoning number of strip clubs that bill themselves as "gentlemen's clubs" illustrates this phenomenon in the U.S. (Bradley, 2008; Liepe-Levinson, 2002). The increasing presence of clubs in more mainstream commercial districts is likely to provoke conflicts over these concomitant spatial and social changes (Hubbard, 2009; Hubbard, Matthews, \& Scoular, 2009). Other recent changes in the industry, including consolidation, new payment structures, and increased supply of sexually explicit materials, have disadvantaged workers and heightened the vulnerability women of color and women of lower socioeconomic status (Bradley, 2008; S. Brooks, 2010a, 2010b).

\section{Strip clubs in the community setting.}

In most U.S. states, strip clubs are permitted by law. The Supreme Court has repeatedly given cities and states wide leeway to regulate sexually oriented businesses in their jurisdictions, citing the imperative to protect public welfare over what have been deemed minor concerns about infringing on free speech (Lasker, 2002). Consequently, state and city regulations vary widely in terms of how much clothing performers may remove, how much clients and performers may touch each other, and whether alcohol may be served.

In Oregon, strip clubs are subject to fewer restrictions than in most other states. Dancers may perform nude, and clubs may serve alcohol and locate in any area that is zoned for commercial use. The lax regulatory climate is the result of a state constitution whose free speech clause is more stringent than the federal constitution's, protecting obscenity as free speech and precluding municipalities from regulating sexually oriented businesses any differently than other businesses. 
Portland, the largest city in Oregon, has the most strip clubs in the state and is generally viewed as the hub of sexual cultures. The city's consequent reputation as a haven for strip clubs and other sexually oriented businesses has earned it nicknames like "Pornland" and the aforementioned Strip City. ${ }^{1}$ Portland's strip club scene is described in greater detail in the Strip City chapter.

Strip clubs are generally considered locally unwanted land uses, or LULUs (Popper, 1981) and often become embattled spaces as a result (Hubbard, 2008, 2009). In many parts of the U.S., conflicts over sexually oriented businesses are forestalled by land use policies that relegate these LULUs to industrial zones and other peripheral areas. However, due to unusual provisions in the Oregon State Constitution, Portland and other cities in the state are barred from creating land use statues that specifically address sexually oriented businesses. My anecdotal observations prior to beginning this study suggested that multiple strip club locations in Portland were sites of controversy.

Strip clubs are a social as well as spatial problem due to their labor practices. Strip clubs rely heavily on women's labor yet do not provide any compensation for dancers' work, which entails a wide variety of physical and psychological hazards (described in further detail in the Literature Review chapter). Dancers are a strip club's main attraction, yet they pay a fee to work and are required to share their tips with management, door staff, and bartenders - thus subsidizing the pay of all club employees. A study of clubs in five North American cities indicated that fees, fines,

\footnotetext{
1 The Strip City term plays on "Rip City," a nickname for the city associated with the city's National Basketball Association franchise, the Portland Trailblazers.
} 
quotas, and "tipping out" other club employees can cost dancers half of the money they gross (Liepe-Levinson, 2002). Even at one San Francisco peep show where workers do earn an hourly wage, minor transgressions could result in permanent wage reductions (Miss Mary Ann, 2006).

Because exotic dancers are treated as independent contractors, they have no recourse to the civil rights protections that protect workers in other settings. Like temporary or on-call workers and freelancers, exotic dancers are members of the growing contingent workforce that faces exclusion from benefits traditionally provided by employers; limited recourse to confront unfair labor practices; and impediments to savings, retirement planning, and other kinds of financial security. Exotic dancers also experience the unique challenges of being sex workers, or people who earn money or goods through providing sexual services. Sexual services may include intimate physical contact, as is provided by brothel workers, or not include contact at all, such as the services provided by phone sex operators. Exotic dancers fall in the middle of this spectrum, because they may have physical contact with their clients during private dances, yet they traffic primarily in fantasy. For this reason, and because of the political associations of the term (Boris, Gilmore, \& Parreñas, 2010), many exotic dancers reject being labeled as sex workers. I choose to use the term, however, because I believe that dancers are indeed performing work and that the failure to identify it as such can heighten their disadvantage in the workplace (Colosi, 2011; Gall, 2007, 2010). Boris et al. (2010) propose "sexual labor" as a better term for these purposes, yet it is not as familiar to scholars or practitioners. Others use the term "erotic labor" (Chapkis, 1997). Sex workers 
share experiences of marginalization and sometimes working illegally. Exotic dancers, and most other sex workers, are also emotional laborers (Hochschild, 1983), whose ability to succeed in the workplace depends on their ability to present a certain emotional façade to their customers, making them part of the growing "emotional proletariat" (Macdonald \& Sirianni, 1996; Wharton, 2009) of the expanding service sector economy.

\section{Purpose and Significance}

Given the extent and salience of this sector of the sex industry and the related urban planning and public challenges, this study set out to explore relationships between strip clubs and neighbors and the ways that neighborhood features influence strip club working conditions. The goal of the study was to describe actors, discourses, and events that have contributed to the location of and working conditions within Portland's strip clubs as well as to identifying drivers of conflicts and tools for resolving them. Because Portland has fewer regulations than most U.S. cities, the setting allows for exploration of a wider array of influences on these formal and informal processes. Since there has been little systematic comparison between clubs in different cities and neighborhoods, this project aims to identify some of the place characteristics that influence these differences in worker experience and neighbor response to strip clubs through in-depth exploration of one city.

While scholarly literature documents both occupational hazards for dancers and examples of local response to sexually oriented businesses, there is limited 
information on how local conditions affect the experience of workers. Portland presents a unique laboratory for exploring these issues because the lack of land use controls specific to sexually oriented businesses allows clubs to locate "naturally" within the city. Because formal policies do not dictate the location of these businesses, their arrangement can illuminate the informal processes that manage their location. Furthermore, because Portland residents regularly experience strip clubs in the urban landscape, the public debate about the issues may be more robust than in other cities. This project has the potential to suggest how meso-level factors (public policy, facility siting, etc.) in Portland conspire with the well-understood macro-level factors (political economy of gender) and micro-level factors (life history) to shape the experience of exotic dancers. As such, it is a response to the call for a cultural approach to research on strip clubs that adds to extensive research conducted within strip clubs by studying them in the context of larger systems (Frank, 2007). The overarching goal of the inquiry is to provide insights that may help communities resolve the problems that can occur in relation to strip clubs.

\section{Conceptual Framework}

I designed my study and explored my data based on a conceptual framework that centers around place processes. By "place processes," I mean the interactions of people, objects, and discourses that occur both in and in relation to a defined physical environment, combining to produce the meanings attributed to a space (for discussion of place and space, see Lefebvre, 1991; Tuan, 1977). I approached the study with a belief that the location of sexually oriented businesses within cities, 
how neighbors respond to clubs, and what exotic dancers experience in the workplace are influenced by a variety of explicit and tacit processes that are rooted in place at different scales. Most evident are the state regulatory functions that affect any business: land use controls that designate commercial zones, building codes that regulate design and facilities, permitting requirements for alcohol sales and other aspects of the business. But a variety of other actors, discourses, and silences affect the spatial order of cities. In the case of strip clubs, neighbors may express concern through formal channels like neighborhood organizations or contact with elected representatives or may employ informal resistance strategies, such as sabotaging club operations. Even a lack of debate reflects social processes: club owners may locate at the margins of neighborhoods in unprepossessing buildings as an attempt to forestall controversy, for example. In this way, the siting process results in a club locating in a given place, and the characteristics of this place may influence how users of other land uses in the vicinity respond to the club. At the same time, place characteristics such as development density, urbanicity, and neighbors' responses to a strip club may affect how a dancer experiences her work. As is discussed in the Literature Review chapter, place characteristics influence the extent of land use conflict and the spatial configuration of industry. Undergirding the social processes that constitute place are cultural, social, and economic systems that also structure the experience of the worker. In the case of exotic dancers, gender, race, and age are important drivers of the workplace experience. The type of club a dancer works in also influences her experience. The interest in place as mediator prompted me to wonder how working conditions within strip clubs may 
influence both how neighbors experience the clubs and the level of conflict or opposition to clubs. For example, can clubs be rid of the LULU designation through practices inside the club or features of the surrounding areas? Similarly, I wondered how neighbors' attitudes toward strip clubs might influence workers' experiences. For example, could the level of occupational hazard be increased through neighbor hostility to a strip club, or are there certain features of the surrounding environment that affect dancers' experiences? This web of relationships suggested the key themes guiding my exploration.

\section{Research Questions and Sensitizing Concepts}

As an exploratory qualitative study, this project's research questions coalesced over the course of my inquiry. Indeed, they are presented as a way of bounding the discussion, as it would be possible to write a different dissertation using the same dataset but different organizing questions. Similarly, I did not have a priori hypotheses, but rather used the web of relationships described in the previous section as sensitizing concepts (Blumer, 1954) that guided my exploration of the data. Sensitizing concepts can be thought of as relationships or variables that will be "tested" through collecting and analyzing data. My research questions and sensitizing concepts were informed by my preliminary reading and reflection about sex, place, and work. Below I present my three key research questions and initial ideas I had about them as I began the study.

My first research question was, What forces drive and constrain the spatial configuration of strip clubs in Portland? Given the absence of land use controls 
specific to sexually oriented businesses, I wondered what informal processes determined the location of strip clubs within the city. I was attuned to how club location might be influenced by neighborhood reputation, presence of other sexually oriented businesses, land use mix, socioeconomic status, and housing tenure in the area surrounding the club.

My second research question was, What influences how neighbors respond to strip clubs? I wondered how people who lived and worked near strip clubs would experience them. I was attuned to the impact that the design of the club might have (for example, displaying a sign that might considered garish might displease neighbors), and expected that neighborhoods whose residents had high socioeconomic status would express vociferous opposition to strip clubs.

My third research question was, What affects the work experience of female exotic dancers? I expected that the opportunity to work in a variety of neighborhoods would make it easier for dancers to get to work and that the number of clubs would increase public tolerance of strip clubs. However, it might also result in increased competition between dancers because less stigma would foster a larger population of people willing to work as exotic dancers. I also thought that opposition to a club by its neighbors might have negative effects for dancers, making them feel that neighbors would not assist them if they were in need.

\section{Overview of Methodology}

The study uses Clarke's (2005) situational analysis methods, which are rooted in symbolic interactionist thought and the grounded theory tradition but 
provide greater flexibility in both data interpretation and theoretical conclusions. The project began by defining a situation of interest—women working as exotic dancers in the context of Portland neighborhoods-and then involved collecting and analyzing data about human and nonhuman factors that constitute the situation. Situational analysis is distinct from a case study methodology because it chooses a situation —or social problem —as the unit of analysis rather than a case, which is generally a functional organizational unit or a field of inquiry whose parameters are defined by the research question (Yin, 2003). Case studies typically entail analyzing a system that is bounded in some way, whether through administrative regulations, historical events, time, or some combination therein. Situational analysis looks beyond the boundaries that confine a case study, integrating information that may not fall within the researcher's initial conception of the situation. Considering the situation allows for analysis of interpersonal episodes and their embedding context (Mitchell, 1983), which may or may not be known during the design phase of the study.

To allow for fine-grained analysis of the neighborhood scale, I identified three particular strip clubs within the situation to serve as focus study sites; these sites were chosen for maximum variation in neighborhood, clientele, age of the business, etc. Three kinds of data collection occurred: in-person interviews, document review, and site observations. Forty-three participants were interviewed, each of them classified as an exotic dancer, a residential or commercial neighbor of a club, an owner or manager of a club, or a public employee who worked on issues related to strip clubs and neighborhoods. The documents reviewed included court 
cases and administrative decisions related to strip clubs, police department and liquor commission records, and media coverage from 2005-2012. Site observations were conducted at the three focus study sites.

My definition of the situation includes all strip clubs within Portland's city limits that feature female performers, but does not include clubs that feature only male performers or other types of sexually oriented businesses, such as so-called adult bookstores and lingerie modeling shops.

The main limitations of the study come from the lack of generalizability the findings to other settings, though some findings may be applicable if not directly transferrable. Furthermore, the study was conducted with limited input from participants in the situation, meaning that my interpretations of the data have not benefited from the critique of people with insider perspective. Additionally, the study was conducted by one early-career researcher, meaning that the protocol may have been unevenly or inexpertly applied and that the study did not have the benefit of multiple "raters" to heighten its reliability.

\section{Organization of the Dissertation}

The dissertation follows a traditional five-chapter structure, with the exception of one interstitial chapter placed between the Methodology and Findings chapters. Following this Introduction is the Literature Review chapter, which discusses scholarly understandings of land use conflict, sexually oriented businesses, and the work experience of exotic dancers. Based on this literature, I propose a conceptual framework that links the factors that affect local response to 
strip clubs to the factors that affect exotic dancers' work experiences through their shared rooting in place. The Methodology chapter describes how I operationalized this conceptual framework using a situational analysis research design and details the procedures I used to collect and analyze data. It also includes descriptions of the places I studied and the people who chose to participate in the study. After the Methodology chapter, I have included a chapter entitled “Describing the Situation,” which presents more information about the exotic dance industry in Portland, gathered over the course of the study and synthesized through my analytical process. It provides important context for the findings and their implications, so I have chosen to incorporate it as a distinct chapter to further describe the situation under study. The Findings chapter presents the information I collected as it relates to each of my three research questions, weaving together evidence from the various data I collected. The Discussion and Conclusions chapter begins by connecting my findings to the broader conversations taking place in the academy and public sphere. This discussion of the findings is organized into three that align with my three research questions: location processes, neighbor response, and dancer experience. Next the chapter addresses implications of my findings for practitioners in both the urban planning and public health fields who are interested in or charged with resolving the central problems of (perceived) land use incompatibility and the instability of exotic dancers' work experience. This is followed by a delineation of future areas of research that would build on the present study. Finally, the conclusion section of the chapter encapsulates the entire dissertation in a 
summative statement. The appendices provide supplemental information about my analytical procedures. 


\section{Chapter 2: Review of the Literature}

This chapter describes research in fields such as urban studies, gender studies, human geography, and sociology that serves as the foundation for my understanding of the problems posed in the previous chapter: conflict over sexually oriented business sites and poor working conditions in strip clubs. This literature helped to answer some of my initial questions about why strip clubs end up in certain locations, how people respond to the presence of these (presumably) locally unwanted land uses (LULUs), and what working conditions are like within strip clubs. It also spurred me to develop my research questions and explore them in this study. I return to many of these books and articles in the Discussion and Conclusions chapter, reflecting on how my findings build on this work.

This literature shows that formal and informal processes drive the location of sexually oriented businesses within cities and that human actors' responses to these and similar land uses vary between places depending on characteristics of the population and the land use. The literature also shows that while working as an exotic dancer offers distinct benefits, working conditions are generally poor due to the social status of the job and the venue in which it is performed. The chapter concludes by identifying gaps in the literature that drive my inquiry into the role of place processes in Portland strip clubs: a relative dearth of information about how meso-level factors affect land use conflict and working conditions, and a limited understanding of variation within the sex industry. 


\section{Sexual Commerce in the City}

The anonymity and bustle of city life have historically created spaces where sexual minorities and sexually oriented businesses can exist with less opprobrium than in smaller communities, yet the high level of interaction between diverse populations also means that the expression of sexuality in urban public space often results in conflict (Knopp, 1995). By virtue of their continued existence, sexually oriented businesses clearly provide a service to some members of the public. Yet it is rare that a neighborhood will embrace them because processes of social distancing depersonalize users of the facility and privilege residents' ideas sense of ownership of the space.

The meanings of the places where sexually oriented businesses are located and of the cultural understanding of people who use these locations are constituted by a wide variety of social processes, including individual and collective actions and processes that have both human and nonhuman elements. Nonhuman actors include media representation (Hubbard, 1998a; O'Neill, Campbell, Hubbard, Pitcher, \& Scoular, 2008) and governance, such as land use controls (Hubbard et al., 2009) and regulation on advertising (Hubbard, 2002). While arts establishments and districts are often at the center of economic development plans (Florida, 2002; Strom, 2003), sites of sexual commerce like exotic dance are generally located in peripheral areas that reflect and reinforce negative stereotypes of these activities (Domosh, 1999; Hubbard, 1998b).

From a human geography perspective, place is an influence on the experience of people who engage in sexual commerce. Tracing the theoretical lineage of 
contemporary scholarship on sexuality and place, Browne, Lim, and Brown (2007) explain how Butler's work on the performativity of gender $(1993,1997)$ laid the groundwork for a queer geography that contends "that space is not simply the vessel in which things happen, but is actively constituted through the actions that take place" and which "challenges how the everyday repetition of heterosexual relations becomes normalized such that quotidian space is not assumed to be sexual at all" (Browne et al., 2007, p. 9). Queer geography explores an array of sexuality and sexual expression, much of which may be heterosexual in character, using the term "queer" to refer broadly to sexual heterotopias (Foucault, 1986), or spaces of non-hegemonic sexuality/gender. These lines of inquiry have been used to understand how space is sexualized, but also racialized, classed, and otherwise arranged based on social hierarchies for the purpose of constructing cultural meaning (Browne et al., 2007). This formal and informal regulation of sexuality privileges certain sexual expressions as appropriate and others as deviant, yet "these ideas are not stable and what is considered acceptable is always contingent upon time and place" (Johnston \& Longhurst, 2010, p. 85). This constant reconfiguration is done not just as a result of the migration of people with queer or dissident sexualities to the city, but because of the concentration of wealth, power, and social control in cities. As Hubbard (2012) puts it,

[The city] is a location where sexual orders have been worked and reworked, where ideas of the 'normal' and 'perverse' have been both instituted and contested. This is because cities are not just comings-together of people in the interests of social and economic reproduction; they are also sites of 
governance from which power is exercised through various apparatuses of the state. Cities are indeed host to the key institutions that have a vested interest in regulating sex as part of a project of maintaining social order: the police, local government, departments of planning and housing, the courts, hospitals, probation services, social services and so on (p. xiv).

These social processes establish norms and reify them in space.

Linking these geographic processes and social control, Johnston and Longhurst (2010) explain that "there are parallels between the treatment of the commercial sex industry and the industrial and manufacturing industries - both are constructed as polluting and unsightly and therefore need to be contained" (p. 92). Because sex work finds its place in near-derelict spaces, the other users of these spaces tend to be people with limited social power to resist the presence of commercial sex work (Cameron, 2004). "Adult entertainment" areas are often in close proximity to neighborhoods of concentrated poverty with a high proportion of residents who are women of color-all of this reinscribes intersecting race-classgender-place stigmas (Lasker, 2002).

Metropolitan areas may employ normalization or spatialization strategies to manage the stigma of sex work, which is seen to affect the entire community even if only some engage in the practice. Normalization entails treating sexually oriented businesses like other businesses, through land use or other regulatory decisions that allow them to operate under the same conditions as "normal" businesses. Spatialization segregates sexual commerce to specific geographic areas. The tension between these approaches to concentration and dispersion of the sex industry 
emerged in the post-World War II era, when conflict over sex districts crystallized in American cities (Sides, 2006). Sex workers may like spatialization because it helps them separate their work from the rest of their life, whereas normalization may be the case in environments where sex work is decriminalized or where social norms are accepting of sexual commerce (Maticka-Tyndale et al., 2005).

In a case study of the escort industry ${ }^{2}$ in Windsor, Ontario, Maticka-Tyndale et al. (2005) found that that the city's normalization strategy increased workers' legitimacy and, consequently, stability and safety, yet did not fully rid the sex worker identity of stigma. Though escorts were licensed and performing legal work, their low status was established in ways not codified in the law: the removal of ads purchased by escorts in tourist publications, police hostility and entrapment, the city council's failure to provide appropriate legal information to licensees, and resident demands for spatial segregation of sexually oriented businesses. The licensing of escorts served the interests of many other groups of people:

- Civic boosters wanted to attract U.S. tourist dollars with a "Sin City" image. (Windsor is across the Detroit River from the eponymous U.S. city.)

- Residents desired to retain an image of their city as clean, respectable, and well ordered despite the tourist industry.

- U.S. tourists were interested in pursuing commercial sex without the threat of arrest.

\footnotetext{
2 Escorting is a form of indoor sex work in which clients make an appointment to meet with an escort for "in-call" (on the agency or sole proprietor's premises) or "out-call" (at the client's location) services which may or may not include intercourse.
} 
- The police wanted increased access to intelligence on the illegal aspects of sexual commerce.

However, licensing and normalization had limited benefits for escorts themselves.

In many U.S. cities, spatialization strategies have relocated sexual commerce to industrial and manufacturing districts (Cameron, 2004). This type of refiguring of the urban sexual landscape is considered by some to be part of the revanchist agenda3 $^{3}$ for the city (Hubbard, 2004; Papayanis, 2000). Sexually oriented businesses may fill an economic niche in metropolitan development, occupying lowvalue spaces because their presence would not be tolerated in prime retail space (Cameron, 2004; West \& Orr, 2007). A historic preservation textbook (A. C. Moore, 1998) proposes that the sexual frisson of such spaces is a valuable tool for urban redevelopment: "The preservation of old buildings and sexually permissive activities have a scenographic affinity which can be exploited so that together they become another reliable economic rehabilitation resource for the city of the future" (as cited in Hanna, 2005, p. 126).

\section{Response to Sexual Commerce}

In most communities, sexually oriented businesses are seen as LULUs. Distinct from facilities like incinerators or water treatment facilities that produce toxins and may be detrimental to environmental health, socially noxious uses are perceived to have negative impacts on the social environment of the community. While it is difficult to make the case that sexually oriented entertainment is as

\footnotetext{
${ }^{3}$ See Smith (1996) for discussion of the recolonization of city centers by White upper-
} middle class interests. 
profound a social need as are waste management and drug treatment services, sexually oriented businesses can be understood as useful for capital-for example, the profit to be gained by a strip club owner-in contrast to a LULU needed for the overall social good, such as a waste-transfer station (Ellis, 2004).

\section{Local resistance to sexually oriented businesses.}

Resistance to the siting of strip clubs can be rooted in a variety of concerns. Citizens resist these land uses on the presumption that they will decrease property values, negatively impact health, increase traffic, make the neighborhood ugly, or invite any of a number of unwanted outcomes (Schively, 2007). Moral concerns include the presumed exploitation of the dancers or the exposure of local children to a sexually oriented business in their neighborhood, which adults may be uncomfortable explaining. While moral objections may include rhetoric about the exploitation of women, rarely are concerns about labor conditions expressed. Safety concerns include the possibility of customers harassing passersby as well as crime-especially prostitution-attracted to the club. Economic concerns include decreased property values near the club and the possibility that other businesses will be disinclined to locate near a sexually oriented business. Disputes over strip club location can be costly and confrontational for all parties. Local governments may enter into long and costly legal battles in their attempts to regulate clubs. Clubs may be picketed, employees harassed, and club property vandalized. Citizens may object to the expense of policing clubs or lawsuits over failed ordinances-which can reach seven-digit figures (Hanna, 2005). 
Though every siting process is different, similar roles and discourses emerge across settings. The urban planning literature describes roles taken by actors in land use conflicts and dynamics of LULUs and NIMBYism, or "not in my backyard" activism. Economists view NIMBYism as a result of market inefficiencies, whereby selling a home and changing residences is so costly that homeowners will stage political campaigns against a LULU rather than exercise their exit option (Deng, 2003). Krause (1992) draws on the urban planning literature to identify participants in the interactional field of LULU siting. Boosters support growth of any kind, even with the negative externalities of LULUs. Guardians- $50 \%$ of the field participants, by Krause's estimate-are most concerned with the way in which negotiations are conducted. Ellis (2004) presents a more refined schema of LULUsiting participants based on case studies of planning conflicts in Ireland. He describes boosters as "prodevelopment conservatives" who employ a propertyrights argument. Preservationists, or "antidevelopment process sheriffs" in Ellis's terminology, resist all development and are skeptical of established planning processes. The public-interest guardian is invested in collective citizen action, and the individual proceduralist is motivated by self-interest and has a high faith in bureaucratic processes.

Resistance to a given LULU is determined by the character of the location (Takahashi \& Dear, 1997). According to Schively (2007), several factors influence the degree of conflict over LULUs: perception of impacts (externalities of the land use), perception of actors (trust between stakeholders), and perception of siting processes (fairness of land use practices). Research on NIMBYism suggests that, as 
one's income increases, one's level of objection to development also increases. Homeownership and childrearing also predict objection, as people try to protect the value of their investments and the value of their families' use of their property (Ellis, 2004). A public-opinion survey in Providence, Rhode Island, confirmed that morality was far more important than economics in shaping attitudes about the adult-entertainment industry (West \& Orr, 2007). From a symbolic interactionist perspective, people are willing to devote many resources to opposing LULUs because they view the land use as a threat to their identity (Krause, 1992).

As Schively (2007) explains, neighborhood residents have great motivation to act on a LULU, but the land use may also draw interest from a wider area depending on the political currency of the service it provides. Thus establishments like strip clubs or abortion clinics may provoke response from morally outraged people who will not be directly affected by the facility. The literature suggests that those who expend great energy in protest may have greater personal resources and an elevated risk of losing investment than does the average community memberwealthy property owners with the educational backgrounds to easily navigate the system of public participation fit this description (Schively, 2007).

Hubbard and colleagues' case studies (1998a, 1998b) of street sex work suggest these kinds local activism may affect sex workers' experience. O’Neill et al. (2008) found a variety of responses both between and within neighborhoods, which they chart on a continuum from action aimed at displacing sex workers (no tolerance) to sympathy for workers (tolerance). Coexistence was most successful 
when a variety of parties were engaged in negotiation and mediation and where awareness building was foregrounded.

\section{Spatial stigma and social distancing.}

The location of sexually oriented commerce reflects the social position of the people who engage in it, and the meanings of these places-which are generally marginal—confer an identity on these same people (Hubbard, 1998a, 1998b). NIMBYism often entails a social-distancing process: resistance to sexual commerce commonly villifies sex workers (Hubbard, 1998a, 1998b) as people who are at odds with family life as embodied by monogamous, heterosexual, procreative spaces (Hubbard, 2001). As Chiotti and Joseph (1995) discuss in their study of siting an AIDS hospice in Toronto, controversial land uses reflect a sociospatial dialectic, where the relationships between structure, agency, and social reproduction both result from and reinforce one other. This "othering" process can serve to strengthen the identity of the people resisting. For example, Hubbard (1998a) concludes that male South Asian Muslims' gendered and ethnicized campaign against street prostitution in Birmingham, England, fostered the collective identity of this minority group that felt disenfranchised from electoral politics, and also marginalized women in the process.

Discourse about sex work can induce and maintain these spatial and social orders (Kerkin, 2004), as it is used as the basis or justification of policy decisions. Lasker (2002) describes this dynamic in a legal comment on the role of sexuality in the cityscape, critiquing the purported neutrality of formal regulatory tools. She asserts that "the 'rational' science of zoning and secondary effects often masks a 
complex web of moral judgments, class perceptions (which tend to be racialized), conceptions of 'normal' sexuality, and assumptions regarding gender roles" (Lasker, 2002). Reflecting on zoning as a tool of social reproduction, she concludes that zoning of sexually oriented businesses is "a reactionary 'containment policy' for the porn problem, produced by and for the preservation of exclusive communities and of a certain moral status quo: white, middle- and upper-middle-class, detached single-family home, heterosexual, nuclear family, reproductive, missionary position" (p. 1149).

Resistance to sexually oriented businesses is both a reaction to them and a force that constitutes the meanings of these businesses and the people who patronize and work at them. In a case study of protests against street prostitution in neighborhoods in two British cities, Hubbard (1998a) found that where residents had more social and political power, they were most successful at recruiting state participation to quell sexual commerce. But Hubbard also found that, even for illegal prostitution, community rather than police power was used to regulate location - and that this exercise of power drew on a moral authority that "othered" commercial sex and its participants as deviants whose presence would foster incivility and crime. Thus, examining informal processes is an important strategy for understanding reactions to sexual commerce.

In a case study of street sex work in Australia, Kerkin (2004) described how customers as well as workers were constructed as violators of the social order: residents claimed that customers drove through the neighborhood at dangerous speeds, screeching their car tires as they stopped and made turns. Media coverage 
stokes this kind of anxiety and antagonism (Hubbard, 1998a; O'Neill et al., 2008). Stereotyping people as committing antisocial behavior depersonalizes them and facilitates their exclusion from public decision-making. Social distancing has also been seen in studies of opposition to mental health facilities, services for people with HIV, and drug-treatment facilities (Dear \& Wolch, 1992; Takahashi, 1998). Conflict over spaces of sexual commerce is a battle for reputation rather than the achievement of some objective standard of neighborhood condition. Hubbard (1998a) found that residents were more disturbed by the association of commercial sex with their neighborhood than by any specific encounters they had observed; he describes the threat as a disruption to the moral order of the community. There is also a long history of associating commercial sex with crime, the ultimate antisocial activity. Hubbard (1998b) traces the tenacious trope of criminal activity collocated with public sexuality back to the Victorian era. Recent scholarship (Hanna, 2005; Lasker, 2002; Paul \& Linz, 2001) shows how this discourse has been perpetuated by U.S. jurisprudence, which has repeatedly accepted the same methodologically flawed studies as evidence of deleterious "secondary effects" of strip clubs. Subsequent peer-reviewed research (Linz, Land, Williams, Paul, \& Ezell, 2004) has also failed to document increased crime in the vicinity of strip clubs. Therefore, public opinion rather than empirical evidence has driven planning for sexually oriented businesses in the United States, in effect allowing for zoning based on morality (Lasker, 2002; Papayanis, 2000).

Discussing the geography of commercial sex, Hubbard concludes that it is "a broad reflection of the differential ability of social groups to control space, with 
more powerful groups seeking to identify themselves with things that are culturally valuable, denigrating the powerless by associating them with things that are viewed as objectionable or socially undesirable" (Hubbard, 1998a, p. 273).

Sex workers are well aware of these spatial hierarchies, and therefore they carefully negotiate urban space. Commercial sex work has niche markets that are geographically segregated to certain streets or certain blocks. In Kerkin's (Kerkin, 2004) study of an Australian city, one street sex worker described avoiding sites where she might be recognized by someone from her family's community. This same worker also described cordial interactions with neighborhood residents, showing the complexity of the relationships between users of space. Sanchez (1997) describes how taxing it is to manage these relationships: "Most of their [sex workers'] energy is directed at negotiating consent, resisting violence, and avoiding the surveillance of the police and the local community" (1997). Though sex workers patronize local businesses and may live in the neighborhoods where they work, they often do not feel a part of the community (O'Neill et al., 2008). By contrast, the club owners and customers experience fewer sanctions and greater rewards.

\section{Scholarly Understandings of Exotic Dance}

Scholars of performance studies place stripping squarely within American dance history (Glasscock, 2003; Liepe-Levinson, 2002; Shteir, 2004). Stripping is an extensive and elaborate art form, as demonstrated by the scores of pages in LiepeLevinson's (2002) Strip Show that detail the narratives and moves she documented during in-depth research at strip clubs across the United States. Stripping is one of 
many dance forms that express and shape cultural understandings of sexuality (Hanna, 2010). However, stripping is at the bottom of the pecking order in terms of socially valued dance, where ballet is at the top (Hanna, 2013). Hanna (1998) defines dance as "purposeful, intentionally rhythmical, and culturally influenced sequences of nonverbal body movements" (p. 44) and identifies its patterns as vocabulary, grammar, semantics, and pragmatics that are interpreted by viewers in a naturalistic manner. The pragmatics of exotic dance-for example, the fact that it occurs in bars and requires personal interaction with the spectator-prevent it from developing the same training system and elite organization that occurs with ballet and other types of dance (Hanna, 1998).

Like many "pink-collar" jobs where women predominate-such as waitressing and secretarial services-stripping involves extensive emotional labor (Hochschild, 1983). That is, success at the job requires presenting the mood and disposition that are expected by the client. Sex work depends, even more explicitly than other pink-collar jobs, on creating an aura of erotic fantasy regardless of the worker's actual feelings about the client or the situation. This subset of emotional labor has been called erotic labor (Chapkis, 1997). The hazards of emotional labor often go unrecognized because it is often not considered real work, sometimes even by dancers themselves (Colosi, 2011).

\section{The exploitation question.}

Whether sex work constitutes exploitation, empowerment, or a mix of the two has been the subject of long and heated debate among scholars, activists, and policymakers. Feminist scholars have struggled to analyze the power dynamics of 
commercial exchange rooted in sexual acts or fantasies, sorting themselves into camps whose clashes were particularly bitter during the "sex wars" of the 1980s. The historical contours of these debates are covered in detail elsewhere (see, for example Sloan \& Wahab, 2000; Wahab, Baker, Smith, Cooper, \& Lerum, 2011; Zatz, 1997). While acknowledging the debate, my project starts from a theoretical stance that stripping is sex work that women are capable of choosing freely to do, and from which they may gain money, confidence, and satisfaction. My perspective is heavily informed by in-depth researchers who have themselves worked as exotic dancers (e.g., Danielle Egan, Kate Frank, Bernadette Barton, and Mindy Bradley-Engen). For the most part, these scholars' experiences show that exotic dancing is work subject to the same sorts of exploitation experienced by workers in other jobs, and that the working conditions rather than the job title are the key influence on workers' wellbeing. An emerging school of thought about sex work contends that both sex workers and their clients are mutually exploiting each other in a kind of symbiotic relationship (Bell, Sloan, \& Strickling, 1998).

While these debates rage on, ample evidence has been gathered for both the benefits and harms of working as an exotic dancer. Not surprisingly, research on strip clubs shows that working as a stripper is neither unalloyed empowerment or exploitation but rather that dancers' feelings go back and forth at different stages and even moments of their career (Deshotels \& Forsyth, 2006). Barton (2002) describes this experience as a Möbius strip, where an individual dancer has seemingly opposite feelings about the same experience. 
There are many reasons to like working as an exotic dancer. Some women describe the feeling of empowerment that comes from performing, expressing their sexuality, and even controlling their customers (Bott, 2006; Bradley-Engen \& Ulmer, 2009; Deshotels \& Forsyth, 2006, 2008; Pasko, 2002; Ronai, 1989). Some dancers go as far as describing their time on stage as a spiritual experience (Barton \& Hardesty, 2010). Many dancers see relationships with coworkers as the best part of their job (Barton, 2006) and report great pleasure at being surrounded by strong, self-confident women.

Another major benefit of stripping is that it offers higher earning potential than many other the other entry-level jobs readily accessible to women (Jeffrey \& MacDonald, 2006) with little experience in the workforce. As Bruckert (2002) puts it:

Stripping may not always be a "nice" job, but neither are the alternatives. For some working-class women, stripping may be a viable strategy to realize the economic and social benefits afforded by participation in the paid labour force while also offering sufficient flexibility to accommodate their many other commitments (p. 31).

Flexible scheduling is hugely valuable to parents and to dancers who have other occupations on the side, such as small businesses or art careers.

Stripping is one of many semiskilled service-sector jobs that form an increasingly large part of the North American economy; strippers are part of the growing proportion of workers who are self-employed (Bruckert, 2002). Like most contingent workers, exotic dancers' employment is very precarious. The informality 
of the sector limits the stability of the jobs and the opportunities for recourse when problems arise in the workplace.

Exotic dancers have no guarantee that they will be able to work the shifts they are assigned and can be fired at any time with no justification. Bias on the parts of clients and management makes it especially difficult for women of color to succeed in the workplace, particularly in the higher-paying segments of the industry (S. Brooks, 2001; Chapkis, 2000). Because strip clubs capitalize on dancers' appearance, "beauty" is considered a bona fide occupational qualification for the job (Rutman, 1999), disadvantaging those whose bodies don't call to mind the Barbiedoll ideal. Meanwhile, stereotyping sex workers as available "allows men to see dancers as legitimate prey for sexual harassment and assault" by customers, employers, and landlords (Maticka-Tyndale, Lewis, Clark, Zubick, \& Young, 1999, p. 20). Blasé response by law enforcement reinforces both the stereotype and the harassment (Maticka-Tyndale et al., 1999).

Dancers have little leverage to negotiate with club management because they lack both collective solidarity and individual identity—that is, dancers are interchangeable to management (Bradley-Engen \& Ulmer, 2009) and have a limited sense of shared interests with other dancers. Their role constraints lead dancers to take out their hostilities on each other because acting out with customers would decrease their income and resistance to management can result in job loss (BradleyEngen \& Ulmer, 2009). This behavior can be extremely isolating; as Barton (2007) puts it, "Exotic dancers are first 'othered' by mainstream society, then 'other' one another" (p. 585). 
Confronted with these working conditions, exotic dancers often employ individualistic, ad hoc, and covert resistance strategies, which are "concerned largely with immediate, de facto gains," as is common among informal-sector workers (Scott, 1985, p. 33 cited in Lewis, 2006). As one example, Egan's (2006) ethnographic research describes dancers expressing frustration by performing to music of which club management disapproves: while this can provide momentary catharsis, it does little to change working conditions.

While dancers in several U.S. cities have attempted unionization, the greatest successes have been in San Francisco (Gall, 2007). According to Barton's research (2006), San Francisco has spurred so much activism because the local culture of sexual openness and limited regulation has made customers very demanding of sex industry workers, galvanizing a collective response. Despite the fact that San Francisco has a unionized peep show and that strippers won a court case entitling them to employee status, low pay and draconian club policies are the norm. Explains Chapkis (2000):

The case of San Francisco demonstrates that while obtaining the status of worker is necessary for unionization, it is by no means a sufficient condition to ensure worker rights. In order to benefit from a change of status from independent contractor to employee, workers must collectively confront management's workplace regulations and exploitative wage system. In the absence of such organizing, workers may find themselves with even less power than they enjoyed as nominal independents (pp. 199-200). 
Major obstacles to sex worker organizing include limited acceptance of the "sex work discourse" (i.e., that sex workers perform a specific type of labor in exchange for a wage and are consequently entitled to the same benefits as other workers) among dancers and the general public, the instabilities of self-employment, a slack labor market in the industry, and individualistic coping strategies (Gall, 2007).

\section{Workplace hazards.}

There are distinct physical and psychological strains associated with working as an exotic dancer. As one dancer declared in an interview with a dancerresearcher, "you age in dog years because it's so hard" (Barton, 2006). The occupational hazards faced by sex workers - which operate at many levels - are a function of their working conditions rather than the result of engaging in sexual commerce per se (M. L. Johnson, 2006; Spice, 2007; Weitzer, 2000a).

Dancing itself is physically exhausting, and exotic dancers almost always perform in very-high heeled shoes, contending with makeup and costumes that can irritate skin. Some bacterial and viral infections are easily spread to exposed skin (Frenken \& Sifaneck, 1998), making props shared by dancers an especially worrisome vector (Barton, 2006; Maticka-Tyndale, Lewis, Clark, Zubick, \& Young, 2000). Sprains and strains result from the contortions of acrobatic stage tricks, and falls are common as dancers' heels trip on litter or slip on bodily fluids or spilled drinks (Frenken \& Sifaneck, 1998). Loud music, bright lights, and powerful air conditioning are the norm, and some clubs still permit cigarette smoking (in Portland, where the present study was conducted, smoking was permitted in bars until 2009). 
Overall, female sex workers complain most of sore feet (long-term consequences of "stripper heels" include foot abnormalities and arthritis), shortness of breath, general fatigue, and insomnia (Shaver, 2005). A recent study at one U.S. club found that $30 \%$ of dancers surveyed reported experiences of workplace violence, 28\% reported experiencing sexual assault at work, and 29\% had been injured at work in the previous year (Schlanger \& Choo, 2012). Dancers also use dieting, tanning, and plastic surgery to improve their marketability; each of these practices has its own, usually negative, health consequences (Maticka-Tyndale et al., 2000).

The verbal harassment and physical violence that are common in the nightlife industry are aggravated by the sexualized nature of dancers' encounters with customers and the exposure of working without clothing; bites, bruises, and chapped skin are not uncommon (Frenken \& Sifaneck, 1998; Jeffreys, 2008). Violence is a constant threat for exotic dancers (Cohan et al., 2006; Jeffreys, 2008; Sanchez, 1997; Sanders, 2004). Some customers take advantage of dancers' nudity and social situation to grope and otherwise harass them (Barton, 2007; BradleyEngen \& Ulmer, 2009; Maticka-Tyndale et al., 2000). It has become increasingly difficult to fend off these advances as "no-touching" rules have fallen by the wayside in the age of lap dances (Barton, 2006; Jeffreys, 2008; Sanchez, 1997). The rules that do exist are in place to protect the establishment from litigation, and dancers receive little assistance in enforcing them (Bruckert, 2002; Chapkis, 2000; Jeffreys, 2008). 
Stripping also affects dancers' lives outside of the workplace. Dancers report problems in personal relationships, such as hostility toward men, difficulty expressing sexuality, conflict with partners, and alienation from family (Barton, 2006; Deshotels \& Forsyth, 2006; Maticka-Tyndale et al., 2000; Sanders, 2004). The stigma of their job leads to sexual harassment by people who expect them to be constantly sexually available (Maticka-Tyndale et al., 2000), discrimination in the housing market, and threats of losing custody of their children (Barton, 2006).

Substance use is another way of distancing oneself from the strain of the workplace, and the self-medication that is common in all types of emotional laborers (Bruckert, 2002) is rampant in strip clubs . One ethnographic study of a New York club (Frenken \& Sifaneck, 1998) reported that $90 \%$ of the dancers used alcohol or other drugs, with 75\% using mostly cocaine, alcohol, marijuana, or some combination thereof, and several individuals being dependent on heroin. Chemical dependency can increase risk taking as the need for drugs supersedes the desire to avoid unsafe situations (Bradley-Engen \& Ulmer, 2009; Sanders, 2004; S. G. Sherman, Lilleston, \& Reuben, 2011). In a strip club, dancers under the influence may have impaired observational and decision-making capacities (Maticka-Tyndale et al., 1999) and may become less desirable performers because of their affect and the stigma of addiction (Frenken \& Sifaneck, 1998). Substance use also increases the likelihood of losing one's balance or falling while performing, yet dancers are expected to drink with customers to increase revenues (Maticka-Tyndale et al., 2000). Dancers who do not wish to become intoxicated must conspire with 
waitstaff to be served watered-down or nonalcoholic beverages (Barton, 2006; Lewis, 2006).

The conditions of the work environment, including worker locus of control and the level of stigma associated with the work, influence how great the toll of erotic labor will be (M. L. Johnson, 2006; Maticka-Tyndale et al., 2000; Spice, 2007; Vanwesenbeeck, 2005; Weitzer, 2000a). These conditions include the type of sex work, its legality, the physical environment in which it is performed, and the workplace culture. A study based at a sex-worker health clinic in San Francisco (Cohan et al., 2006) found that those who engaged solely in collective sex workthat is, sex work, like stripping, that occurs in group settings-had better health outcomes than those who engaged in any independent sex work. A study comparing female indoor sex workers and female nurses (Vanwesenbeeck, 2005) showed higher levels of burnout in sex workers and identified features of the work environment that contributed to sex workers' emotional exhaustion: lack of job autonomy, lack of social support (especially by work supervisors), negative work motivation, and negative responses to their work by others (including job-related stigma). Factors like quantity of hours worked, money earned, and type of labor were not important influences.

Much of the research has shown that indoor sex workers-a category that includes not just strippers but also massage-parlor and brothel workers - face less violence than do street sex workers (Lilleston, Reuben, \& Sherman, 2012; Sanders \& Campbell, 2007), mainly because they are more are likely to have other people working with them and to have more predictable hours and earnings; one study also 
suggests there is a lower likelihood of drug use in indoor venues (Spice, 2007). However, violence is still a major threat for indoor workers (Sanchez, 1997), and one study (Cohan et al., 2006) found strippers to have a higher risk of violence than other types of indoor sex workers.

The "safety climate" of a workplace affects how safe workers feel and how likely they are to put their health at risk and is a major influence on sex workers' experience because there are few formal regulations that control their work environment (Lilleston et al.). Research suggests that sex workers feel safer with increasingly formalized workplaces where colleagues are nearby and security measures have been instituted (Spice, 2007). In one Canadian study, health threats were fewer in clubs where management and dancers had cordial relationships and dancers were supported in setting limits about the types of dances they would perform (Maticka-Tyndale et al., 2000). Clubs were safer when they had no private booths or rooms, or when booths were monitored by bouncers. While indoor sex work is considered safer than outdoor work, safety varies depending on features like security cameras and relationships between workers (Lilleston et al., 2012).

Working for tips, dancers must compete with coworkers for customers' attentions - a formidable task given the overbooking of dancers that is the norm. In some settings, women are expected to tolerate sexual contact from clients and, depending on the type of club, may break the rules for the specific purpose of getting more money from customers (Bradley-Engen \& Ulmer, 2009; Deshotels \& Forsyth, 2008). Competition in clubs can push women into even less regulated situations like performing at bachelor parties, which can be more dangerous and 
more profitable (Sanchez, 1997). Dancers stand to earn more by offering the most explicit performance, pushing the envelope of legality-which can put them in physical and legal danger. Bruckert (2002) elaborates:

strippers have experienced a labour trajectory that mirrors that of many of their working-class sisters-consumer-service-sector employment, intensified labour expectations and non-standard labour practices. At the same time, unlike more reputable labour sites, the industry itself is subject to particular restraints that are imposed by the state precisely because it operates on the margins of morality. In practice, this regulation not only operates contrary to the interests of strippers, but actually positions clubs to exploit the vulnerability of their workers to an even greater extent (p. 66). These arrangements discourage solidarity in the workplace (Bruckert, 2002), and dancers generally hesitate to speak up about working conditions for fear of losing their already precarious status; accounts abound of mass firings after organizing attempts (Aimee, 2012a). These impediments to collective action are especially notable because support from management and coworkers has been shown to improve the occupational health of sex workers (Spice, 2007).

Bradley-Engen and Ulmer (2009) showed that clubs that have more egalitarian payment structures foster relationships between dancers, customers, and staff. Comparing different types of clubs, they explain that "women in social clubs felt closely tied to their identities as dancers as well as the establishments in which they worked. Many indicated that working in these clubs is personally satisfying" (p. 48). Alternatively, show-club dancers had a sense of superiority that 
kept them from engaging with coworkers. The quality of relationships between dancers is so important because sex workers rely on their coworkers for training and safety (Lewis, 1998). The repertoire of professional skills that exotic dancers develop through relationships with their peers is a critical contributor to workplace safety (Brents \& Hausbeck, 2005; Sanders \& Campbell, 2007).

\section{Gaps in the Literature}

While these studies provide insight into the dynamics of strip club location within cities and the working conditions in strip clubs, they leave several questions unanswered. First, while the factors that influence NIMBYism are well-described, most of the urban planning literature treats sexually oriented businesses categorically as LULUs, and the field has done little empirical exploration of the drivers for emergence and resolution of conflict concerning sexually oriented businesses in general and strip clubs in particular. It is presumed that sexually oriented businesses are a problem for cities, but there is little concrete evidence for this presumption. Similarly, there is ample literature about working conditions in strip clubs but limited research about how contextual factors influence these conditions (Vanwesenbeeck, 2001) despite the call for a cultural approach to research that describes what happens within clubs by studying them in the context of larger systems (Frank, 2007).

The configuration of and services offered by sexually oriented businesses vary among cities, neighborhoods, and even individual clubs, yet most research on place presumes that these businesses all interact with their surroundings in the 
same way. However, emerging research suggests that different types of sexually oriented businesses have different relationships with their surroundings (Edwards, 2010). While various types of businesses have been studied, distinct types of sites have not; these potential variations remain difficult to discern in U.S. cities because in most cases sexually oriented businesses are strictly limited in the number of locations and in the type of site-or in both respects.

Furthermore, the literature on land use conflict has given limited attention to smaller scopes of interaction, with most of the focus on formalized actors (Krause, 1992). And while the literature on NIMBYism (Ellis, 2004; Schively, 2007) thoroughly describes these discourses of objection, it lacks a discussion of how these objections affect the users of disputed facilities. These impacts on facility users are important not only because the users are citizens, as are those who resist the facilities, but also because these users may be especially vulnerable to harms that result from the stigmatization of the facility they use. While geographers have taken up the issue of sexuality, few have addressed the impact of sexual geography on the experience of sex workers (Hubbard, 1998b). Yet this is critically important, given the challenge faced by legal workers like Portland strippers, whose work is "ostensibly understood as a zone of legitimate business employing legitimate women" (Sanchez, 1997, p. 552, emphasis the author's) but operates in such poor conditions. Of the research that does discuss site-specific resistance to sex work, most focuses on street prostitution (Hubbard, 1998a, 1998b; Hubbard \& Sanders, 2003; Kerkin, 2004; Tani, 2002), leaving questions about how these processes may affect indoor sex work and sex work with less physical contact-like stripping. 
Additionally, some very rich case studies aside (Hubbard, 1998a; Maticka-Tyndale et al., 2005; Tani, 2002), much of this literature on conflict over sexually oriented businesses describes the issues at a macro level, addressing phenomena such as national legislation (Hubbard, 2009) or geopolitical trends (Hubbard, 2011a; Maginn \& Steinmetz, 2012; Weitzer, 2000b), or offers a theoretical perspective (Hubbard, 2001; Hubbard et al., 2009; Hubbard, Matthews, Scoular, \& Agustín, 2008).

Similarly, the literature on occupational hazards for dancers incorporates limited information on how local conditions mediate or moderate these hazards. The bulk of research that has been conducted about contextual influences on sex workers' experiences has focused on street prostitution (Kingston \& Sanders, 2011), despite the fact that the majority of sex workers work indoors (Sanders, 2005). Furthermore, most of this research has been conducted in the United Kingdom and often addressed the issue of stigma at an theoretical level rather than empirically studying workers' reports of their experiences (Hubbard, 1998a, 1998b; Hubbard \& Sanders, 2003; Sanders, 2007; Sanders \& Campbell, 2007).

As a result of these gaps, there is limited understanding of how meso-level factors like local policies and neighborhood dynamics affect exotic dancers and neighborhood conflict.

\section{Conceptual Framework}

This study aims to help fill these gaps in the literature by using place as a conceptual link between neighborhood response and worker experience. As such, it 
responds to calls to study the city and sexuality in concert for the purpose of elucidating the role that space and place play in constituting social power and exclusion (Hubbard, 2012) and how these processes operate at and across different geographical scales (Johnston \& Longhurst, 2010). The project first explores how place factors influence neighbors' responses and how place influences workers' experiences, and then explores how these two domains (neighbor response and worker experience) may influence each other through their shared rooting in place. Place itself is influenced by social, cultural, and economic factors, all of which are powerful influences on dancers' work experience. Place contributes to land use conflict because of perceived incompatibilities in how people expect the place to be used. Place affects the configuration of the sex industry because certain places are perceived to be more or less appropriate for its presence.

That is, a club exists in a given physical place as a result of the siting process, and the characteristics of this place may influence responses by people who live, work, or otherwise spend time in the vicinity. At the same time, place characteristics—such as development density, urbanicity, and neighbors' responses to a strip club-may affect how a dancer experiences her work. As discussed in the literature review, place characteristics influence the extent of land use conflict and the spatial configuration of industry. Undergirding the social processes that constitute place are cultural, social, and economic systems that also structure the experience of the worker. In the case of exotic dancers, gender, race, and age are important drivers of the workplace experience. 
This conceptual framework, developed in the course of data collection and analysis, led to the identification of the study's central research questions:

(1) What forces drive and constrain the spatial configuration of strip clubs in Portland?

(2) What influences how (residential and commercial) neighbors view strip clubs?

(3) What affects the work experience of female exotic dancers?

I also had a series of second-order research questions about interrelationships among elements in the situation, or how place might function as a mediator:

(1) How does the spatial configuration of strip clubs influence land use conflict?

(2) How do worker experience and land use conflict affect each other?

(3) How does the spatial configuration of the industry affect dancers' work experience?

For example, I wondered how working conditions within strip clubs club might influence how neighbors experience the clubs and the level of conflict or opposition to clubs. Might clubs be rid of the LULU designation through practices inside the club or features of the surrounding areas? Similarly, I wondered how neighbors' attitudes toward strip clubs might influence workers' experiences: could the level of occupational hazard be increased through neighbor hostility to a strip club, or are there certain features of the surrounding environment that affect dancers' experiences? 
In the chapters that follow, I discuss how I explored these questions and what I found.

\section{Summary of Literature Review}

This literature review has identified key themes in the scholarly understanding of location processes for sexually oriented businesses, responses to sexually oriented businesses as locally unwanted land uses (LULUs), and experiences of women working as exotic dancers, which are summarized below. It also discusses gaps in knowledge about these issues, which I take up in the research described in the successive chapters of this dissertation.

The meaning of sexually oriented businesses and people who patronize them is constituted by social interaction and by nonhuman actors. Consequently, cities are the site of assertion of sexuality and of controversy over these assertions, which manifests in tensions over how to control the location and other aspects of sexually oriented businesses. Because sexually oriented businesses are typically located in marginal areas, these location processes both constitute and reinforce stigma for the areas and businesses.

For this and other reasons, working as an exotic dancer remains stigmatized despite the fact that it is a legitimate job that can be empowering and involve creative expression. Stripping and other erotic labor are forms of gendered emotional labor, which can be taxing and underappreciated. The extent of the toll is affected both by the type of work and by the conditions under which that labor is conducted, which in most cases in the United States are relatively poor. These 
conditions endure with little resistance because of the lack of legitimacy afforded exotic dance.

While the literature provides a rich description of how social structures facilitate this delegitmation as well as the conflict over controversial land uses, in addition to the individual-level factors that influence an individual dancer's level of risk, it contains relatively little discussion of the conditions in between these macro and micro levels. The urban planning literature includes discussion of the factors that influence the likelihood that a given community will resist an unpopular land use, but does little to understand the differences between the various types of sexually oriented businesses. It seems likely that characteristics of a given strip club-in terms of siting, site design, or response to neighborhood concerns-would affect the level and type of resistance the club would provoke. Similarly, while research on exotic dancers has repeatedly established the influence of context on the worker experience, there is little description of how place might affect dancers. My study addresses these gap by applying a conceptual framework that links club siting, local response, and worker experience through place. Ultimately, this framework asks whether neighbor response and worker experience may affect each other because they are collocated and both influenced by place. In the Methodology chapter, I present this framework in more detail and describe how I operationalized the study based on it. This leads to a discussion in later chapters of how place processes can be part of resolving conflict and assuring safe work environments for dancers. 


\section{Chapter 3: Methodology}

This study employed situational analysis methods to explore relationships between strip clubs and place, and specifically how these relationships affect land use conflict and occupational health. The study began by defining a situation of interest—women working as exotic dancers in the context of Portland neighborhoods-and then collecting and analyzing data about human and nonhuman factors that constitute the situation. I wanted to learn:

- What forces drive and constrain where strip clubs locate (in the absence of land use regulations)?

- What determines how (residential and commercial) neighbors view strip clubs?

- What factors influence the work experience of female exotic dancers?

The outcomes about which I was curious occur at a relatively small scale: a club locates on a specific lot, neighbor resistance to a land use centers on a specific site, and opinions about one's work experience are very individual. Yet each of these outcomes is influenced by processes that operate on a wide variety of geographic, social, and economic scales. For example, whether strip clubs are permitted is based on state law, and the demand for nude female entertainment is based in broad cultural constructs about gender and commerce. In order to explore these interrelationships among scales, I chose to use a situational analysis (Clarke, 2005) method to conduct the research. 
Though I did not set out to test specific hypotheses, my starting point was a series of propositions that I believed to be true in at least some settings, based on my personal experience and reading of the literature:

- Cities are centers of sexual culture, and they thus provide an opportunity to study the spatial organization of sexuality.

- The location of strip clubs (and other land uses) is influenced by a variety of formal and informal processes.

- Hazards faced by exotic dancers are a result of the working conditions rather than of exotic dance itself.

- The physical and social characteristics of an area influence the degree of land use conflict.

These propositions informed my selection of a research method and data collection and data analysis procedures, which are discussed in more detail below.

To assure the availability of data that reflected these diverse processes, I selected three focus sites to study in closer detail and collected multiple sources of data (as discussed in the Research Sample and Data Sources section). The study sites were individual strip clubs within their neighborhood contexts; at each, I conducted field observations and in-depth interviews with staff and neighbors and reviewed the business' Oregon Liquor Control Commission file and records of calls for police service at the address. I also reviewed newspaper coverage from 2005 to 2012 as well as public documents about court cases and ballot measures related to 
sexually oriented business. Finally, I used geographical information systems (GIS) to conduct spatial analysis of club locations, land use, and demographics.

This chapter of the dissertation describes in detail how I designed and implemented the study. It begins by discussing the roots of the situational analysis method and how they are suited to this project and then continues to describe the particulars of conducting the project. I describe the research setting-Portland, Oregon—and then the research sample. Next, I present the methods used to collect data and the ways I analyzed these data. Finally, I discuss my role as a researcher and describe the limitations of the project.

\section{Research Orientation}

This project set out to study interactions that exist within a complex social system, rather than a discrete relationship between specific causative variables and one definitive effect. As such, it entailed limited a priori generation of hypotheses. Put another way, it was a study of how rather than how much; such questions demand qualitative methods. To an extent, this orientation was a personal choice, based on my worldview and interests. However, there was also a methodological prerogative given the area of inquiry.

Because relatively little is known about the relationships I am studying and because I believed that the situation is constituted by processes operating at multiple social and spatial scales, I elected to use situational-analysis methods. Green-Rennis, Hernandez-Cordero, Schmitz, and Fullilove (in press) suggest that situational analysis is a promising tool for understanding how spatial change affects 
city life due to its utility for providing insight into these interrelated processes. This section describes in greater detail the qualitative research tradition and the situates situational analysis in this traditions, with specific emphasis on how these strategies are employed to address my research questions.

\section{The qualitative tradition.}

As mentioned above, my selection of research questions and corresponding methods is informed by my own philosophical orientation to an interpretivist paradigm; that is, I assume that knowledge is produced from ongoing interaction between people and ideas rather than abstracted from quantitative measurements. I purposefully refer to the people I spoke with as participants rather than subjects because I do not want to suggest that the scientific mode of inquiry has more validity than the lived experiences that are "captured" in the research process. Instead, researchers and the researched co-create understandings of the world we live in. Several aspects of my study merit the use of such methods.

First, relatively little scholarship exists on the topic addressed by this study. While, as discussed in the literature review, researchers have studied conflict over sexually oriented businesses and the occupational hazards of sex work, there has been limited conversation about the spatial aspects of these phenomena or about how they vary across places. Qualitative research can serve to illuminate variables in relationships about which little is known (Cresswell, 2003).

Second, the situation under study is rather unusual. Because there are few U.S. sites besides Portland that have a spatially unregulated sex industry, an indepth study of the processes at play can provide more insight into the dynamics of 
sexual commerce than could a study attempting to compare Portland with very different contexts. Maxwell (2005) identifies this type of inquiry as one of the five intellectual goals for which qualitative methods are suited. Furthermore, Portland's high number of sexually oriented businesses was not encouraged by any official policy but rather is the indirect result of several policies and other factors. Qualitative methods are especially suited to exploring this sort of unanticipated outcomes of policies (Marshall \& Rossman, 1999).

Third, though the strip club industry is legal, there are many informal systems that govern its operations: most notably, because dancers are not characterized as employees, they are not tracked by government data systems. This makes some of the most important people in my study basically invisible in largescale datasets, which means that personal conversations constitute one of the best ways to gain insight into the experience of this group of people. Likewise, the conflicts between strip clubs and their neighbors may be low-level problems or interactions that do not make it into official records such as police reports and legal proceedings. As such, ascertaining more about what the problems were and how they were resolved requires combining existing data sources with personal interactions. I also strove to find a way to understand the meanings of these interactions as described by participants, another goal that is suited to qualitative methods (Maxwell, 2005).

Finally, though each of my three axes of inquiry (about Portland strip clubs, about conflict with neighbors, and about dancers' working conditions) is interesting in its own right, a better picture of the situation can be obtained by integrating the 
findings of each of these subinquiries. Analysis of nested social settings is typical of qualitative research, which is generally concerned with processes more than with discrete individual units (Miles \& Huberman, 1994). The reflexive or dialectical relationship between levels and processes demands looking at them in concert rather than studying discrete strata, which has the danger of robbing the situation of meaning (Guba \& Lincoln, 1994). Ultimately, I am interested in the role that place plays in mediating each of these relationships, yet I began the project unsure about this role. Consequently, I also sought qualitative methods for their flexibility (Maxwell, 2005): I knew I would need to make decisions "in the field" about the directions in which my study would continue. This type of dynamic research procedure is not possible with quantitative methods that require consistent measurement tools and predetermined protocols (Singleton \& Straits, 2005).

\section{Situational analysis.}

Situational analysis suggested itself as a method that could help me achieve my goals of exploring these various scales and relationships amont them. Clarke $(2003,2005)$ describes her iteration of situational analysis as a toolkit for conducting grounded theory analysis "after the postmodern turn." This eclectic qualitative methodology shares grounded theory's utility for inquiry into processes, interrelationships, and conflicts (Charmaz, 2005; Glaser \& Strauss, 1967) but extends the method to allow for consideration of a wider variety of data and conclusions that illuminate multivocality rather than produce a totalizing theory (Clarke, 2005). Like grounded theory, situational analysis employs ongoing comparison between data and interpretations (Charmaz, 2005; Cresswell, 2003). 
This switching back and forth between observations and hypotheses, like changing objectives on a microscope, can be considered abductive reasoning-the process of working through a variety of hypotheses in an effort to find the most reasonable explanations for the data (Clarke, 2007b). According to Clarke (2005), situational analysis shares Straussian grounded theory's interest in generating theory but is interested more in illuminating the complexity and multivocality of a situation than in developing totalizing theory from it.

Situational analysis is distinct from a case study approach in that it chooses as the unit of analysis a situation—or social problem—rather than a functional organizational unit (Yin, 2003). The situation is not merely a setting for the social processes but also an actor. While seeking to situate postmodern voices in context, Clarke also aims to move from grounded theory's interest in social processes to a meso-level focus on social worlds (or arenas), incorporating discourses, organizations, and institutions as actors in the situation of interest.

In addition to coding concepts that emerge from the data, situational analysis relies heavily on conceptual mapping of key elements, social worlds, and discourses encountered in the situation. This approach provides increased flexibility over traditional grounded theory because it is more amenable to multisite research and to the incorporation of visual and other material culture into the analysis (Clarke, 2005).

Though Clarke emphasizes the grounded theory roots of her situational analysis tools, the study of situations has a long history in sociology, psychology and other fields (e.g., Argyle, 1981; Barker, 1968; Goffman, 1974; Thomas \& Thomas, 
1928). Key aspects of situations include the goals of the key players, the elements of the social and behavioral repertoires of the players, the roles players fill, the rules governing interactions, the skills needed to fill the roles and follow the rules, the difficulties people face in carrying out their roles, the environmental setting, and the social and cultural concepts used to describe interactions (Argyle, 1981).

Notably, some scholars refer to their methods as situation analysis rather than situational analysis; it is difficult to know how much to make of those two additional letters and how distinct these approaches are. Situation analysis has been the identified method in a variety of public health studies (e.g., Juma, Askew, \& Ferguson, 2007; McGrath, Fullilove, Kaufman, Wallace, \& Fullilove, 2009; Uganda Ministry of Health, 2008), which bear some resemblance to Clarke's approach. However, none use her situational mapping tools, and several integrate quantitative and qualitative data with the goal of driving policy development, implementation, and monitoring. This application of the findings seems quite far from Clarke's goals, yet is appealing to those who crave "real world" application of research findings.

\section{Study Parameters}

The situation under analysis is strip clubs featuring female entertainers in Portland, Oregon. A situation may be defined as a social problem, which I believe the location of strip clubs in Portland's various neighborhoods to be because it entails conflict over land uses at some sites and potential health hazards for workers at most sites. I designated geographic parameters of the situation for both practical and theoretical reasons. I chose strip clubs rather than sexually oriented businesses 
in general because the barriers to entry to the setting are lower relative to other parts of the sex industry. First, strip club performances are legal, which is not the case for the work done by some of the most vulnerable sex workers; this choice increased the likelihood that people would discuss the situation with me. Furthermore, my interaction with workers and owners would be facilitated by the fact that strip clubs are semipublic spaces unlike many other sex work settings, where interactions between clients and workers occur in more private spaces. As for the focus on female-gendered dancers, they are the only dancers at the overwhelming majority of establishments and have been the focus of the bulk of research on strip clubs. Because of the power of gender roles in American society, social processes likely operate very differently in clubs with male performershence the exclusion of clubs that feature them. Another important practical consideration was that, as a woman, I felt more comfortable approaching other women to participate and felt better able to develop rapport with female dancers than I might have with male dancers.

As for the geographical bounds of the situation, Portland is both an interesting location and my current home. Because I thought that city policy might affect the issues I studied, I felt that focusing on one municipality would best allow me to see the interplay between policies and the outcomes of interest. I also thought that issues might function very differently in Portland than they do in other jurisdictions because Portland is more urbanized and more socially and political liberal than the rest of Oregon, including the surrounding suburban areas. Finally, I thought the higher population and development density in Portland might produce 
richer data because it heightens the likelihood that residents come into contact with strip clubs; interviewees would therefore have more to stay about clubs than would someone from an area with few of them. Practically speaking, the study encompasses most of Oregon's strip clubs because the city has a preponderance of the state's residents and economic activity.

\section{Research Sample and Data Sources}

A traditional grounded theory maxim holds that "everything is data," which fits well with the naturalistic (following the terminology of Lincoln \& Guba, 1985) approach of situational analysis. Yet a researcher must start somewhere; my starting point was determining the types of data I would collect. I decided that I wanted to know about three axes of the situation: the situated knowledge personal experiences, the symbolic interactions in the landscape, and the public discourse. I also identified four geographic scales that I believed would influence the outcomes of interest (geographic distribution of clubs, land use conflicts over clubs, and occupational hazards at strip clubs). These scales were the individual club, the neighborhood, the city, and the state.

Table 1 below shows how three types of data helped me understand the intersections between these axes and scales: in-person interviews, site observation, and document review. Data collection is discussed in more detail in below. 
Table 1

Data Collected by Scale, Axis, and Type

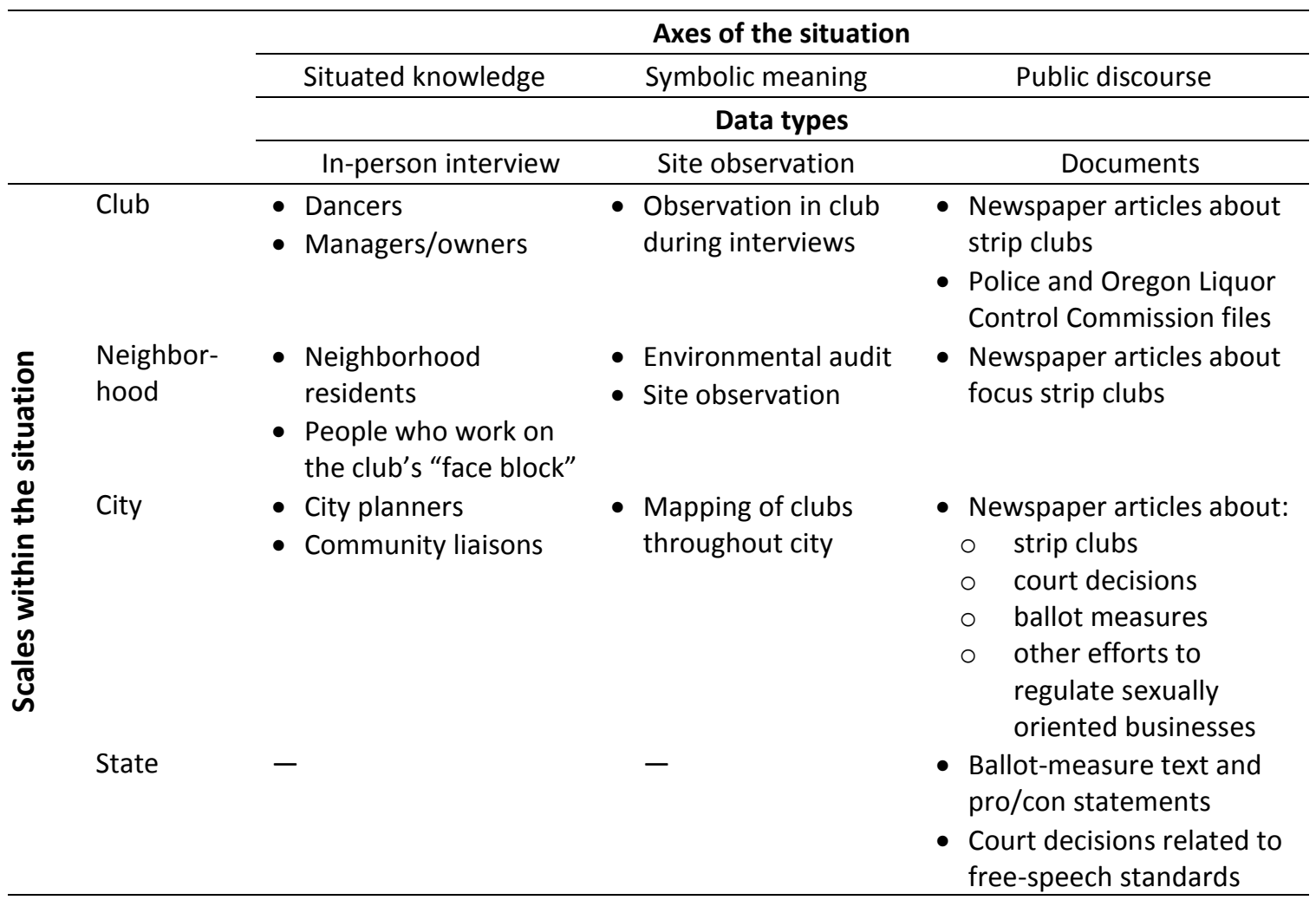

Because a bird's-eye view of the situation could make it difficult to see the fine-grained details of how individual clubs interact with their surroundings, I selected three clubs to serve as sites of focus for my research. The selection of these clubs is described in the next section.

\section{Study sites.}

I selected three clubs as specific study sites to assure that I had the opportunity to observe dynamics at smaller spatial scales. These sites were starting points for data collection but are not considered units of analysis for the study. When findings are presented about individual clubs, they sometimes discuss these 
focus sites but also describe several other individual clubs whose stories emerged in the process of research. Because qualitative research uses theoretical inference to develop plausible explanations for the findings instead of the statistical inference characteristic to quantitative research, I employed theoretical rather than probabilistic sampling to select these sites. Like most qualitative research, this one used a small sample size/number of sites to allow for in-depth exploration of context (Miles \& Huberman, 1994).

Of the variety of qualitative sampling strategies, I used the maximum variation strategy, seeking sites that varied based on sensitizing concepts discovered in my literature review. That is, research on zoning, land use conflict, and sex work suggests that these systems may be influenced by factors such as site history, location, land use mix, neighborhood socioeconomic composition, and club ownership. These sites are described the paragraphs below, with comparisons provided on key sampling dimensions in Table 2. The sites are presented pseudonymously. While a truly naturalistic study would serially select sites until redundancy was achieved (Lincoln \& Guba, 1985), resource constraints led me to predetermine a sample size of three and select sites based on criteria related to my lines of inquiry. 
Table 2

\section{Study Sites and Sampling Dimensions}

\begin{tabular}{|c|c|c|c|}
\hline & Club Rio & The Lagoon & Babydolls \\
\hline \multicolumn{4}{|l|}{ Club } \\
\hline Opening date & $1960 \mathrm{~s}$ & $2000 \mathrm{~s}$ & 1990s? \\
\hline Ownership & Family & $\begin{array}{l}\text { High-profile } \\
\text { owners with } \\
\text { several other clubs }\end{array}$ & $\begin{array}{l}\text { Low-profile owners } \\
\text { with several other } \\
\text { clubs }\end{array}$ \\
\hline $\begin{array}{l}\text { Other sexually oriented } \\
\text { businesses within } .5 \mathrm{mi}^{\text {a }}\end{array}$ & 7 & 2 & 0 \\
\hline Lot type & $\begin{array}{l}\text { Middle of block, } \\
\text { street parking }\end{array}$ & $\begin{array}{l}\text { Corner lot, street } \\
\text { parking }\end{array}$ & Strip mall \\
\hline Aesthetic/clientele $^{\mathrm{b}}$ & Mainstream & Alternative & Low-budget \\
\hline Tentative assessment of conflict ${ }^{b}$ & Low & Moderate & High \\
\hline $\begin{array}{l}\text { Tentative assessment of working } \\
\text { conditions }^{b}\end{array}$ & Good & Fair & Poor \\
\hline \multicolumn{4}{|l|}{$\begin{array}{l}\text { Census tract characteristics } \\
\text { Housing }\end{array}$} \\
\hline Median house age (years) & 71 & 58 & 55 \\
\hline Residential bldgs. with $<5$ units & $3 \%$ & $72 \%$ & $89 \%$ \\
\hline Owner-occupied housing units & $10 \%$ & $45 \%$ & $60 \%$ \\
\hline $\begin{array}{l}\text { Households that include } \\
\text { families }\end{array}$ & $9 \%$ & $50 \%$ & $54 \%$ \\
\hline $\begin{array}{l}\text { Income level }^{b} \\
\text { Race/ethnicity } \\
\text { Non-Hispanic, single race }\end{array}$ & Low & Middle & Moderate \\
\hline American Indian & $2 \%$ & $1 \%$ & $1 \%$ \\
\hline $\begin{array}{l}\text { Asian/Hawaiian/ Pacific } \\
\text { Islander }\end{array}$ & $5 \%$ & $7 \%$ & $7 \%$ \\
\hline Black & $9 \%$ & $3 \%$ & $9 \%$ \\
\hline White & $73 \%$ & $76 \%$ & $49 \%$ \\
\hline Hispanic of any race & $7 \%$ & $9 \%$ & $31 \%$ \\
\hline Other, or two or more races & $4 \%$ & $4 \%$ & $4 \%$ \\
\hline
\end{tabular}

Note. Demographic information was tabulated based on Census Bureau data by TeleAtlas and obtained the Federal Financial Institutions Examination Council Geocoding System (http://www.ffiec.gov/geocode). a. Based on review of Exotic magazine's "XMap" (http://www.xmag.com), September 2012.

$b$. Subjective classification by author based on initial impressions.

c. Containing at least two related individuals.

$d$. Based on Community Reinvestment Act Classifications, which compute the ratio of tract median family income to area family median income. If the result is $<50 \%$, then tract is classified as low income. Fifty to $79 \%$ is moderate, $80-119 \%$ is middle, and $120 \%$ or higher is upper. 
The Lagoon opened within the past decade and is one of a handful of local strip clubs run by a local management team that is quite visible in the nightlife scene. The Lagoon is known for its "alternative" aesthetic, featuring many dancers with tattoos, body piercings, and punk-rock hairstyles. The physical footprint of the club is very small, probably under 1,000 square feet, with one stage, a bar with limited seating room, several small tables, a pool table, and video poker machines. On my visits I did not notice a private dance area, but there may be a small one that gets little use. This club is in on a commercial street in a predominantly residential neighborhood that is experiencing slow but steady gentrification. The census tract that includes the club is middle income, residences are mostly single-family homes, and the majority of inhabitants are non-Hispanic White. The club has a wellmaintained and reasonably attractive façade and no parking lot. I initially thought there might be some conflict over the site because it had recently opened in a residential area and had had several calls for police service, though further research revealed limited conflict.

Located in a commercial district, Club Rio has been run by the same family for decades. The club is small (likely under 1,500 square feet) with one stage, several small tables, a bar, and a small semiprivate area for lap dances. The façade and immediate area are run down, and the surrounding census tract is low income, with housing in apartment buildings; most residents are White, but there is a relatively high number of Black residents. There are very few families living in the area. The club is located on an arterial with limited street parking and is near many nightlife venues, including a few strip clubs. The club has a reputation for 
welcoming a wide cross-section of customers and seemed at the outset of the study to have escaped criticism from neighbors.

Babydolls is a seedy club in a dilapidated strip mall at the edge of an industrial area; neither Babydolls nor the other sexually oriented businesses in the shopping center (a video store and a "lingerie-modeling" establishment) advertise or post prominent signs. Babydolls is a large club with a bar and couple of stages that does most of its business in private rooms where many dancers exchange sex for money; the club does not have a liquor license or telephone line. Both Babydolls and the strip mall in which it is located are owned by members of a family that has several other strip clubs in town; their businesses are incorporated into multiple overlapping ownership entities, which makes it difficult to determine who owns what, and members of the family are difficult to contact. The club has a large parking lot, and the address is frequently visited by police responding to a wide variety of issues, including outstanding warrants, kidnapping, and nuisance issues. Neighbors are very displeased by the club's presence and have sought to restrict the club's operations in many ways. The surrounding neighborhood is predominantly residential with residents diverse in terms of race and ethnicity.

\section{Data Collection}

My primary data sources were individual interviews, site observations, and newspaper articles. This section describes how I delimited the scope of each type of data, how I collected each type of data, and how I recruited study participants. All of 
the data were loaded into the ATLAS.ti qualitative data analysis software package (Muhr, 2007).

\section{Interviews.}

I used in-depth interviews to learn about the extent and character of workplace hazards and neighborhood conflict, both at individual study sites and in the city as a whole. I identified several types of people who could help me understand these issues: dancers, club managers and owners, neighbors, and public employees. I focused my initial data collection on the three study sites, and then let the geographical scope expand as interviewees gave me referrals and as interesting issues emerged. An overview of interviewees' characteristics and my recruitment strategies are presented in Tables 3 and 4, respectively. How I defined these various groups is described in more detail below. This portion of the study was overseen by the Portland State University Human Subjects Research Review Committee, who approved the protocol (included as Appendix A).

I defined the population of dancers eligible for the study as women who had worked at strip clubs within Portland's city limits within the previous six months. When I encountered difficulty in recruiting participants who worked at Babydolls, I expanded the eligibility criteria to women who had worked at these clubs within the past two years. I focused my recruitment on the three study sites and started by recruiting through my personal social network. At the end of each interview, I also asked interviewees for referrals.

I sought to interview owners and managers of the three study sites, as well as one manager who had worked at several clubs in the region. I defined owners and 
managers as people who were listed on the club's liquor license application or business incorporation filing, or who were identified by club staff as the management. I obtained much of this information through Internet searches.

Because of the well-established neighborhood-association system in Portland, I defined my neighborhoods of interest following these official boundaries. I sought interviewees from both the neighborhood associations and the neighborhood business associations; when possible, I focused on association members who worked on land use, crime issues, or both. I also interviewed people who work at businesses near strip clubs, using the club's "face block" — the businesses on both sides of the street block that housed the club. Interviewing both residential and commercial neighbors was intended to help me understand relationships between strip clubs and various constituencies and land uses.

To understand policy and regulatory issues related to strip clubs and neighborhoods, I sought interviews with city, county, and state employees whose agencies have related missions. Examples include criminal justice and lawenforcement entities; community-affairs offices; health and welfare agencies; labor regulators; and land use planning bureaus. To protect the confidentiality of participants, I do not provide the specific names of these agencies. I identified most of these people through Internet searches and referrals from interviewees. 
Table 3

Interviewee Identification and Recruitment

\begin{tabular}{|c|c|c|c|}
\hline $\begin{array}{l}\text { Interviewee type } \\
\text { (interviews completed) }\end{array}$ & $\begin{array}{c}\text { Method of identifying potential } \\
\text { interviewees }\end{array}$ & $\begin{array}{l}\text { Initial } \\
\text { recruitment }\end{array}$ & Follow-up \\
\hline \multirow[t]{3}{*}{ Dancers (9) } & $\begin{array}{l}\text { Referrals from personal } \\
\text { acquaintances, pole-dancing studio } \\
\text { employees, social-service worker }\end{array}$ & \multicolumn{2}{|c|}{ E-mail, phone } \\
\hline & $\begin{array}{l}\text { Internet searches for blogs about } \\
\text { stripping in Portland }\end{array}$ & \multicolumn{2}{|c|}{ E-mail to authors } \\
\hline & $\begin{array}{l}\text { Internet searches for online } \\
\text { community for strippers }\end{array}$ & \multicolumn{2}{|c|}{ Chat-forum posting } \\
\hline Club owners (3) & $\begin{array}{l}\text { Internet search of club websites and } \\
\text { liquor-license records }\end{array}$ & \multicolumn{2}{|l|}{$\begin{array}{l}\text { E-mail, phone, } \\
\text { in-person } \\
\text { visiting }\end{array}$} \\
\hline Business neighbors (14) & $\begin{array}{l}\text { Site visit and Internet search to } \\
\text { identify businesses on face block or } \\
\text { adjacent to focus clubs; Internet } \\
\text { searches for business association } \\
\text { officers }\end{array}$ & $\begin{array}{l}\text { In-person } \\
\text { visiting, hand- } \\
\text { delivered } \\
\text { letters }\end{array}$ & $\begin{array}{l}\text { Phone, in- } \\
\text { person } \\
\text { visiting, e- } \\
\text { mail }\end{array}$ \\
\hline $\begin{array}{l}\text { Residential neighbors } \\
\text { (7) }\end{array}$ & $\begin{array}{l}\text { Internet searches to identify } \\
\text { neighborhood association officers }\end{array}$ & E-mail & Phone \\
\hline Public employees (10) & $\begin{array}{l}\text { Internet searches for people with } \\
\text { relevant assignments }\end{array}$ & E-mail & Phone \\
\hline
\end{tabular}


Table 4

Interviewee Demographics

\begin{tabular}{|c|c|c|c|}
\hline $\begin{array}{c}\text { Interviewee type } \\
\text { (interviews completed) }\end{array}$ & $\begin{array}{c}\% \\
\text { Female }\end{array}$ & Estimated age range & Presumed race/ethnicity \\
\hline Dancers (9) & $100 \%$ & early 20 s through mid-40s & $\begin{array}{l}6 \text { White, } 1 \text { White and Asian, } \\
2 \text { unknown (phone } \\
\text { interviews) }\end{array}$ \\
\hline Club owners (3) & $33 \%$ & early 30 s through mid-60s & White \\
\hline Business neighbors (14) & $50 \%$ & mid-20s through 70s & 10 White, 4 Hispanic \\
\hline Residential neighbors (7) & $71 \%$ & early 30 s through 50 s & $\begin{array}{l}5 \text { White, } 1 \text { Hispanic, } 1 \text { White } \\
\text { and Asian }\end{array}$ \\
\hline Public employees (10) & $60 \%$ & early 30 s through 40 s & 9 White, 1 Hispanic \\
\hline
\end{tabular}

I scheduled interviews at times and locations that were mutually convenient and safe for me and study participants. Interview locations included homes, workplaces, cafés, and clubs. Interviews lasted between fifteen and ninety minutes. Generally, interviews were shortest with business neighbors, who were often working while I interviewed them, and longest with dancers.

Prior to each interview, I developed an interview guide (Lofland \& Lofland, 1995) that led my semistructured interviews. Each guide was tailored to the type of person I was interviewing and any issues I thought might be particularly relevant to his or her neighborhood or workplace (see samples in Appendix B). All interview guides followed the general format of beginning with questions about the interviewee's personal background and current work before moving into questions about their experiences with specific strip clubs in Portland and ending with 
discussion of the broader issues about strip club location and worker health. The interview guide evolved over time as a result of iterative changes implemented as I integrated interviews and other data sources.

If interviewees did not consent to be recorded or I had a recording failure, I wrote up interview notes as soon as possible after our meeting. Otherwise, I later transcribed the interview myself or had a transcriber do it. To distill the contents of interviews, I produced précis rather than full transcripts of interviews, condensing the interviews into documents that include the salient features of the interview in the participant's own words in the order they were spoken. This technique was a valuable data-reduction tool that allowed me to form initial analytical ideas before fully immersing myself in analysis. Though I include it in this discussion of data collection, data reduction is in and of itself an analytical procedure because it narrows the information to be used in analysis (Miles \& Huberman, 1994).

\section{Archival document review.}

Reviewing government documents and media coverage provided information about the regulatory and social context for strip clubs in Portland, Oregon. I reviewed the following types of documents: court and administrative case documents, ballot-measure pro and con statements, police and liquor control commission records, and newspaper articles.

I reviewed legal decisions for the court cases that established the state obscenity standards, administrative decisions addressing working conditions in strip clubs, and ballot-measure pro and con statements provided by the Oregon Secretary of State for three measures proposing to change the state obscenity 
standard. Table 5 places the names of the cases and measures on a timeline. For each of the study sites (focus clubs), I reviewed their complete Oregon Liquor Control Commission file and police records for calls for service at the address going back two years.

Table 5

Archival Documents Reviewed

\begin{tabular}{|c|c|c|c|}
\hline $\begin{array}{c}\text { Year } \\
\text { published }\end{array}$ & $\begin{array}{l}\text { Oregon Supreme } \\
\text { Court cases }\end{array}$ & $\begin{array}{l}\text { Oregon Board of Labor } \\
\text { and Industry decisions }\end{array}$ & $\begin{array}{c}\text { Voter } \\
\text { information }\end{array}$ \\
\hline 1982 & State v. Robertson & & \\
\hline 1987 & State v. Henry & & \\
\hline 1994 & & & Measure 19 \\
\hline 1996 & & $\begin{array}{l}\text { Geoffroy Enterprises DBA } \\
\text { Babes Cabaret }\end{array}$ & Measure 31 \\
\hline 1997 & & Acropolis McLoughlin & \\
\hline 1998 & & Bomareto Ent. & \\
\hline 2000 & & & Measure 87 \\
\hline 2005 & $\begin{array}{l}\text { State v. Ciancanelli } \\
\text { Nyssa v. Dufloth }\end{array}$ & & \\
\hline
\end{tabular}

I also reviewed local newspaper coverage of strip clubs from 2005 to 2012 . I used the America's Historical Newspapers and Alt-Press Watch databases to search for articles with the keywords strip club, striptease, adult entertainment, and exotic dance from the paper of record, the Oregonian, and alternative weeklies Willamette 
Week and the Portland Mercury. I also included articles from other sources I encountered in the course of my research.

\section{Field observations and GIS.}

To better understand the spatial aspects of the club sites, I conducted limited site observations and GIS analysis. Using a checklist developed during a previous project (McGrath, 2009), I performed systematic environmental audits of the individual sites in 2009 and also wrote field notes about visits to the club sites during recruitment and interviews in the neighborhoods. I also used the Regional Land Use Information dataset (Metro Data Resource Center, 2012) and ArcGIS software (ESRI, 2010) to explore other aspects of strip club location, such as zoning designation, parcel size, and proximity to other sexually oriented businesses.

\section{Data Analysis}

My analysis of the data began in earnest soon after I started interviewing participants, as I had previous previously gathered many of the documents and conducted field observations in smaller research projects leading up the dissertation. As I gathered new data and entered them into my ATLAS.ti database, I analyzed the data using thematic coding coupled with situational-analysis conceptual mapping tools. Data analysis was an ongoing process of coding, reflecting on my ideas, and revising them as I continued to collect new data. This strategy produced a variety of analytical documents; when I produced them and how I used them are summarized in Table 6. The ongoing collection of data and production of these documents furthered my iterative analytical process by helping 
to integrate codes and categories as I moved through successive rounds of analysis (Emerson, Fretz, \& Shaw, 1995).

Table 6

Documents Produced During Data Analysis

\begin{tabular}{|c|c|c|}
\hline Document & Frequency of production & Purpose \\
\hline Interview notes & $\begin{array}{l}\text { As soon as possible after } \\
\text { interview }\end{array}$ & $\begin{array}{l}\text { Summarize content of interviews that were not } \\
\text { recorded }\end{array}$ \\
\hline Interview précis & After transcription & Distill content of interviews \\
\hline Analytical memo & After each round of coding & Define meaning of codes, identify categories \\
\hline Situational maps & Ongoing & Identify human and nonhuman actors \\
\hline Positional maps & Ongoing & Identify discourses and place actors along them \\
\hline Social worlds maps & Ongoing & Identify domains within the situation \\
\hline Timeline & Ongoing & Develop historical narrative of situation \\
\hline
\end{tabular}

\section{Coding.}

I conducted three phases of coding the data to identify features of the situation: open coding, coding into categories, and coding for theory generation. Throughout the coding process, I periodically wrote memos-short commentaries about a given code, analytic direction, or hypothesis-to reflect on the questions I was generating and conclusions I was drawing.

Open coding was a first pass at the data, getting to know the corpus (called primary documents in ATLAS.ti parlance) by reading line by line and assigning codes to segments of text. These codes were a way to note my preliminary ideas about what various pieces of data suggested about the situation being studied. 
Clarke (2003) describes these codes as "temporary labels" (p. 556). I began this stage of coding after having completed about a third of my interviews.

In the next stage, I collapsed the many codes generated in the initial stage into categories, guided by my research questions. Attuned to codes related to place, conflict, health, and negotiation, I collapsed codes into categories that addressed my questions about the interrelationships between those concepts. Another way of describing this stage is "pattern coding" (Miles \& Huberman, 1994), because the initial codes are grouped based on patterns that the researcher sees in the code list. Because I identified broad research areas prior to coding and was looking for certain types of patterns, my approach was not strictly phenomenological (Rossman \& Rallis, 1998) despite the study's exploratory approach. I developed categories that addressed my three analytical axes (location, land use conflict, and health) and the scales at which I collected data (individual club, neighborhood, city of Portland, and state of Oregon). These relationships are diagrammed in Appendix E.

\section{Conceptual mapping.}

Simultaneous to coding, I employed Clarke's situational mapping tools for analysis of the data. These maps begin as messy brainstorming activities and transform into more sophisticated diagrams that suggest-through a process of continual refinement-relationships between their different nodes. The types of items included in these maps are individual and collective human actors, discourses, political and economic elements, temporal elements, essential events, and major issues. Another situational-analysis technique I employed was creating a timeline of key events (Green-Rennis et al., in press). Situational maps list the human and 
nonhuman actors and actants involved in the situation (see Appendix $\mathrm{F}$ for a sample). Social worlds (or arenas) map group elements into social groups that share a perspective on the situation (see Appendix G for a sample). Positional maps use elements of discourses as the axes for graphs onto which the positions taken by actors in the situation are plotted (see Appendix $\mathrm{H}$ for a sample).

\section{Validity and Reliability}

The main strategies I used to increase the validity and reliability of the study entailed engaging with a variety of perspectives on the situation. I employed multisite design, multiple data sources, and interviewees with a variety of stakeholder types to construct my understanding of the situation.

To assure that differences among sites weren't obscured by looking at the whole city, I looked more closely at specific club sites. Choosing multiple sites reduced the likelihood that I would erroneously draw a conclusion about the whole city based on a phenomenon unique to one club. Because of the ability to compare between sites, a multisite design allows for more specificity in describing how, where, and — possibly—why the findings apply (Miles \& Huberman, 1994).

Similarly, while I conducted individual interviews as a way to understand lived experiences, relying solely on interviews can decontextualize findings and elide tacit processes within the situation (Charmaz, 2005). I used field observations and document review both to contextualize and to interrogate what I heard in interviews. For example, if an interviewee complained about the close proximity of a club to his or her house and about its garish decor, a site visit might confirm that 
this statement was something of an exaggeration, providing guidance for interpreting the rest of the information that the interviewee provided. The document review was particularly valuable for identifying issues that I might want to include in an interview or filling out the details of an incident mentioned by an interviewee that I might have misunderstood.

This diversity of sources and perspectives not only filled in gaps in my picture of the situation but also helped advance the validity of my analysis through triangulation, or using "more than one approach to the investigation of a research question in order to enhance confidence in the ensuing findings" (Bryman, 2003, p. 1142). Triangulation helps to produce more coherent analyses because the limitations of one approach may be the strengths of another (Kirk \& Miller, 1986). Triangulation was especially valuable in my interviews because I had the opportunity to interview people with different perspectives on the situation. When multiple types of people shared an interpretation of something, I had high confidence in drawing conclusions based on it. Conversely, when different interviewees described the same thing very differently, I was clued in to a tension in the situation. The project included multiple types of triangulation: by data source (individuals, documents, field observation), by method (observation, interview, discourse analysis), and by theoretical perspective (urban planning and public health) (Bryman, 2003; Denzin, 1970; Miles \& Huberman, 1994). 


\section{Role of the Researcher}

The design of the study and the application of analytical procedures must be understood in the context of who I am and why I conducted the study, as these factors surely influenced what I noticed and failed to notice as I gathered and interpreted information. I undertook this project because of my personal interests and chose its research methods because of the ways I like to learn. Though I built on the findings of research by other scholars to determine my research questions and strove to align my research questions with established research questions, another researcher may have chosen a different path to answer the same questions and even seen different patterns in the data. Furthermore, the project must be understood in the context of the ethical obligations of researchers, which are discussed later in this chapter to give the reader the contextual information necessary to understand and evaluate my work.

\section{Motivations for study.}

As a feminist, I am deeply interested in women's experiences and particularly in how women find power in the face of marginalization; this has driven my interest in sex work. As a feminist scholar, I am deeply skeptical of positivistic science, which embraces totalizing narratives and casts the researcher as objective observer rather than an active element within the research context, hence my methodological choices. Informed by the feminist critique of science, I chose a mode of inquiry that would allow me to emphasize perspective, lived experience, and intersectionality (Clarke, 2007a). Choosing open-ended research questions about roles and 
processes followed my interest in developing narrative understandings of the situation in collaboration with my participants (Marshall \& Rossman, 1999). I began this the project with concerns about fairness and well-being in strip clubs, and I retain these concerns at the close of the study. I hoped to conduct research that suggested practices or policies that may improve the work experience of sex workers-hence, the study design that focuses on the experience of these women. My focus on these women and their health shows an advocacy orientation (Cresswell, 2003), in line with a participatory-action research tradition that aims for social change and restorative justice through inclusion (O'Neill et al., 2008). However, this is not strictly an advocacy (or participatory) research project because the situational analysis approach places the experience of this ostensibly marginalized group within a larger social ecological context. While much feminist advocacy research may concern itself with the context of oppression, this study also solicited the experiences of people in a variety of roles instead of just members of the ostensibly marginalized group. The drive to give voice to the experience of women, yet to situate that experience within a larger context, positions me in a "society and culture" genre of qualitative research developed by ethnographers and sociologists (Marshall \& Rossman, 1999). It also suggests the grounded theory approach, because these methods can be very effective at describing "the conditions under which injustice or justice develops, changes, or continues" through comparison of different realities described by participants (Charmaz, 2005, p. 508). 
Ethical issues.

Research about sex work requires careful consideration of ethical issues (Sanders, 2006; Shaver, 2005). All people invited to participate in research are entitled to a clear, noncoercive description of the potential risks and benefits of participating in the project, but researchers must pay special attention to this process when working with what are considered sensitive populations. Though I believe that most, if not all, exotic dancers are capable of deciding for themselves whether they would like to participate in this study, I am reasonably content with the "sensitive population" designation that some would consider paternalistic. Though sex work is increasingly socially acceptable, it still bears a stigma in and some dancers may not be "out" to some people in their lives; this covert identity mandates special protection. Strategies I used to build relationships and ensure a robust consent process include providing ample contact information to potential participants, clarifying the roles of a researcher as compared to a representative of a regulatory or social service agency, and minimizing my disruption of the participants' work. Even though other types of interviewees seemed less vulnerable to the potential risks of the study, I afforded them the same consideration. I used standard confidentiality protections like separating identifying details from data, minimizing the use of full names, and keeping project information in passwordprotected computer files. Safeguarding this information is an essential obligation. Beyond the level of individual participants, the research topic itself is socially sensitive. This study hits on at least two of the four criteria for potential sensitivity identified by Lee and Renzetti (1993): being concerned with deviance and social 
control, on the one hand, and impinging on vested interests of powerful people, on the other. Deviance and control are at the heart of sexual geography, and each of the groups of people I have chosen to recruit has interests vested in the phenomena. This project's interest in critiquing policy (and absence of policy) has the potential to suggest changes that could affect each of the parties that I studied. Dancers or club owners were wary of discussions that might suggest changes to the regulation of their work (and thereby reduce their profit), and neighborhood residents were concerned about property values and neighborhood reputation.

One of the most critical skills in research, and especially sensitive research, is cultural sensitivity: the ability to adjust to different settings, anticipate and empathize with people's concerns, and communicate respectfully in a variety of manners (Sieber, 1993). I have had the good fortune to strengthen my crosscultural skills through living and researching in variety of settings. I tried to enter the field with as much humility, authenticity, and openness as possible. Some specific ways I communicated this were clearly articulating my interests and motivations and providing opportunities for participants to obtain more information about me and the study. Shaver (2005) describes researching street prostitutes' strolls in "guest mode," which I find a useful reminder of how to treat the research setting: as if participants are welcoming you into their living rooms. I made it clear that I was approaching interviewees as experts on the topics I was discussing with them rather than as objects of curiosity or victims of the problems described in the literature review. Not only does this fit with my view of their work but it should also make the research more successful: treating sex workers as 
experts rather than research subjects is less intrusive and less marginalizing (Sanchez, 1997).

\section{Limitations}

Both the design of the study and the way I implemented it created limitations to its reliability and validity. Other limitations were related to who I am and the topic I chose. The major limitations are related a lack of generalizability and interrater reliability, my relative inexperience as a researcher, and my choice to take on a topic area where I had limited connections.

First, as is the case with much qualitative research, the study is not easily generalizable to other settings. Delving so deeply into one particular situation make it difficult to apply findings to other environment, especially given the unique configuration of the issues under study in Portland. This is particularly problematic for planning and public health (and other) practitioners, who are pressed to employ "best practices" or develop "evidence-based" programs. The messy picture of the situation produced by situational analysis can also make it difficult to identify the relative magnitude of contributions to the situation or to prioritize strategies for resolving the conflicts identified in the study.

There are also many limitations that come from being a one-person research project. Both my time in the field and my ability to immerse myself is the data were limited by real-world constraints (e.g., a full-time job doing something unrelated to this dissertation research), and the reliability and validity of analysis conducted by a sole analyst. Qualitative research employs inductive reasoning, the framing of 
research questions is based on the researcher's worldview (Charmaz, 2005). Thus, the choices I made about data to pursue and the conclusions I drew from the study were likely strongly influenced by what I find personally or professionally important. For example, I undertook the study assuming that there was some level of conflict between neighbors and strip clubs and that there were occupational health problems in the workplace. Predefining my interest in those issues within the situation could have created "tunnel vision," impeding my ability to discern important stories in the data (Clarke, 2005). More time and resources (for example, colleagues engaged in the same inquiry) would have allowed for greater intimacy with the setting, one of the most important criteria for grounded theory research (Charmaz, 2005) and for a level of inter-rater reliability. While my diverse data sources strengthened the quality of my conclusions (Miles \& Huberman, 1994), I did not employ "member checks" (Lincoln \& Guba, 1985) to have respondents review the conclusions I drew based on our conversations.

The study also faced challenges due to my being an early career researcher. Despite Clarke's admonition (2003) that "thoughtful memos on the computer are intellectual capital in the scholarly bank" (p. 561), I still succumbed to inadequate memoing, which she calls " the major problem of almost all research projects." The result is likely that I missed opportunities to learn more from my data by failing to pick up on interesting contradictions or patterns that would have been identified by more assiduous memoing. While qualitative researchers are generally strive to collect and analyze data until reaching the point of theoretical saturation (Glaser \& Strauss, 1967) - though how to ascertain saturation is an ongoing debate (Mason, 
2010; O'Reilly \& Parker, 2012)—an honest accounting of my research procedures requires disclosing that I moved from interviewing, memoing, and situational mapping into writing up results more out to exhaustion than a belief that I had captured all that was possible to know about my research questions. This decision was motivated by the overwhelming feeling that the pursuing saturation was a “potentially limitless” (J. Green \& Thorogood, 2004, p. 120) endeavor.

Finally, research on sex work presents a variety of methodological challenges that are especially daunting for a beginning researcher. I struggled to recruit a robust sample of dancers, a common pitfall noted by Bradley-Engen and Ulmer (2009). My sample skewed toward people like me, since they were easier for me to find and build rapport with. For example, in my efforts to recruit business neighbors, I was highly unsuccessful at securing the participation of small immigrant-owned businesses and in some cases would not have been interview the neighbors because we did not have a language in common. With dancers, my use of snowball sampling likely resulted in the bias of which Shaver (2005) cautions, where the sample includes only the most cooperative members of the population and consequently reflects only a certain type of perspective on the situation. My approach to recruiting residential neighbors through neighborhood associations also likely resulted in the underrepresentation of the diversity of resident opinions. Because sex work remains stigmatized both by the general public and sometimes by academic "squeamishness," it can be difficult to develop a trusting relationship with people working in the field and to build a case that research will be useful (Hubbard, 1999). There are also of getting into the setting, understanding what is happening, 
and addressing the emotional impact of being in potentially uncomfortable situations (Sanders, 2006).

\section{Summary of Methodology}

To better understand the processes driving where strip clubs locate, how neighbors perceive strip clubs, and what influences the workplace experiences of women working in strip clubs within the unique environment of Portland, I drew on a the qualitative research tradition to design a study of these issues using situational analysis methods. I devised a data collection strategy based on my initial belief that these processes operated at different geographical scales (individual club, neighborhood, city, and a state) and were embodied in individual people's lived experiences, the physical environment of the strip club, and the sociocultural environment of public discourse about strip clubs. I designated a study period of 2005-2012 and conducted in-person interviews, site observation and mapping, and archival research. I used theoretical sampling for maximum variation to identify three strip club study sites to serve as the focus of data collection and interviewed 43 people who worked at strip clubs, lived or worked near a strip club, or worked with strip clubs in their capacity as a public employee. Archival research included review of newspaper articles and ballot measure pro and con statements. I used coding and conceptual mapping (Clarke, 2005) techniques to identify themes and categories in the data. The study is limited in generalizability to other settings and likely provides an incomplete picture of the situation due to sampling strategies, implementation of the research protocol, and the practical limitations of a one- 
person research team. The following chapter, entitled Describing the Situation, presents a picture of the study setting developed through this research. It is followed by the Findings chapter, which presents the data as they relate to the research questions. 


\section{Chapter 4: Describing the Situation}

This chapter, situated between discussions of Methodology and Findings, serves to further describe the situation under study: strip clubs in the city of Portland, Oregon. It is a hybrid of background and findings, as it provides context useful for interpreting the study findings, yet the information was generated through application of the research protocol. This chapters discusses the distribution of clubs throughout the city and diversity among clubs, in terms of their siting, aesthetic, and clientele. It then describes the legal and economic context for the strip club sector in Portland. The goal of this chapter, which is based primarily on the document review, is to help the reader understand how and why Portland has developed a reputation as Strip City.

\section{Welcome to Strip City}

Portland's many strip clubs constitute a local cottage industry that has emerged since the 1980s, earning the city nicknames like Strip City. The presentday strip club sector is notably diverse in geography, aesthetic, clientele, and working conditions. With almost 600,000 residents and almost 46 strip clubs, Portland has a remarkable number of strip clubs. Many more-populous cities have far fewer clubs and much stricter regulations on alcohol service, attire, and contact between customers and performers (Brunner, 2006). Local folklore holds that Portland has the most strip clubs per capita of any U.S. city (A. S. Moore, 2005), a belief confirmed by my systematic review of Portland's trade magazine for the sex industry (Exotic) and listings on "The Ultimate Strip Club List" website 
(http://www.tuscl.net). I found 7.5 strip clubs per 100,000 Portland residents in March 2012. By comparison, "Sin City" (Las Vegas) had the same population as Portland but only 26 strip clubs, or 4.5 per 100,000 residents. Statistics for Portland and several other cities are presented in Figure 3 below.

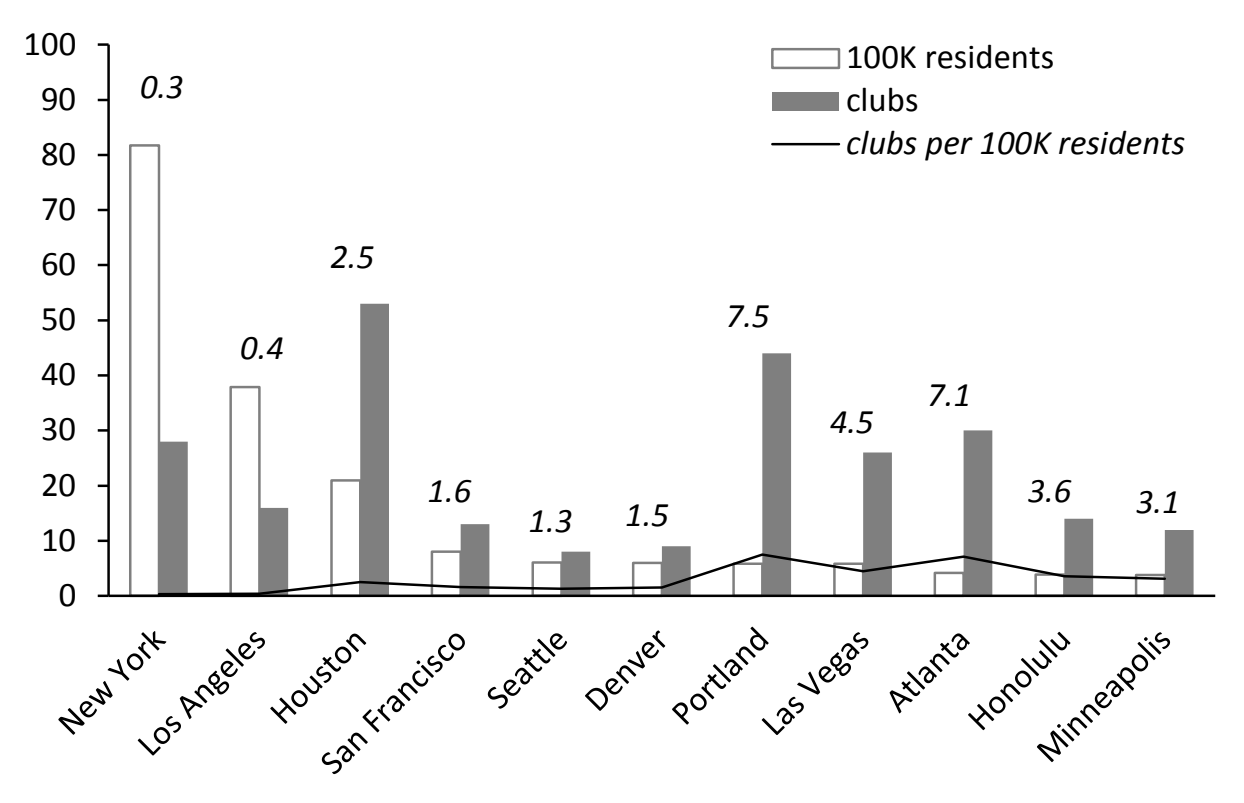

Note. Population statistics taken from Census 2010, strip club numbers from The Ultimate Strip Club List.

Figure 3. Strip clubs per capita, selected U.S. cities, 2012.

Clubs are also geographically diverse and found in every quadrant of the city, near homes, schools, places of worship, highway exit ramps, and industrial districts.

Figure 4 below illustrates the present-day locations of clubs throughout the city. 


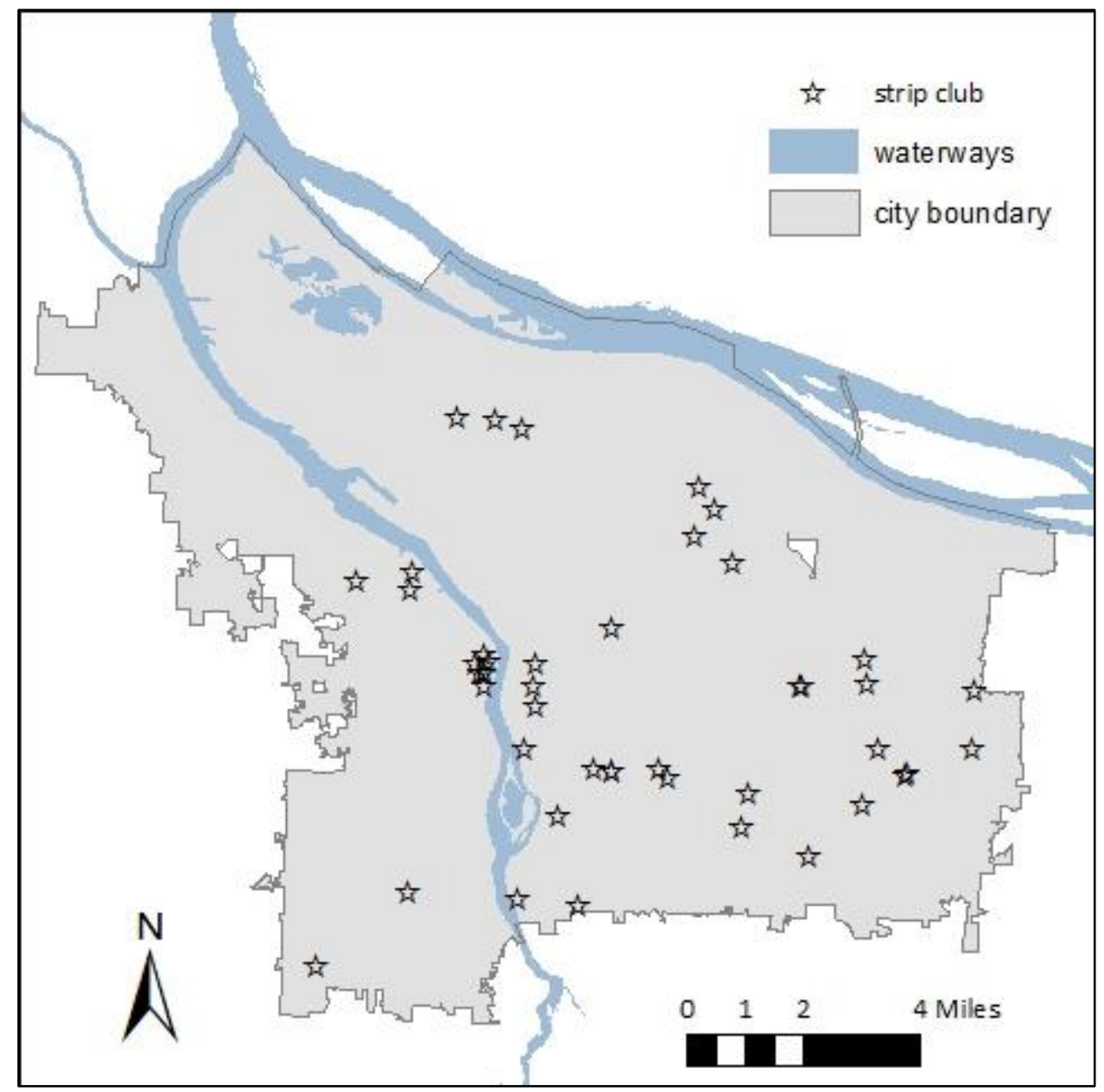

Note. Geospatial data from Metro Regional Government Regional Land Use Information System (RLIS)

Figure 4. Portland strip clubs, March 2013.

Both local and national media include strip clubs in their description of Portland, in tones ranging from the prurient to the outraged. For example, a 2007 press release for the trendy Ace Hotel described the town as having "a 'villagey' bookishness not unlike Hay-on-Wye and the seediness of Amsterdam with its 56 strip clubs." Soon thereafter, ABC News called Portland "the erotic epicenter of America," saying that the city promotes "its reputation for sleaze as part of the 
funky, offbeat culture that thrives here" (Donaldson James, 2008). The ABC article continued, linking the local arts scene and socially liberally policy decisions such as Oregon's medical marijuana and assisted suicide laws with the local slogan, "keep Portland weird." A rhapsodic Travel + Leisure article entitled “American Eden" (Austin, 2007) described the situation with some bemusement, calling Portland an idiosyncratic indie scene, where fair-trade cafés and strip clubs draw the same clientele... oddly enough, reasonable-looking young couples in the crowd are not an uncommon sight. Strip bars are as ordinary as the city's ubiquitous microbrew pubs, which are full of evolved frat boys in SNOB (Supporter of Native Oregon Beer) t-shirts.

A recent New York Times travel article on Portland (Gross, 2009) described a visit to a strip club as an "inevitable" part of a visit and linked strip clubs to the city's foodie scene, recommending the Acropolis Steakhouse-which is also a strip club-to readers on the basis of its free-range organic beef raised on the club owner's ranch.

Downtown's Mary's Club was “Portland's first topless," and its retro neon marquee is a landmark for locals and tourists alike. The club's iconic cocktailwaitress logo is a familiar sight on jackets and t-shirts around the city, and Mary's was named one of the 10 best strip clubs in the U.S. by Men's Health magazine (Gould, 2005). Today, the third generation of the Keller family runs the club and the marquee bears an epitaph for patriarch Roy, who died in 2006.

Portland is proud of its famous strippers, such as rocker Courtney Love, who worked at Mary's, and Viva Las Vegas, who immortalized the local scene in her memoir Magic Gardens (2009). The strip club industry is a visible if minor 
participant in civic life, through activities such as a fundraiser for breast cancer research and one club's annual bikini dog wash, the proceeds of which go to the local humane society.

As a relatively large industry in Portland, sexually oriented businesses have become increasingly visible in public life. Some club owners are also professionalizing, joining forces, and being more proactive about engaging with neighbors and government agencies. One indicator of this professionalization is the existence of Exotic magazine, a trade magazine, which began publishing in 1993. Although the bulk of Exotic's content is advertisements for strip clubs and other sexually oriented businesses, there is some editorial content that sometimes includes commentary on policy issues affecting the industry. Several club owners manage multiple properties and are regularly quoted in local news coverage. One example is Frank Faillace, who started Exotic magazine and is full or part owner of clubs including Sassy’s, Devils Point, Lucky Devil, and Boom Boom Room. Club owners have been particularly visible during times when there have been threats of additional controls on the industry, such as Claude da Corsi's statements on behalf of the Association of Club Executives during periods of debates over proposed ballot measures (Bates, 1996).

\section{Typologies of Clubs and Sites}

As mentioned above, strip clubs are spread throughout the city; below I discuss characterization of club locations and club types. Though extensive geographic classification is beyond the scope of this project, I propose a simple 
typology of sites (peripheral, commercial, and neighborhood) and discuss the typology of clubs, with special attention to the Portland institution of the "neighborhood strip club."

In most cities, strip clubs are restricted to very specific areas, but in Portland they are sprinkled throughout the city. In many cases, clubs are sited in what I would consider stereotypical strip clubs locations: industrial areas peripheral to retail and community services, where there is little foot traffic and limited humanscale features and amenities. For the purposes of this study, a simple way of designating such locations was to select clubs located in areas with an industrial land use designation (approximately 20\% of Portland clubs). Another location type is commercial area, such as the Central Business District (about 10\% of strip clubs), Convention Center, or shopping mall areas. These locations have primarily commercial development, with few housing units but the bulk of the city's hotel rooms. A third type of location is in the city's residential neighborhoods; as businesses, strip clubs are located in commercial districts or districts that mix commercial and residential land uses. This location type would be very unusual for a strip club in most other U.S. cities. Figure 5 shows strip club locations and land use designations throughout the city of Portland. Figure 6 shows strip club locations and population density as another way of illustrating the proximity of strip clubs to residential land uses. 


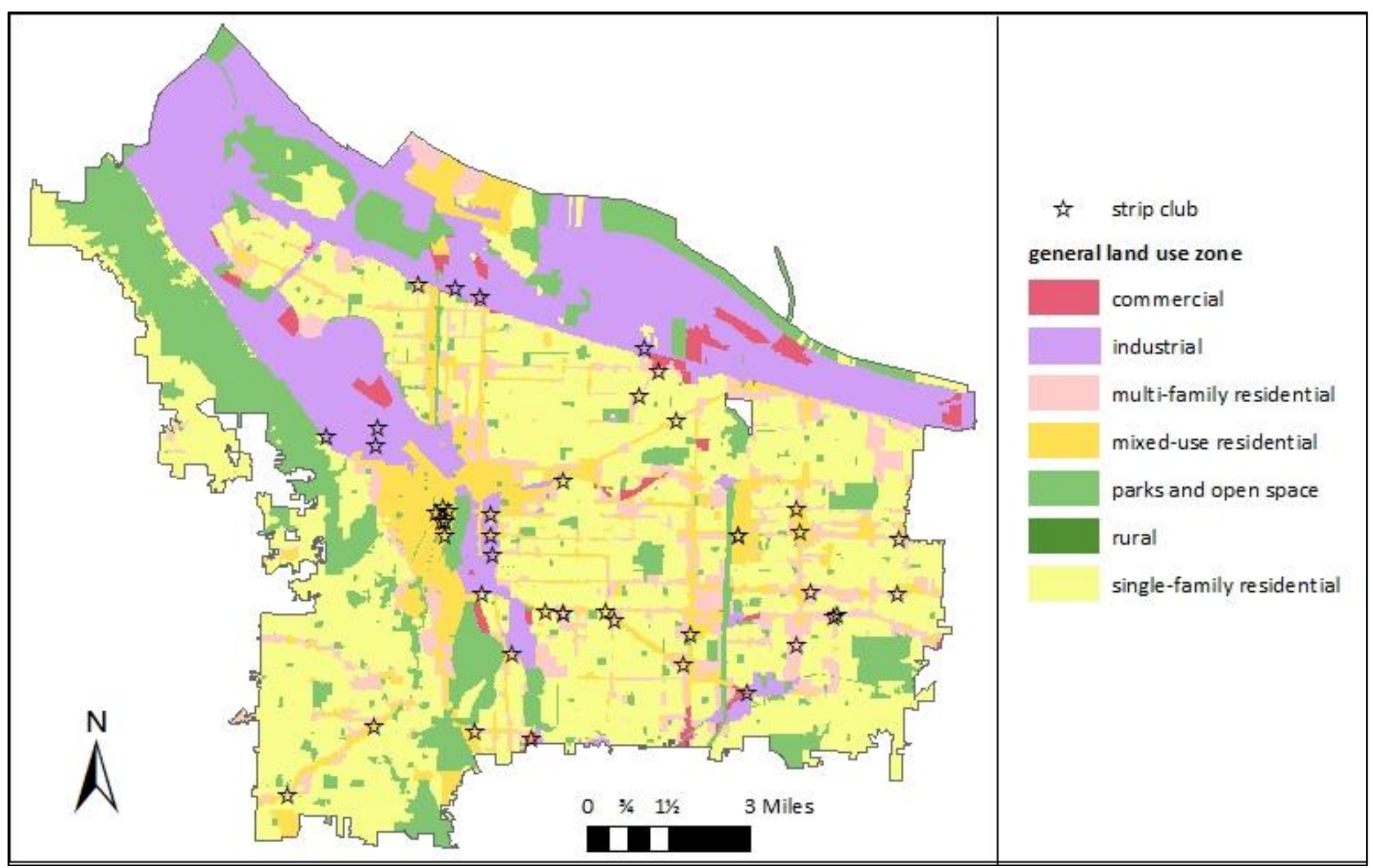

Figure 5. Portland strip clubs and land use designation, 2013. 


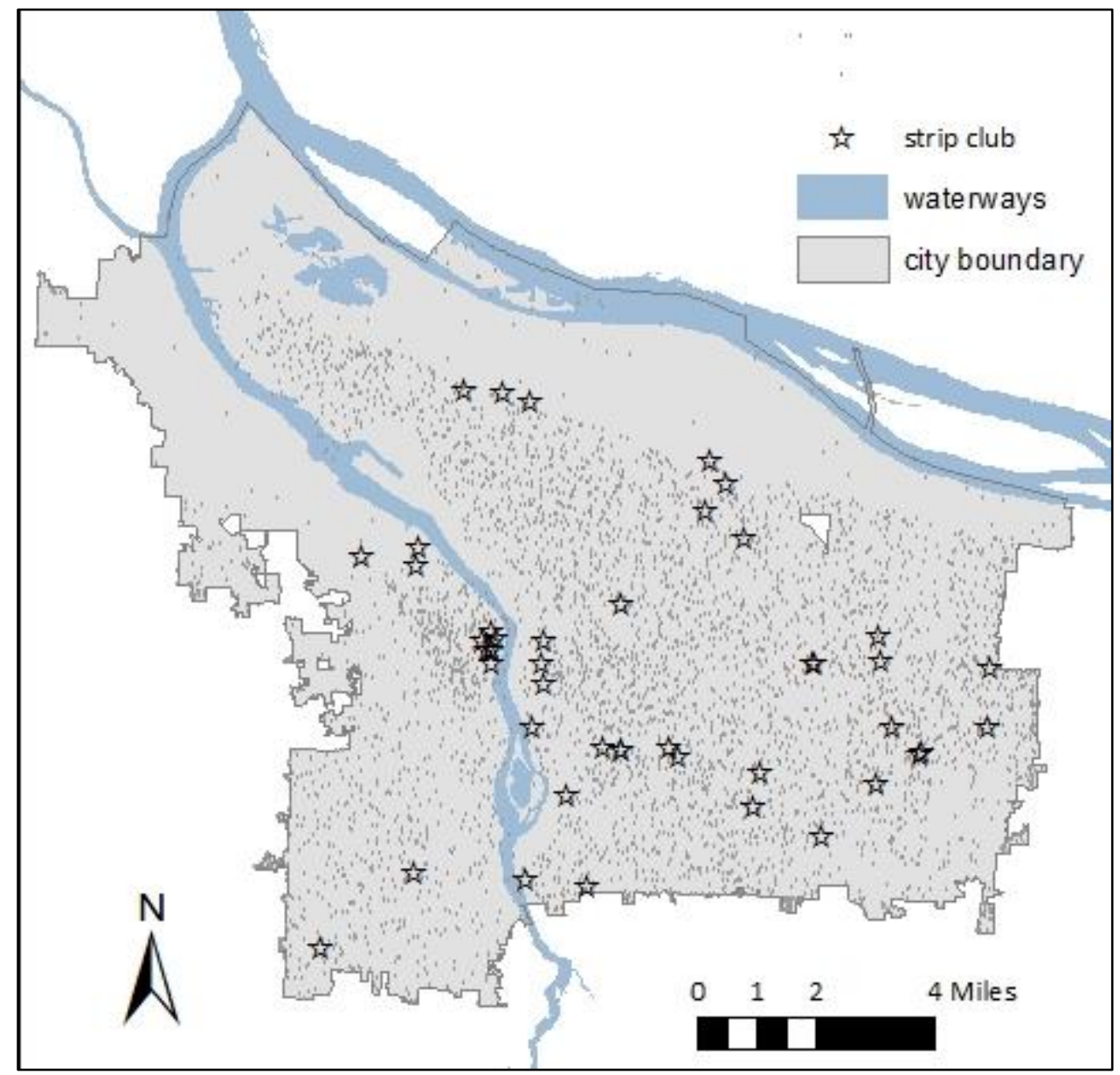

Note. One dot equals 150 residents.

Figure 6. Portland strip clubs and population density, 2010 population, 2013 strip clubs

Just as there are different types of sites, there are also different types of clubs. Again, it was beyond the scope of this project to classify all of the clubs in Portland, yet my research suggests that most of the city's clubs fit within the 
typology of show clubs, hustle clubs, and social clubs proposed by Bradley-Engen (2009), though show clubs are somewhat rare in Portland. Carly, who has worked at Portland strip clubs for decades, estimated that about a third of Portland clubs would be considered hustle clubs and about half would be social clubs. Of the social clubs, about half of them (or a quarter of all clubs) are very small, with fewer than 10 women performing on a given day. Many interviewees referred to these as "neighborhood clubs." Other observations and interviews supported Carly's characterization.

As noted in the Methodology chapter, the three clubs designated as study sites were the pseudonymous Lagoon, Club Rio, and Babydolls, each of which is located at a different type of site in the typology described above (residential, commercial, and peripheral, respectively).

\section{Club Aesthetics and Clientele}

While the striptease conducted in Portland clubs is clearly the same activity as that in Las Vegas or New York clubs, Portland's clubs have a local flavor. In addition to their geographic diversity, Portland's strip clubs also vary widely in aesthetic and clientele. Because of this variation, there is a wide spectrum of performance spaces and styles, which gives the city a reputation for innovation in striptease.

Although it is difficult to substantiate empirically, document review and interviews suggested that strip clubs in Portland are frequented by a wider swath of the population than is the case in most other U.S. cities. The most obvious difference 
is the significant number of female patrons, which is especially notable given the fact that some strip clubs in other cities deny entry to women unaccompanied by men. Other customers include mixed-gender groups and couples of various sexual orientations; it is not unusual for a restaurant staff to go together to a strip club to decompress after work, for example. Going to a strip club is generally socially acceptable in Portland: as many interviewees on all sides of the issue reported, "It's different here." These nontraditional audiences may be attracted to the clubs by their nontraditional performances and nontraditional locations.

Portland dancers are known for acrobatic pole tricks and signature routines, some of which are closer to performance art than boudoir fantasy. Dancer Fiona explained the experience of performing at her favorite Portland club: "It's a show, entertainment. They've got monkey bars on the ceiling, girls are swinging from the rafters. It's crazy, it's fun, the lighting is more complementary to the dancers ..." She contrasted this with another club, where "You have to be really good at the pole, it's more edgy, there's more tattoos, there's more of the rockstar punk [vibe]. You have to be more of an acrobat there." Club owner Timothy described his club's style: "We're more on the burlesque side of entertainment. Most of the girls that work for me also spin around the pole and do crazy tricks and it's really entertaining. They don't just come out, prance around, and take their top off." The performance style in Portland clubs has been compared to that of Cirque du Soleil and other carnivalesque acts.

Portland even has themed strip clubs: while the swashbuckling Pirate's Tavern has closed, the Casa Diablo vegan strip club (no animal products on its menu, 
and dancers avoid costumes with leather, fur, or feathers) appears to be going strong, with managers planning to expand to a second location. Portland is also known for helping to launch the "Suicide Girls" aesthetic, named for a pinup website that started in Portland and that featured women appearing in an "alternative" or "goth" style, with brightly dyed hair, tattoos, and body piercings. Many of these adornments are banned in strip clubs in others, but they have become mainstream in Portland clubs.

Some of Portland's best-known strippers are decidedly punk rock, taking names like Malice and Rocket, and performing in multicolored Mohawks and leather jackets, accessorized with ripped fishnet tights and artillery belts, a sharp departure from the stereotypical feminine imagery that prevails in the average strip club. Eschewing the Top 40, these dancers perform to their personal favorites, which might include death metal or brooding atmospheric singers like Tom Waits. Portland style may be more than other areas can handle, as Malice recently lamented in an interview with Portland stripper Kat (posted on the "Tits and Sass" blog on March 15, 2011), even a toned-down version of her heavy metal number involving a nun costume, a gas mask, and a fake gun did not fare well in Los Angeles' more staid strip clubs. Another legendary Portland strip club performance is the Devils Point club's weekly Stripperaoke night, where the strippers serve as backup dancers (and show-stealers) for the customers' onstage singing. Devils Point's strippers also offer weekly fire dancing performances.

Though Portland dancers report instances of discrimination by club managers or customers based on their appearance, the city's clubs do present a 
wider spectrum of dancer appearances than is seen in other cities. Just as a certain body type is associated with ballet, there is a stereotypical stripper body: slim with large breasts (often silicone implants) and a small waist, with tanned, white skin and long, blonde hair. Women whose bodies do not meet this ideal often face discrimination from strip club owners, patrons, and dancers (S. Brooks, 2001, 2010a, 2010b). Suburban Portland clubs tend to feature the stereotypical "Barbie doll" type dancers, while a club in the city's African-American neighborhood favors African-American women and women with a more substantial body type. One way Portland's dancer population is not especially diverse is in terms of race: Portland has relatively few people of color, and most Portland dancers are White. It was unclear from my research whether the racial demographics of the dancer population reflect the city as a whole.

\section{Legal Context}

A series of legal cases and ballot measures have laid the groundwork for Portland's large strip club industry and the kind of clout suggested by local club owner Claude da Corsi, who warned the Portland Mercury against increased regulation of strip clubs. He told the newspaper, "I can't see anyone winning when alienating 10 to 12 thousand people," intimating that the adult-entertainment industry could cause "political death" for elected officials trying to regulate sexually oriented businesses (Busse, 2003). These court cases and ballot measures, along with policies of state regulatory agencies, have affected both the distribution of and practices within Portland strip clubs. 
Jurisprudence.

In 1971, the Oregon legislature deregulated access to sexually explicit materials, and in 1982 the state Supreme Court's State v. Robertson decision established the precedent for obscenity as protected speech. The Court ruled prohibiting "the enactment of any law written in terms directed to the substance of any communication" (ACLU of Oregon, n.d.), a protection that is more stringent than the federal First Amendment and which is considered "near iron-clad" (A. S. Green, 2002a). On this foundation, State v. Henry (1987) established that there are no exceptions to freedom of speech standards for obscene speech, meaning that the state cannot regulate the location of sexually oriented businesses or the attire of those businesses' employees. In Sekne v. City of Portland (1986), which paved the way for fully nude dancing at clubs that served alcohol within Portland city limits, Judge Jones wrote,

The city does not quarrel with the concept that within in the confines of the city of Portland nudity is permitted on television, in the movies, in magazines, and on stage at the Civic Theater. Why may nude bodies be viewed in many places within the city but not taverns? ("Suit ends city's ban on nudity," 1985).

These cases are considered the catalysts for the explosion of strip clubs in Portland, and were more recently followed by a second wave of decisions that served to cement the presence of the industry. Twice in 2005, the Oregon Supreme Court decided in favor of sexually oriented businesses. In State v. Ciancanelli, the court affirmed a club owner's right to put on live sex shows; Nyssa v. Dufloth 
invalidated a small city's ordinance mandating four feet of distance between customers and nude dancers, a case that had been wending through the courts for years (Sottille, 2005).

\section{Oregon legislature.}

In the face of these court decisions, the Oregon House and Senate have repeatedly tried to alter the constitutional free speech standard, but the legislature has yet to circumvent State v. Henry. After a 1994 ruling by the Oregon Court of Appeals overturned a law criminalizing payments to view child pornography, there was a spate of efforts to find other ways to regulate sexually explicit material (Bates, 1995a). In 1995, Oregon legislative bodies proposed nine bills and resolutions designed to limit public availability of sexual materials, from requiring "adult cabarets" to register with the Department of Revenue to mandating that cable providers furnish scrambling devices to customers (Bates, 1995b). In 1999, House Joint Resolution 52 proposed an amendment to the state constitution that would allow cities to regulate sex shops and adult entertainment; the bill had bipartisan support and the backing of the Oregonian editorial board ("Zone sex shops," 1999), but still did not pass (Roberts, 1999). During the 2011 legislative session, the Oregon House and Senate considered three different measures related to changing the free speech standard or regulating sexual entertainment or materials, but all stalled in committee (Associated Press, 2011).

\section{Regulatory agencies.}

Though the legislature and local governments have not been able to regulate strip clubs directly, the state does regulate certain activities that occur in strip clubs. 
Since strip club location cannot be controlled by land use rules, and because dancers are not considered employees, neither the state Board of Labor and Industry nor the Occupational Safety and Health Division oversees working conditions. However, most strip clubs have liquor licenses, so neighbors and politicians have turned to the Oregon Liquor Control Commission (OLCC) to regulate conduct in clubs through the rules for all establishments that serve alcohol.

In July 2002, the OLCC restricted "lewd" conduct—such as dancers touching their genitals while performing—on premises with liquor licenses (Dunn, 2002), but such rules were later invalidated by State v. Ciancanelli. Instead, OLCC personnel now visit licensed strip clubs regularly and enforce rules about where underage performers may spend time and lines of sight "private dance" rooms (to prevent illegal alcohol service in areas out of view). Also in 2002, the OLCC increased enforcement of an existing rule prohibiting dancers under the age of 21 from loitering on the floor at clubs (Dunn, 2002). The rule also applies to musical performers. Ostensibly to prevent underage drinking, this confinement of 18-20 year-olds to the stage greatly decreased underage dancers' earning power, since dancers' tips in such clubs are gained primarily by socializing with the customers throughout the establishment. At the same time, the commission also introduced a rule requiring club owners to write a management plan for each underage dancer hired, creating a disincentive for allowing the youngest dancers to work.

\section{Municipal ordinances.}

Municipalities including Portland have attempted to craft ordinances that skirt the Constitution by limiting clubs in terms of number, location, and activities 
conducted on their premises. However, virtually all municipal governments have abandoned these efforts after legal challenges to the laws. What follows is a summary of some of the efforts by the City of Portland.

In September 1999, Mayor Vera Katz began working with the Portland City Council on regulations she hoped would stem the prostitution associated with escort and lingerie modeling businesses, an issue she had broached during her election campaign (Farrell, 2000). By April 2000, she had abandoned the project, citing inevitable nullification by the state Supreme Court, as had happened when the city tried to draft a similar ordinance in 1986. In 2002, the City Council began discussing the creation of zones of exclusion around schools and residential areas, as well as the prevention of concentrations of sexually oriented businesses, such as the clusters located in several Portland neighborhoods (Stern, 2002). However, while commissioner Jim Francesconi was adamant about acting to stem the "cheapening" of these areas, other commissioners maintained that drafting successful regulations would be challenging and not necessarily a high priority for the municipal government (Stern, 2003).

\section{The ballot box.}

As the sex industry flourished, citizen-initiated attempts to alter the Constitutional standard were put on the state ballot in 1994, 1996, and 2000. In 1994, Measure 19 aimed to change Oregon's free speech standard to outlaw obscenity. Two years later, Measure 31 pursued the same goal, focusing more explicitly on sexually oriented businesses ("Don't zone out rights," 1996). In 2000, Measure 87 proposed to allow the zoning of sexually oriented businesses. Measure 
31 was supported by organizations such as Safe Neighborhoods and the Oregon Women's Leadership Task Force, but a large free-speech movement was bankrolled by the sex industry. Local sexually oriented business owners donated to the campaign, as did out-of-state businesses such as Playboy Enterprises. More mainstream businesses, including regional grocery chain Fred Meyer and the New York publisher John Wiley, also contributed (Bates, 1996). All of these measures failed to pass. In every case, the measure did not obtain a majority largely because Portlanders, who form the largest concentration of voters in the state, did not vote for it.

The electoral record provides evidence that Portlanders are in general more tolerant of sexually oriented businesses than are people in less urban areas of the state (see Table 7). In 1994, residents of Multnomah County-the majority of whom live in Portland-rejected Ballot Measure 19 by a higher margin than did the state as a whole, despite the fact that the measure's proponents argued that sexually oriented businesses were causing extensive problems for the county (Killian, 1995). In the 1996 and 2000 votes on Measures 31 and 87, Multnomah County also voted at lower rates than the state as a whole for additional restriction of sexually oriented businesses. 
Table 7

Votes on Referenda Proposing Increased Restrictions on Sexually Oriented Commerce

\begin{tabular}{|c|c|c|c|c|}
\hline & \multicolumn{2}{|c|}{ Yes votes } & \multicolumn{2}{|c|}{ No votes } \\
\hline & Multnomah County & Oregon & Multnomah County & Oregon \\
\hline Measure 19 & 93,303 (39\%) & $549,754(46 \%)$ & $145,118(61 \%)$ & $652,139(54 \%)$ \\
\hline Measure 31 & $111,736(43 \%)$ & $630,980(47 \%)$ & $145,118(57 \%)$ & $706,974(53 \%)$ \\
\hline Measure 87 & $117,913(42 \%)$ & $694,410(47 \%)$ & $165,693(58 \%)$ & 771,901 (53\%) \\
\hline
\end{tabular}

Note. Election returns data from Oregon Secretary of State

(http://bluebook.state.or.us/state/elections/elections06.htm) and Multnomah County Elections Division (http://web.multco.us/elections/elections-results-and-history).

\section{Economic Context}

Oregon's weak economy may have also spurred the industry's expansion within this legal context. Sexually oriented commerce tends to expand in times of economic restructuring (Tani, 2002), which has occurred in Oregon and the Portland metropolitan area in recent decades. Extractive industries, such as timber and fisheries, have declined, and Portland has seen significant in-migration by middle-class people drawn by the city's reputation for livability. The region lacks sufficient job opportunities for these migrants, who may displace less-skilled local workers (Cortright, 1999; Jurjevich \& Schrock, 2012).

Spatially, sexually oriented businesses may fill an economic niche in metropolitan development, occupying low-value spaces because their presence would not be tolerated in prime retail space (Cameron, 2004; West \& Orr, 2007). My interviews with owners of sexually oriented businesses and community leaders 
showed that the decline of the real estate industry post-2007 was a boon to sexually oriented businesses, which found opportunities to expand because of lowered rents and the weakened real estate market. Property owners who would not ordinarily have rented or sold their property to a sexually oriented business may no longer have had the luxury of turning away a tenant or buyer that would be unpopular with neighbors. Deirdre, who worked at a business association, put it this way in our interview, “[Sexually oriented businesses] are part of Portland's economy. People wish all the jobs could be Silicon Valley, high paying, educated. They aren't going to be. Portland needs all the economic drivers it can get and this is one of them."

Unlike a Silicon Valley start-up, the costs of opening a strip club are relatively low. Clubs do not need a license to have entertainers and do not need to pay any additional taxes or fees when providing this service. In Oregon, costs to incorporate a business are low, and getting a liquor license is easy and inexpensive. In the case of an existing bar, adding exotic dancers to its format may actually subsidize the bar's costs because dancers pay fees to perform and share part of their tips with management, security staff, and bartenders. In the wake of the legal decisions protecting sexually explicit speech, a number of existing bars simply set up a stage in the corner of the room and added strippers, to see if it might increase their revenue.

\section{Summary of Describing the Setting}

Though this study does not systematically compare Portland to other cities, the data collected make it clear that the city has an extensive and diverse strip club 
scene, unique for the number of clubs as well as their distribution throughout the city and their business model and aesthetics. Understanding what makes Portland Strip City lays the groundwork for the following chapter, which discusses findings related to processes of location, neighbor response, and worker experience that occur in this specific context. The implications of these findings in this context are discussed in detail in the concluding chapter of the dissertation. 


\section{Chapter 5: Findings}

The extent, diversity, and complexity of the situation described in the previous chapter provided ample opportunity to study relationships between strip clubs and neighboring land uses. This chapter is devoted to answering the research questions of the study and is organized accordingly; it draws heavily on the interviews conducted and integrates information from the other types of data collected. In the first section, which builds on the previous chapter, I focus on the first research question, which asks (1) what forces drive and constrain the spatial configuration of strip clubs in Portland? This chapter continues with an account of my findings related to the second and third research questions, which are, respectively, (2) what influences how neighbors view strip clubs? and (3) what determines the work experience of female exotic dancers?

Most simply put, I found that there is variation in the level and type of conflict between clubs and their neighbors and there is also variation in the conditions under which exotic dancers perform. Among the many strip clubs in Portland, some are despised by their neighbors, a few are cautiously embraced, and most are ignored or grudgingly tolerated by the people who live and work around them. While sexually oriented businesses are generally considered socially noxious land uses, clubs in Portland may have more amicable relationships with their neighbors depending on how long they have been at their site, how their property looks, who their clientele is, and how they respond to neighbor concerns. I found that all of the occupational hazards described in research about strip clubs are present in Portland clubs, but that many dancers consciously take these risks 
because they value other aspects of the work highly enough. While some clubs provide a more stable, supportive environment for dancers than others, I found no evidence of substantive career pathways for dancers even under the best working conditions. Many interviewees attributed neighborhood conflict and working conditions to decisions made by the managers of individual clubs, but I also saw ways that factors at the metropolitan, city, and neighborhood levels influenced these issues. Perhaps most notably, I found that "neighborhood strip clubs" may offer not just better working conditions but also better relationships with neighbors than other kinds of clubs. Similarly, while dancers remain a vulnerable workforce, smaller club size and club locations within mainstream business districts foster dancers' sense of camaraderie, safety, and investment in the community surrounding the club.

\section{Research Question 1: Local Context}

The number and diversity of Portland's strip clubs invite the exploration of the aspects of the city that support this somewhat unusual industry. In this section, I build on the Strip City chapter and present additional information that responds to the first research question of this study: what forces drive and constrain the spatial configuration of strip clubs in Portland? I discuss social contexts and structures that appear to have shaped the industry based on my interpretation of the data collected.

\section{Social context.}

Many aspects of Portland's social environment foster a civic culture where strip clubs fit in or at least are tolerated. Because any city is home to many different 
viewpoints, Portland's reputation for strip clubs fits well with some aspects of the city's image and conflicts with others. The result is that residents may justify their comfort or discomfort with strip clubs by laying claim to their version of Portland. For example, strip clubs are seen as an artifact of the city's role in the nation's westward expansion, a creature of the contemporary alternative arts scene, and evidence of both progressive and libertarian political sensibilities. Depending on an individual's perspective, these aspects of the civic image either foster tolerance for strip clubs or allow clubs to threaten the well-being of residents.

Several of my interviewees saw the tolerance of strip clubs as the legacy of freewheeling days when many men left Portland to seek fortune in the Gold Rush, and lawlessness was the norm. Nineteenth-century Portland has been described as a Wild West town of sailors and lumbermen, where many of the few female residents worked as prostitutes. Indeed, commercial sex has a long and storied history in narratives of the American West (Dando, 2009). In Portland as the rest of the West, this history has fostered libertarian values and resistance to government regulation, particularly when it comes to individual conduct or the use of land. Liana, a public employee, drew on the city's history as she connected the libertarian perspective on strip clubs with westward migration. She told me, "pioneers who came out here to 'do their own thing' didn't want a lot of rules and regulations about things." Steven, a small business owner who worked near The Lagoon, embodied that spirit today. He told me in our interview, "My beef is more with government intrusion than it is with Mistress Suzie!" His comment echoed a ballot measure statement by arts organizations warning against Measure 31, which read, "The 
government—not you, and your family—will decide what you can see, read or hear, even in the privacy of your own home!" Consequently, a "live and let live" perspective on strip clubs is common. As civil rights lawyer Charles F. Hinkle was quoted saying in the Oregonian,

I don't really think that it really is a politically sensitive issue in Oregon.... There are enough voters in Oregon who like the free-speech clause interpreted as it has been and who have made that clear three different times in referenda on regulating adult entertainment (A. S. Green, 2002b).

Very mainstream interests, such as Powell's Books and librarians' associations, have joined with sexually oriented establishments in speaking out against these measures, usually on grounds of free speech.

Like many Portlanders, Irene, a public employee, questioned whether striptease is art, and acknowledged that the industry, while tolerated, is not entirely welcome: "There's really not any neighborhood that wants these," she told me. Yet, she felt almost obligated to sidestep these issues in view of her strong attachment to a local identity that embraces free speech. She told me,

As Portlanders, we value individual liberty above community rights .... Because of that we're more tolerant, not because we want it but because I know the Constitution. I may not like it, but you have a right to it .... I don't think, as some people portray it, we enjoy all the strip clubs necessarily. I just think that we say it's an ugly part of freedom of speech, it's a side that's not everybody's favorite. If someone wants to stand on the corner and yell racist slurs all day long, they have a right to do that. It sucks. Is it the 
smartest thing to do? No. Is it hurtful to people? Absolutely. But somebody has a right to do it.

Though she was clearly concerned with the problems faced by exotic dancers and the frustrations of neighbors who struggled with problem clubs, Irene had concluded that these harms were an almost inevitable consequence of a democratic society. She also felt that many of her fellow Portlanders had reached the same conclusion. To wit, a Portland-based coalition offered an impassioned plea to reject Measure 31 because of its potential to threaten arts and expression, using an example of suppression of the arts in post-World War II Detroit as a touchstone: The threat of self-appointed guardians of public virtue is as real today as it was in 1947, when police censor Charles Snyder said, “Lady, I don't care what kind of prize he's won, he can't put on a dirty show in my town." The "he" was Eugene O'Neill; the prize was the Nobel Laureate for Literature; and, the show was A Moon for the Misbegotten. Our scarce police resources should not be used investigating allegations of "dirty" words and pictures.

Similarly, a statement opposing Measure 87 by citizen Rob Reynolds, drew heavily on the liberal value of tolerance to support the presence of the industry:

Both tolerance and intolerance have a way of spreading. If we as individuals become intolerant of the views of those around us, they will in turn become intolerant of us. We needn't accept the views of our neighbors, we only need to realize that they have just as much right to express their views as we do. As tolerance grows, our society as a whole becomes a better place to live. Opposing this measure doesn't necessarily mean that you support the adult- 
entertainment industry. It means you recognize its right to exist, regardless of whether you support it. There is a fine line between showing someone how you believe life should be lived, and telling them how they should live. Portlanders fiercely defend this perspective. Frank, who lives in a residential area with strip clubs, told me that when he e-mailed fellow parents with his concerns about strip clubs in the neighborhood, he receiving several nasty responses from people angered by what they saw as "dictating morality" in their children's names. Mixing with this laissez-faire attitude toward strip clubs is an emphatic embrace of freedom of expression and diversity, a feature of the progressive consensus that has crystallized in the city since the 1970s. With large gay, lesbian, and feminist communities, the city's residents consider it a sexually open place. For example, public nudity is legal in Portland, a fact that is most evident at the city's annual Naked Bike Ride, which attracts thousands of participants of all ages and all states of undress. Fiona, an exotic dancer who grew up in the area, told me, "We're very colorful people, very accepting, a lot of artists, there's tattoos everywhere ... I love it about Portland: it's just accepting, it's just like be who you want to be. We're all a bunch of hippies."

However, this aspect of the civic image creates tension with some other ideas of what the city is about. For Diana, who worked near a strip club, the embrace of these businesses was a result of a changing moral landscape that includes the increased visibility of homosexual people and the migration of young people from other parts of the country. She explained, 
I grew up here. And Oregon has always been very straight-laced and very family, and just clean. And then it's just been in the past 20-25 years that everything is going upside down. We have a gay mayor, we used to have a lesbian ... today I would say most people-young people, youth up through their 30's, maybe a little more-don't seem to have too many values.

Our discussion also touched on her displeasure with the increased visibility of homosexual people among her business' clientele and her belief that the number of people purchasing sexually explicit magazines and videos in the neighborhood had increased.

Though she had a very different social and political orientation from Diana, Deirdre, who worked in a commercial area with strip clubs, agreed about the changes in Portland. She believed that, because of the changing demographics of the city, Portland is more tolerant of sexually oriented businesses and sexual diversity than other cities. She told me,

I think it goes with the younger, nobody-actually-from-Portland in-their-20'sand-30's in Portland vibe. You get a lot of people who came for the lifestyle and have a lot of open acceptance. We see in Portland a very strong mix of the LBGT community and allies, especially in the younger audience.

Indeed, this was part of Deirdre's personal experience. She told me, When I moved to Portland, my roommate went to Caliente and that is where he met his girlfriend. She was a dancer and she eventually moved in with us. That whole mentality—“we're open, we're free, we accept people for who they are"-I think that is a generational shift. That generational shift is very 
strong in Portland, and that is part of the reason that the adult entertainment industry has been able to exist relatively peacefully.

It is not just age, but occupation, that shapes this attitude. Deirdre explained, "If you are bringing in established banks, investment firms, it would change a lot; the whole DNA would change. If you bring Google, wind-energy, like-minded people, the active-wear industry, I think you'll see, again, the vegan strip club idea." She believed that spatial configuration of the city contributes to tolerance, citing the polycentric nature of Portland and the large number of gay businesses throughout the city: "The fact that Portland used to have the 'Pink Triangle,' which is now the Crystal Hotel, they are not so exclusionary any more, and more spaced out; I think that shows the commingling."

Several of the neighborhood leaders and public employees I interviewed discussed the contradictions and complexities of these perspectives on Portland. Todd, a neighborhood leader, resisted the association between the city's reputation for quirkiness and the preponderance of strip clubs, which he considered exploitative businesses at odds with the idea of a city concerned with human rights. He explained in our interview:

You see this history of progressiveness, like we had the first woman police officer ever. We also had the first Black-owned business on the west coast, and yet Black people couldn't come in to Downtown Portland. We have this contradiction in human value and devalue that's just weird. 
From Todd's perspective, Portlanders' belief in free expression overrides critical examination of how sexually oriented businesses function. Liana, a public employee I interviewed, shared this frustration:

It's kind of hard for me to embrace or quite understand people's ignorance about the effect of pornography and sex abuse and sex-oriented businesses. [They think] everybody should be free to do what they do, but [are] not realizing that many people aren't.

These various ideas about what Portland is like compete with or complement each other in terms of whether and where strip clubs belong in the city. They also underpin many aspects of neighbors' response to having a strip club located nearby, as I discuss in the next section.

\section{Research Question 2: Land Use Conflict}

In this section, I continue my exposition of the findings by describing neighbor responses to strip clubs, which I situate on a spectrum of conflict and coexistence. After presenting individual strip clubs as examples along this continuum, I discuss dynamics that appear to affect the relationships between clubs and their neighbors. I identified several ways that place influences whether a strip club will be embraced or opposed by the people who live and work near it. These dynamics include systems of governance, neighborhood characteristics, site-specific factors, and temporal effects. 
Conflict and coexistence.

Conflict over strip clubs ranged from subtle to very visible. While the later sections of this chapter describe potential drivers of conflict and coexistence, this section provides examples of three (pseudonymous) clubs and their relationships with neighbors as a way of illustrating the variety of relationships between clubs and their neighbors. I categorized these relationships as embrace (Club Rio), indifference (The Lagoon), and opposition (Glitter) based on my overall judgment of the relationship as seen through the data I gathered, but it is important to note that in each instance there is a variety of opinions within the neighborhood. The research I conducted allowed me to discover just a few of these many perspectives, but I provide these descriptions here in order to illustrate discourses of acceptance or objection and the tactics people use to express them. I was able to characterize the relationships at Club Rio and the Lagoon because they were two of my three study sites, where I began focused data collection. The conflict at Glitter, on the other hand, became evident over the course of the study as the situation repeatedly came up in interviews and media coverage despite the fact that the club was not one of my focus sites.

\section{Embrace.}

Club Rio is a local institution. Its kitschy sign is a well known landmark, and Harold, a local business owner, told me that it was "kind of cool" to have his business next door because of the club's cachet, even if he did not patronize it. If fact, it also offered a very pragmatic benefit to Harold's business: he had found that 
in giving directions to customers, referring to Club Rio was always more effective than mentioning other landmarks like main streets.

Of all the people I interviewed about Club Rio, none could recall hearing about any problems taking place there. The people who worked at the club liked the neighborhood and were well known in the area. Even a staunch opponent of strip clubs I interviewed had to admit that he had no information to suggest that anything untoward went on at Club Rio. While some of the people I interviewed appeared to be uncomfortable thinking or talking about strip clubs, almost all described Club Rio as unthreatening, kooky, or even charming. Though the air of positivity surrounding Club Rio was rather unusual, its status was not unique among Portland clubs.

\section{Indifference.}

More typically, neighbors were indifferent about strip clubs, as was case for most of the neighbors of The Lagoon. The attitude was epitomized by Edward, who shrugged and told me, "He's working retail, as far as I'm concerned," when I asked his opinion of the club located across the street from his business.

Most of the other business and residential neighbors I interviewed echoed this disinterest, and in the course of my interviews, I discovered that some neighbors were not even aware that The Lagoon featured nude entertainment. Susanna, who managed a nearby restaurant, contended that the strip club "minded its P's and Q's," so residential and business neighbors should have no concerns. In contrast, Diana, who worked across the street from the club, reported feeling disgusted by strip clubs, and believed that the presence of The Lagoon 
discouraged customers from coming to her business. Despite her displeasure and the perceived negative economic impact of the club, Diana had not acted to change the situation in any way. Though her business had been in the same location for many years, she had never met the owner of The Lagoon; had not discussed the matter with other business owners, the neighborhood association, or the business association; and had never consulted with the police about her concerns. She expressed a sense of disenfranchisement from the dominant political culture in Portland, despite having been raised there. She seemed unlikely to act on her distaste for her strip club neighbor because she felt that she held the minority position.

\section{Opposition.}

In other instances, however, displeasure with a strip club was visible and vocal, as was the case with Glitter. While Glitter was not one of my study sites, ample information about it emerged during my research because of ongoing conflict. When neighbors heard that the owners, who operated another strip club in town, planned to open Glitter on the site of a restaurant that had been closed for more than a year, the response from the neighborhood association was fast and furiousdespite the fact that the business would be located at the very edge of the neighborhood on a large commercial street.

Initially, the neighborhood association lobbied the OLCC to deny the club's liquor license application, ostensibly on the basis of the owner's mismanagement of a bar in another state. The information about the owner's background was 
unearthed by a neighborhood association member who presumably drew on his training as a lawyer to conduct the research that turned up in the court file. The association presented his findings to the media, which seized on the prurience of a strip-club controversy.

Though Glitter did eventually receive a liquor license, the OLCC placed conditions on its operations, such as a requirement that the owner be on the premises on weekend nights. This counted as a victory for people who opposed the club on the grounds that it might cause livability problems like noise and litter. However, it was a loss for people who wanted the club prohibited because of the type of performances it marketed.

Once Glitter opened, residential neighbors kept an eagle eye on activities at the club and contacted the city whenever they observed something that could possibly have been considered a negative impact of the club. They kept track of infractions related to the special liquor license, including monitoring the owners' presence on the premises. Acts of vandalism in the neighborhood were attributed to club patrons.

\section{Governance.}

Both state and municipal government influence the extent of conflict over strip club sites, through what they do and do not regulate and the manner in which they enforce regulations. This section discusses how the Oregon Liquor Control Commission and the State Constitution operate at the state level and contribute to conflict over strip clubs in Portland. This is followed by a discussion of the 
municipal level, where City of Portland ordinances and programs show evidence of both spurring and resolving conflicts.

\section{State level}

As noted previously, both Oregon's constitutional free speech provision and its liberal liquor licensing process set the stage for conflict over strip clubs. In each case, the legal framework limits capacity for restricting these establishments, either in accordance with public opinion or to address negative externalities associated with their activities. The gap between what the law allows and what residents wish it would allow can provoke outrage or exacerbate tensions between neighbors and clubs. Conflict over strip clubs may be especially common in Portland, which, as the largest city in the state, is home to much of Oregon's nightlife. Further, the dense population and development patterns (including mixed-use zoning) make it more likely that alcohol service and sexually oriented businesses may be located in close proximity to residential or community sites.

The OLCC's simple and inexpensive application process for liquor licenses makes it easy for businesses - strip clubs or otherwise-to serve alcohol. This sets the stage for conflict between licensees and their neighbors because of the noise, violence, and traffic collisions associated with alcohol service and the density of licensed outlets. The conflicts are exacerbated by the infrequency with which the OLCC denies a license application or revokes the license of a problem licensee. People concerned about the impact on their residence, business, or community of new or existing strip clubs have difficulty understanding the narrow scope of OLCC 
control. That is, the OLCC may deny a license or restrict the hours or other aspects of operation only for very specific reasons: if the applicant has a relevant felony conviction, a poor record of compliance with a previous license, or a history of using alcohol or drugs to excess; or if there have been problems at the same location under a previous licensee. Additional antiquated criteria that are obsolete in practice include "maintaining an unsanitary establishment" or an owner's physical incapacitation. OLCC previously cited and restricted certain types of conduct on licensed premises, but this so-called "lewd law" was invalidated in 2005.

While state regulations do consider the impact of alcohol services on "protected facilities," such as hospitals, nursing homes, and places of worship, the OLCC is unlikely to do anything beyond notifying the protected facility owners that a new license is being issued. Tina, a public employee, explained the threshold for restrictions in our interview,

They [complainants] have to show proof of how this operation is going to impact their core function. Just the fact that kids are going to see this or walk by it is not enough. [The complainant] has to show how it's going to impact these kids' learning at this facility, which is nearly impossible. How can a bar stop you from teaching a classroom full of kids?

Further, the OLCC cannot and will not consider issues related to parking, traffic congestion, devaluation of property, building or zoning codes, or problems with signage or litter (unless these are specifically related to alcohol service, such as posters advertising alcohol or discarded beer cans). 
Though battles over strip clubs' liquor licenses have been very visible in local newspapers, Tina suggested that this high-profile incident does not reflect the reality of conflict over licenses. She said,

Strip clubs get the most publicity in the newspaper when there's problems or there's input from the neighborhood, but I do not think that they're the ones that cause the most problems or that give us the most grief or that we even get the most input on.

The narrow scope of the licensing process angers people who expect that the OLCC will prevent any potential negative impacts of alcohol service, or will put neighborhood priorities over the right of businesses to sell alcohol. Interviewees who had sought the OLCC's assistance to limit strip clubs were disillusioned and cynical. Some accused the agency of being more driven by the profits of alcohol sales (on which it earns tax revenues) than by its public health and safety mission. Some neighbors I interviewed felt that that the OLCC had not taken their concerns seriously enough. These individuals had contacted all manner of public agencies and elected officials to try to have more sway over the OLCC. One resident who participated in a failed campaign to block the licensing of a new strip club looked to other regulatory systems in a last-ditch effort to stop the business from opening after failing to get the OLCC to do so. He told the Oregonian, "We'll start pulling building permits and making sure those are all done correctly" (Feulner, 2011), although his true concern was with the services that would be provided rather than the quality of the construction. 
Like the liquor licensing process, the state's free speech standard provokes bemusement that can turn into anger when residents discover that a business they dislike cannot be controlled by the government. Residents who contact public agencies or elected officials to lodge a complaint are often shocked to learn that Oregon governments cannot regulate sexually oriented businesses, since most presume that doing so is a government function (as it is in virtually all other U.S. states). Even city officials have found themselves in this position, such as when Mayor Vera Katz gave up on attempts to regulate sexually oriented businesses after an ordinance requiring business licenses for escort services was overturned by a Multnomah County court. She later told the press that she continued to support regulation of sexually oriented businesses, "but until there's a change in the Oregon Constitution that allows us to control where these businesses are located, there's little we can do about it" (Redden, 2002).

Diana, who worked near The Lagoon, was incredulous as I shared my understanding of the Oregon Constitution during our interview. She rejected the idea that the free speech standard might represent the framers' intent or the will of the people, telling me,

Who knows what quick-witted attorney came through and played the game! I'm going to guess people either weren't aware of what it [the ballot measures] truly said or else, within city limits, Downtown, we have so many freethinking, how do you word it ...? 
She trailed off and then blurted out, "What does that have to do with art?!"questioning the alignment of sexuality with artistic expression in discussions of sexually oriented businesses.

The alarm and frustration that people like Diana experience can feed feelings of being under siege by sexually oriented businesses, what one columnist called "an avalanche of smut" (Bates, 1995c). Each successive court case that affirmed the free speech standard or dismantled an administrative regulation (e.g., the OLCC "lewd law" that barred dancers from touching their genitals while performing), provoked a wave of fear that the state was being invaded by predatory sex businesses. Liana, a city employee, used the metaphor of Pandora's box to describe the impact of the Oregon Supreme Court's decisions, while a dancer interviewed in a news feature about Portland's "burgeoning sex industry" in 1995 said the growth was "like the Andromeda strain," referring to the exponential growth of Michael Crichton's fictional extraterrestrial superpathogen (Bates, 1995b). This dancer also told the reporter interviewing her that dancing had become "gynecological" since the court's affirmation that fully nude dancing was legal.

More recently, one of the club owners I interviewed, in positioning his business as a "gentlemen's club," employed a similar narrative of an industry unleashed. Discussing the impact of the State v. Nyssa and State v. Ciancanelli decisions, Darren posited that while clubs like his maintained a "classy" standard out of self-regulation, the industry as a whole was devolving rather than evolving:

Since the [Oregon] Supreme Court case has opened up the floodgates, there's been a lot of clubs taking it to the level of "we'll do whatever we want 
because we can," not realizing the potential negative effects. You see clubs advertising live sex shows-six years ago that was unheard of. Six years ago a woman couldn't even touch her own breast, that's how extreme it [the OLCC lewd law] got.

Despite these assertions, I only heard of one Portland club offering "live sex shows" in my research; based on comments from dancers, media, and online message boards, the shows do not appear to be especially outré.

Furthermore, concerns about an ever-expanding number of clubs seem unfounded. After Sekne v. City of Portland (1986) established that the City of Portland must allow nude dancing, some new clubs opened and some clubs that had previously featured topless dancing went nude. By the end of that year, there were 15 clubs within the city limits (which were then smaller than they are today) (Hogan, 1985), which the Oregonian suggested was a large increase. However, four years later, another Oregonian article suggested that there had already been about a dozen strip clubs in Portland in the years preceding the decision (Bella, 1989). That places the surge in number of clubs surged between 1985 and 1989, quadrupling to 50. I did not conduct archival research about the number of clubs open each year, but a count based on Exotic magazine back issues suggested that there were 36 strip clubs in Portland in 2002, and 42 in 2012. Not only has the number of clubs remained relatively stable over the past decade, but there also are very few examples of clubs opening at new locations: name changes were far more common than new sites opening up. Thus, while there are many clubs, and the number did 
increase as the free speech standard was affirmed by successive court cases, the notion of an "avalanche" is hyperbolic.

Nelson, a public employee, found this kind of hysteria about strip clubs a challenge to his efforts to work with neighbors on safety issues. He shared frustration in our interview, telling me,

The neighbors are always upset ... instead of focusing on how to properly run a bar, what kind of security measures are you going to take, how are you gonna check ID, how are you going to ensure you don't have overservice, how are you gonna ensure your lighting is good, what measures are you going to take into place that's gonna diminish the queuing outside so you don't have issues, the smoking impact, the concerns were: there's gonna be naked girls, and it's next to a school.

Despite these fears of strip clubs, Oregonians have affirmed free speech over the ability to further regulate sexually oriented businesses in three statewide ballot measures. As a result, the potential for site-specific conflict is high.

\section{City level}

Although opposition to strip clubs often centers on issues under the purview of urban planners, such as proximity to certain land use types, facility design and signage, and concentration of businesses, Oregon's Constitution prohibits such regulations to be targeted at sexually oriented businesses. Consequently, urban planners exercise no control over strip clubs, and for all intents and purposes are absent from Portland's conversation about strip clubs. This is quite remarkable, 
given that Portland has an international reputation for its proactive approach to urban planning, sustainability, and livability. While the recently adopted Portland Plan addresses such far-reaching topics as health, education, economic prosperity, and social equity, planners have played no role in addressing the working conditions in strip clubs or neighbor concerns about strip clubs. Nevertheless, the liquor licensing program, city's nuisance ordinances, and neighborhood association programs offer some means for regulating the character, if not the location, of strip clubs within Portland's city limits.

The City of Portland's local process for reviewing liquor license applications provide leverage for managing licensees' effects on neighborhoods, but the utility of this process is limited by the narrow license denial criteria that the state agency employs. The OLCC also solicits local government recommendations on all license applications, but leaves it to individual jurisdictions to determine how they develop these recommendations. Of Oregon municipalities, Portland has the most stringent process for reviewing license applications-and the most licensees within its borders. Portland's process includes a full-time liquor license manager who tracks the applications and works to notify neighborhood associations and help them document any concerns about the application. The license manager works closely with the city's Office of Neighborhood Involvement and the Police Bureau's nightlife detail, and manages a process that informs neighbors of changes to liquor licenses and channels their feedback to the OLCC. The license manager also documents neighbors' concerns about licensed businesses and monitors "good neighbor agreements" (GNAs), which lay out neighbors' and licensees' obligations to meet 
negotiated community standards. (The key ordinances related to neighborhood effects of alcohol service are discussed below, as are the neighborhood association program and good neighbor agreements.)

However, the application and renewal processes are mainly rubberstamping, because the OLCC may only deny a business a liquor license on the few specific grounds discussed above, most of which are related to the individual licensee rather than the effects of the business. Tina, a public employee who had seen many license applications, told me that delays—let alone denials—are rare: "In the Portland area, I would say it's probably less than five percent that truly are hung up. It may be as much as ten, but it's usually more the applicants' problems" with turning in paperwork on time than being slowed down by community concerns. Thus, it is virtually unheard of for an application to be denied based on local objection, rendering the city's recommendations on licenses almost irrelevant.

However, both the Chronic Nuisance (City Code Chapter 14B.60) and Time/Place/Manner (City Code Chapter 14B.120) ordinances and the neighborhood association program create channels for identifying and resolving concerns about strip clubs. Although these programs were not created specifically for the regulation of sexually oriented businesses, they are the most useful tools for managing the effects of strip clubs in the absence of land use controls. However, they are not sufficient to defuse all the conflicts between strip clubs and its neighbors.

The Chronic Nuisance ordinance allows the city to close a business or restrict access to the property for six months to a year if three nuisance activities have 
occurred at the site within a 30-day period. The seizure occurs if the property owner fails to meet with the Police Bureau and complete an abatement plan within 60 days of being notified that the property has been cited. The list of nuisances includes issues that the liquor licensing system does not address, such as litter on the property. This is a valuable tool for neighbors frustrated by the limited scope of OLCC enforcement. Public employees who are approached about these concerns work with neighbors to carefully document any violations that could lead to sanctions under either of these ordinances. The codification of nuisance activities and their potential consequences makes it easier for neighbors and businesses to understand acceptable conduct and grounds for objection. The Chronic Nuisance statute is less frequently applied than the Time/Place/Manner statute, which has been central to liquor license enforcement activities in recent years.

The Time/Place/Manner ordinance is a more flexible regulation designed specifically for establishments that serve alcohol. The rule allows the city to regulate the time, place, and manner in which alcohol is served at establishments that have been found to adversely affect the community. Adverse impact is determined by a code officer hearing, which takes place after three nuisance activities have been reported within 60 days, or after one serious violation, such as a shooting on the premises, has occurred. The procedure also provides the opportunity for the licensee to develop and follow an abatement plan.

The Time/Place/Manner ordinance was adopted in 2004; the city became more aggressive at employing time/place/manner restrictions in the latter part of the decade. Such restrictions might include limiting a business's hours of operation, 
allowing a bar to sell patrons only one drink at a time, or requiring security patrols on the premises. While the ordinance does not give the city the authority to revoke a liquor license or close a club that is bothering residents, stringent time/place/manner conditions could easily put a bar out of business. Several strip clubs have been subject to time/place/manner proceedings.

The two ordinances are complementary, in that the Chronic Nuisance rule applies to any type of property, and the Time/Place/Manner rule pertains specifically to establishments licensed to serve alcohol. Because many of the "secondary effects" attributed to strip clubs—-theft, driving under the influence-are either caused or exacerbated by alcohol service, time/place/manner is a valuable tool for managing them. However, the shortcomings of these policies are severe because they are only usable in the case of major problems and only at businesses that serve alcohol.

The neighborhood association is the key venue for cataloging nuisance behaviors and negotiating for community interests with club owners and managers. Not only do neighborhood associations shape the city recommendation on the liquor license application or renewal, but the associations also channel community concerns and may—with a mediator from the city—negotiate a GNA with a business. Such agreements, unlike nuisance and time/place/manner restrictions, can help to influence the character, if not the existence, of strip clubs in a particular neighborhood.

Portland has a strong, formalized neighborhood association system (Chaskin, 2003; S. R. Johnson, 2004) that plays a major role in resolving conflicts between 
strip clubs and neighbors. The city is divided into 95 neighborhoods, and each has an officially recognized association. The associations are organized into seven district coalitions that provide services to their constituent associations; examples of these services include grant-writing workshops and beautification programs. The city's Office of Neighborhood Involvement provides a wide variety of services to the district coalitions and neighborhood associations, including the crime prevention program, and assigns staff members to help the associations identify and address public safety problems. These crime prevention coordinators work closely with police officers assigned to work with the neighborhood, and sometimes with the neighborhood district attorneys assigned by the County. The crime prevention coordinators make a major contribution to preventing and resolving conflicts between strip clubs and neighbors. They field residents' concerns and serve as mediators when problems arise. Because they are also available to work with business owners to prevent theft or vandalism on their property, crime prevention coordinators are not purely advocates for homeowners.

My interviews revealed that crime prevention coordinators are not only responsive to local problems but also are proactive about preventing them. For example, a crime prevention coordinator might approach strip club entrepreneurs to troubleshoot before their clubs even open. They become aware of these new businesses by walking through the neighborhood and chatting with people selling and renovating properties and through close collaboration with the liquor license manager. Keeping abreast of these new openings lets them work proactively with neighbors who might object to the clubs. 
Crime prevention coordinators also play the unique role of coaching neighbors about where and how to direct their objections to clubs. In many cases, residents object to their strip club neighbors on moral grounds or because they fear their property values will be affected by the club's presence. When residents demand that a club be closed or the city laws be changed to disallow clubs near schools, crime prevention coordinators affirm the rights of businesses to operate and explain the existing policy tools to manage their effects. For example, Valerie, a public employee, told me about how she dissuaded one neighborhood association from issuing a press release declaring their categorical opposition to sexually oriented businesses by explaining that doing so would damage the group's credibility. She instead suggested opportunities to document problems being caused by the club and explained the process of negotiating a GNA.

GNAs, which are typically negotiated by Office of Neighborhood Involvement staff, have been valuable tools for resolving conflicts between strip clubs and area residents. They are voluntary, non-binding contracts negotiated between a business and a neighborhood association, making them both a powerful tool and a "paper tiger" because they lack an enforcement mechanism. GNAs can cover any aspect of business operations, and identify responsibilities for both the business and the neighborhood association. For example, a business might agree to patrol its parking lot every hour to prevent noise and illegal activity, while the neighborhood association might commit to call the business with noise complaints to attempt resolving the problems without calling the police. 
The power of the GNA lies more in creating relationships than in controlling activities. Liana, a public employee who was frustrated that city cannot zone strip clubs, suggested that GNAs are the next best thing. She told me:

Those who have good neighbor agreements, not that many of those failed, which is kind of an amazing thing. So people can get together and talk whether they like the business or not. The key thing is it establishes communication and it clearly indicates who the contact people are. People understand that there's not a lot they can do, but at least there is a good faith effort, we can meet, we can establish some things.

Nelson, also a public employee, worked on one very successful strip club GNA. He said club owners were a pleasure to work with, and extremely open to negotiation: They were willing to take every single recommendation. They changed where they put their front door, they changed the signs they were gonna use . .. every time there was an issue they corrected their behavior right away. Their security was very proactive and actually they started patrolling the area and really improved safety because before they were there in the night time there were a lot of issues... So when the strip club showed up it actually made that little corner safer.

By Nelson's account, the owners were more "professional" than others he had worked with, attending meetings in business attire, sharing their business plan, and acknowledging the importance of both city staff and neighborhood needs.

Often, the symbolic value of the negotiations is as important as their substance. Liana described how one strip club owner was reluctant to negotiate 
with the neighborhood association, but very simple concessions earned him the good will of the neighbors. In this case, neighbors were bothered that the door to the club's kitchen was left open, allowing views into the club (though not of any performances) from the street. The club owner found this ridiculous, but he repaired the air conditioning and closed the doors - and quelled neighbor frustration. The fact that the neighbors saw the club making any concession gave them a sense of empowerment and countered feelings they may have had about the club invading their sphere. GNAs also help residents feel empowered because they bring parties responsible for a potential nuisance property to the bargaining table.

Additionally, GNAs serve to establish the legitimacy of strip clubs by including them in a formal governance process. Although conflicts would be less likely if clubs were located far from residential areas, proximity and conflict can actually create an opportunity for relationship-building through the GNA negotiation process. The mediation process can help get to the root of the conflict by identifying legitimate and illegitimate complaints and interrupting stigmatization and social distancing processes. Irene, a city employee, explained in our interview that land use conflict "always brings out the ugly in people" because they are often motivated by fear:

When we get fearful, we start looking at people. "Oh, she wears a purple sweater, and I heard that all people that wear purple sweaters are bad people." Or, "They look like they're homeless." We have a lot of perceptions. Strip clubs is a great example. Race is a big one. People will go all the way around something but you know what their issue is. People will kind of 
bounce around it, especially if they know that there's nothing that can be done. Strip clubs, in a situation like this where they know that we can't shut it down because it's a strip club, they'll probably come up with 50 reasons around the issue. People won't hit the common denominator. It may be that I don't like that I'm living next door to a refugee family because they're different than me and I kind of have bad perceptions.

Bringing different types of people to a bargaining table as equals helps to break down the psychological distance between the groups. Irene explained that mediators read between the lines to help address these unspoken fears: “There's all kinds of stuff we see that we can talk to people [about], and we get that even if they're not saying it." Separating problems that can be resolved from prejudices that provoke fear of the other fosters identification and resolution of genuine problems.

However, these city ordinances and programs are not sufficient to resolve all conflicts between neighbors and strip clubs. Because the OLCC is unlikely to deny a license for a new applicant, or revoke the license of a business that has been causing problems, it is virtually impossible to stop a club from opening no matter what the city recommends. The ordinances can be slow and cumbersome to enforce, and good neighbor agreements cannot work when good faith has not been established. The sanctions of the chronic nuisance ordinance-property seizure-are so severe and the legal costs so high that they are rarely enacted. Time/place/manner restrictions require similar legal proceedings, and in either situation, documenting nuisance activities can be onerous for neighbors. 
For example, the fatigue of India, a young homeowner, was palpable as she described to me her frustration with city agencies that she felt were not doing enough to rein in the activities at the strip club behind her home. Dealing with the club had taken over her life. Her sleep was disrupted by rowdy patrons and she spent a good portion of her days trying to rally neighbors and get agencies to act on her concerns. Every outside noise caused her to jump for her camera so she could gather evidence of nuisance activities (sex, drug use, public urination) going on in her yard to add to the logbook she had been asked to compile for the police.

The onus of documenting nuisances is a longstanding problem. A research report prepared by the Portland civic organization City Club (City Club of Portland Research Committee, 2000) informing voters about Ballot Measure 87 noted how difficult it is to fix the problem of a disruptive strip club: "Existing criminal and nuisance laws cannot solve the problem. These laws place a tremendous burden on citizens to document problems for each business over a long period of time" (City Club of Portland Research Committee, 2000, n.p.). This report echoed an Oregonian opinion piece published five years earlier about law enforcement's experience dealing with the effects of sexually oriented businesses after the 1987 Henry decision affirmed the free speech standard:

Prosecutors and vice cops say they are frustrated and demoralized. They don't know how to get around Henry and have all but given up trying. "It's like our hands are tied," says Portland Detective Don Pahlke. Walters, the deputy city attorney who has tried unsucessfully to find a legal solution for Portland, agrees. "We've been defeated," he says. "There's nothing more to 
do." In theory, local governments still can pass laws regulating the allegedly harmful effects of smut; in practice, prosecutors find that difficult. They have to prove that a particular business or business category has a particular effect in a particular location. "We haven't found it to be practical," Walters says. "We have statistics that show increased crime levels, but it is very hard to tie them to specific businesses" (Bates, 1995c, p. D01).

Even when problems are severe enough or complainants are tenacious enough to result in a business being sanctioned, strip clubs find a way to continue business as usual. My interviewees shared many stories about club owners who, when threatened with loss of their liquor licenses, escaped sanction by transferring the license to someone else or by reducing their investment share in the businessboth perfectly legal maneuvers. Tina described how one strip club owner employed these tactics:

He got time/place/manner so he switched [the license to another woman's name], but he stayed on as landlord and manager. It looks like he did it to get out of having to abide by the time/place/manner charges. So now the two of them again have applied for this liquor license where she's 95\%, he's $5 \%$. [OLCC only cares] about people who have a ten percent or more membership. It was like she really couldn't speak because we never heard her utter a sound in any meeting too, because he is the mouthpiece. He absolutely is running the show. 
A good neighbor agreement cannot resolve a problem like this, where a business owner is following the letter but violating the spirit of the regulations. Irene, a pragmatic public employee, explained to me:

OLCC cannot hold them responsible for following the GNA. Whether it shows good faith, that could sway OLCC a different way. But they [the licensee] can't get in trouble for it. The opportunity is to sit down and say we have some problems, what can we do to work it out? Generally they go pretty well, but you have to get both parties to want to sit down. So if somebody says, “Go fly a kite!" I can't make them do it. So that's why when they're effective, they're really effective... Unfortunately it happens often that once we get to the point of talking about that, sometimes the relationship has deteriorated so much. And that's what happened in [one residential neighborhood]. The relationship was kaput when I came in and so there was no working with them. Both sides had drawn the line. I had nothing left to work with. There's not much we can do when everyone says, "Screw them." In short, while the voluntary nature of the good neighbor agreement and other city programs is a strength, it is also a weakness because there are few enforceable responses to nuisances.

\section{Neighborhood characteristics.}

Though all Portland neighborhoods are subject to the same state and city laws, I saw variation in how neighbors viewed strip clubs and how a strip clubs got along with their neighbors. My findings suggest that it is not absolute features of the neighborhood that influence these relationships, but rather how the neighborhood 
compares to other neighborhoods in the city and metropolitan area. In this section I discuss two such neighborhood dynamics: neighborhood socioeconomic status and urbanicity-how urban or suburban a place is. I describe socioeconomic status and urbanicity as a relative rather than absolute conditions because my data suggested that a neighborhood's symbolic value was more important than any specific threshold value (e.g., population density or median household income). For example, interviewees often discussed urbanicity and socioeconomic status in terms of how one neighborhood compared to another. I found that as the environment became increasingly urban, conflict over strip clubs became less likely. The role of neighborhood socioeconomic status in conflict over clubs was more nuanced.

\section{Urbanicity.}

The more urban neighborhoods are, the better they seem to tolerate strip clubs. While this project focused specifically on the area within Portland's city limits, many of my conversations with interviewees included discussions of the differences between urban and suburban experiences. These distinctions were made between areas in and outside the city limits, but also among neighborhoods within the city. That is, certain Portland neighborhoods were described as "urban" or "suburban" in relation to each other, despite the fact that all are located in an area designated urban by the U.S. Census Bureau. The concept of urbanicity, or that human settlements range in character along a spectrum from rural to urban, proved to be a useful organizing framework for understanding these distinctions. 
Though urban and rural are often thought of as opposites, the categories are not simply dichotomous. Though some places-for example, a family ranch on a remote parcel of land —are definitively rural and others definitively urban-e.g., the dense apartment towers of Singapore - there is a wide variety of human settlements that fall somewhere in along the spectrum that lies between these two poles. Scholars have termed this variation "urbanicity," as a way to compare places to each other with more nuance than the crude urban/rural binary. There is no uniform measure of urbanicity, but most conceptions take factors such as population density and socioeconomic diversity, transportation network density and quality, and presence of health and social services facilities into account (Dahly \& Adair, 2007; Jones-Smith \& Popkin, 2009; Vlahov \& Galea, 2002). It was beyond the scope of this project to compute or map relevant variables for the city, but a general description would hold that Downtown Portland is the most urban area of the city, as it has the tallest buildings, greatest economic diversity, and densest transportation infrastructure. Perhaps the least urban area of Portland is the West Hills, an area that is almost completely residential, with limited transportation infrastructure and virtually no tall buildings or commercial activity. In Portland, there are topographical components to urbanicity as well: the more urban neighborhoods are on an easily navigable street grid, whereas the more suburban neighborhoods occupy hilly terrain with curving streets and limited sidewalks and other services. In this study, urbanicity is defined by the participants' descriptions of neighborhoods, the representation of neighborhoods in the documents reviewed, 
and my personal observation. Thus, in this case, urbanicity is a subjective concept rather than an empirical measurement.

The Downtown area of Portland, highly urban by Portland standards, was cited by many interviewees as an appropriate place for strip clubs. Because of its reputation as center of both business activity and social services for transient and otherwise in-need people, Downtown was described by interviewees as a place where "nobody really lives." Currently, about $10 \%$ of the city's strip clubs are located in the Downtown and Old Town neighborhoods. There are some residences in these neighborhoods, though very few are near the commercial areas of the Central Business District; many of the people who do live in these areas are transient and/or extremely low income. Whitney, a dancer who spent years as a student of Portland's personalities, described differences between residents of Portland neighborhoods: "Somebody who moves into the Downtown area has an expectation that they're going to experience more people, a little more noise, and a little more diversity than someone who moves out in the Southwest Hills"-a verdant surburban-like area where streets wind through residential districts rather than hew to the city grid. Carl, who had worked at a variety of sexually oriented businesses, told me he had experienced more opposition to the businesses the farther he got from Portland. He had dealt not only with angry neighbors but also with stonewalling by public agencies that selectively enforced rules on sexually oriented business and not on other businesses. Dancer Fiona agreed that suburbanites cannot handle strip clubs. She told me, 
I think [in] Downtown Portland it's okay. You have to expect all of that and be okay with it. Otherwise, go live in the 'burbs. I think here we can keep it funky and free and be okay with that. Especially in Southeast and Northeast. I think colorful and diversity and just living is fine.

Her comments echo the derision for the suburbs or pride about urban openmindedness that several interviewees expressed.

Valerie, a public employee who spoke matter-of-factly about residents' problems with sexually oriented businesses in their neighborhoods, agreed that different areas have different attitudes. She told me, They're much more vocal in single-[family] homes. Especially in immigrant populations or places where there's a lot of people, they don't think that they have the ability to complain and also it's easier for them to move. If it comes down to it, they'll move. People who live there for 20 years are less willing to move.

Wilma, a spunky small business owner, made a similar comment in our conversation about where strip clubs should be located: "If there's a lot of apartments around that's more commercial in a way. It's more transient, so I don't think that's maybe as bad because the person that's renting it has a choice to move in or not." She pointed out, "They say the average renter stays seven months," supporting the idea that renters-who are more common in the more urban neighborhoods-will move rather than attempt to resolve a nuisance issue.

Timothy, an amiable club owner, told me about what he observed when a sexually oriented business opened in a suburban county adjacent to Portland: 
The neighborhood went crazy. [Moms] were out there protesting, people were taking pictures of people getting out of their cars, posting on the website. As far as I'm concerned, that's suburbia. It's way out there, maybe they shouldn't have opened it up in that particular area-there's no other adult businesses around there, there's a school four blocks away. Maybe that wasn't the best decision to put that out there.

In his mind, sexually oriented businesses are a creature of the city.

Mara, a stylish young Portlander who spoke with me in her home a few blocks away from The Lagoon strip club, contrasted the spirit of her neighborhood with the suburban jurisdiction where she worked, which I call Orville. In the Portland neighborhood where she lived, residents were unruffled by the presence of strip clubs, and the neighborhood association even considered having a social gathering at one of them. However, Mara explained,

Orville is not a community that would embrace a strip club. This is a point of pride in Orville: [the strip clubs] are not actually in Orville. The Roadhouse is in Portland and Samantha's is in unincorporated [county name]. It's a fine distinction, but it is made with regularity.

Nelson, a public employee, explained to me that urban neighborhoods regularly deal with more complex challenges than do their suburban counterparts: "The density, the politics, the conflicting interests of Downtown, the fact that the transportation patterns for not [only] the city but also the metro region [converge] makes this particular [area] very very complicated." He contrasted this with his experience with more suburban areas within the city limits: 
You're dealing with predominantly residential concerns and they tend to be lower-level criminal issues, a lot of livability stuff. For example, I've [seen] more than one neighborhood meeting on egging. ${ }^{4}$ When there is a larger issue that takes place, the community reacts extremely explosively and there's a lot of emotion involved.

The complexity of life in highly urban environments may result in the presence of more formal avenues for controlling land uses or managing conflict over them. While Portland's built form has diverse land uses in close proximity to each other, it also results in a wide variety of governance structures, such as business improvement districts, neighborhood business associations, and very detailed zoning codes. Thomas, a thoughtful businessperson who had seen an array of controversies in neighborhoods around the city, explained that problems are easier to resolve in the City of Portland than in outlying areas because its land use regulations are both stringent and designed to account for the conflicts that arise when diverse land uses are present. He said,

If there wasn't any zoning code, there could be conflict but there wouldn't be a mechanism for dealing with it, and then the conflict becomes more internalized as opposed to something out in public. Here, every interpretation is a public process so it appears to be a conflict even though it's really more of a discussion and a resolution. When somebody opens up a place in Beaverton [a suburb], it seems to cause more uncertainty and conflict than [in] a Portland location. Maybe it's a suburban mentality that

\footnotetext{
${ }^{4}$ That is, vandalizing properties by tossing eggs at them.
} 
we don't want to see these things because we're out here with our two-acre lots and our three cars and this doesn't fit in.

The absence of these systems in the suburbs, or the simplicity of the systems that do exist, may make it difficult to resolve the conflicts that arise when residents are angered by an unexpected land use.

In summary, three aspects of the urban experience limit the degree of conflict over strip clubs: residents of urban areas expect to be exposed to a variety of activities and land uses, they have more pressing problems than the mere presence of a sexually oriented business, and they have more policy tools available to forestall or manage conflict.

\section{Socioeconomic status (SES).}

Evidence from the study both supports and refutes the notion that areas with wealthy residents are more likely to resist strip clubs-or other noxious land usesthan are neighborhoods where the residents have fewer economic and political resources. Few of Portland's strip clubs are located in the most prestigious quarters, and many interviewees assumed that clubs are more likely to locate in areas where residents are less economically and socially powerful, and therefore less likely to mount an effective resistance to the club. However, interviewees also suggested that socioeconomic status (SES) is not the most important determinant of a neighborhood's response or the effectiveness of its resistance. In this section, I discuss attitudes about clubs in areas of low SES, examples of resistance in areas of 
high SES, and the factors that moderate the influence of neighborhood SES on response to strip clubs.

Interviewees affirmed that many strip clubs are located in neighborhoods that are less wealthy, socially stable, or desirable from a residential real estate perspective. Many also reported that residents and business owners in these areas raise little resistance to the clubs, even when they associate the club with noise, littering, or criminal activity. Carl confirmed that he had selected a site in a low-tomoderate SES residential area for his business because he knew the neighborhood would not complain. Oscar, who worked at his family's restaurant nearby, agreed that strip clubs fit with the character of the neighborhood, which he described as "kinda ghetto." He explained to me, "If they're going to be somewhere, they're going to be here. You come to bars over here, you know where you're going." Mara, a neighborhood leader who lives nearby, suggested that the clubs in the area might not spur many complaints because of the characteristics of the area's inhabitants and landscapes. She told me,

It's a pretty diverse neighborhood ethnically, I think there are a lot of people who don't speak English as their first language, there are worse land use issues than the strip club. There's all these car repair shops and a lot of industrial uses, which I think are probably more of an irritant. For the most part people have kept their heads down, maybe not thought too much about it. Among all the things that people complain about, that's probably the least noxious. 
Interviews with people who worked in another ethnically diverse neighborhood with many low-SES residents and several strip clubs had a similar perspective. Everett, a public employee, described the neighborhood, which has a somewhat high turnover in residents, as a "forgotten" place that gets little attention from politicians. From his perspective, the area is primarily an industrial one, with dirty businesses and "junky" cars; many residents live in apartment buildings. He reported hearing few complaints about strip clubs from residents, which he said was because they know it is impossible to shut the clubs down, or because they are numb to their presence. When I met with three women who worked in education and social services in the neighborhood, they told me about a wide variety of problems they attributed to the neighborhoods' strip clubs. They then listed a host of reasons that residents do not act on their frustrations about the clubs, which I will paraphrase as follows: Residents don't have much choice about where they live, so they don't complain much. A lot of residents are immigrants or don't speak English, so they are unlikely to make a fuss. If a problem gets really bad, they will just move. The population does not speak English, does not know the laws or understand government systems, and has limited education. Families do not call 911, so crime statistics underreport problems. These interviewees explained that residents do not have the time and resources to organize against strip clubs because they are struggling to meet their basic needs. They gave the very stark example that car theft in the neighborhood is driven more by the need for transportation than by a desire to profit from selling stolen goods. 
Nelson, a public employee, and Whitney, a dancer, echoed this perspective when they told me how clubs have thrived in one commercial neighborhood. Though she loved working in the neighborhood because of its vibrant character, Whitney believed that it lacked the social resources to mobilize in response to problems caused by an unpopular or nuisance business:

Obviously, there are serious problems with the neighborhood that these clubs are in. Mostly socioeconomical. There's drugs and crime. There's a bum hotel over Club Rio and always has been. And then Rendez-Vous, that place upstairs is condemned, and ... there's traditionally not any real people living down there. Which makes a huge difference: when people are living in the neighborhood they tend to take better care of it.

About the same neighborhood, Nelson asked rhetorically, "Say all the SRO's ${ }^{5}$ were occupied by high-end condos, would you have the same amount of bars? Probably not." It was taken as truth that strip clubs choose to locate in places where neighbors are unlikely to try to control their operations.

The other side of this coin was that socially powerfully neighborhoods were seen as fiercely resistant to strip clubs. Some of the most visible resistance to strip clubs in Portland has focused on sites that were in or near wealthy and politically connected neighborhoods. Local media seized on these conflicts, and in my interviews, public employees recounted their experience with several notorious

\footnotetext{
${ }^{5}$ Single-room occupancy hotels, which can be rented by the night or week and serve as short-term housing for many high-need, low-income individuals.
} 
examples, sometimes sighing with frustration about how much time and effort they spent dealing with the controversy.

For example, Tina, whose warmth seemed almost at odds with her detailed knowledge of her agency's many bureaucratic rules, told me of her work related to the strip club I call Glitter. The club, located in a high-SES residential neighborhood, had spurred conflict that had consumed countless hours of Tina's time. She told me with exasperation about residents' complaints:

They think that all the problems in the neighborhood are still coming from Glitter. There have been five [police] reports within 500 feet of the bar in the last year. I can only attribute two of those to the bar itself. I probably have 500 emails from these people, and I have boxes and boxes of paperwork, and it's just so ugly.

Valerie, another public employee, was similarly inundated while working on the case of Silk Stockings, which is located in another high-SES area. She told me that the conflict between residents and the club owner had grown so acrimonious that both sides were accusing each other of harassment, and one individual had already threatened a lawsuit. From her perspective, the conflict had exploded recently not because of any changes at the club, but rather because of changes in who lived nearby. The most vociferous complaints were coming from new residents who had recently purchased a home in the neighborhood, where property values had been rising and the schools ranked well. They wanted to see the strip clubs shut down, despite the fact that the clubs had been operating for many years with few 
problems. From Valerie's perspective, as the neighborhood had gentrified, newer, wealthier residents were demanding city resources to protect their investments.

Tina listed a number of prominent citizens, including legislators and government appointees, who share their neighborhood with The Roadhouse and Silk Stockings. She spoke of the club owners with sympathy: "They definitely have a disadvantage than if they picked some neighborhood where people really don't look that closely or get that involved in what's going on in their neighborhood." She also recalled the tenacity of Glitter's neighbors, who contended that a the new club would ruin the character of their neighborhood—even though the club was at the very edge of the neighborhood boundaries on a commercial street. Tina contended that the clubs at the center of these controversies were not especially problematic. She explained:

They really aren't doing anything different than any of these other clubs. [The neighborhoods] just have people who have more money and power. They're used to feeling like their voice can be heard. As opposed to somebody who might live out at $92^{\text {nd }}$ and Foster-they have several strip joints, but they tend to be more renters, low income, they're trying to get food on the table. They're just thankful they have a roof over their heads. The people who scream the loudest are the people who have money.

Every type of interviewee affirmed their familiarity with this pattern to me.

However, while these ideas about the enduring power of SES came up in many of my interviews, SES was not always the definitive factor in neighborhoods' response to strip clubs. When clubs appeared in or encroached on more visible and 
valuable sites (either financially valuable, such as a luxury property, or symbolically valuable, such as a school or church), conflict seemed very likely to ensue, regardless of neighborhood SES. This suggests to me that the perception that the neighborhood is being overrun by sexually oriented businesses, or that children may be affected by the business, may be more powerful sparks to action than the the sense of entitlement that comes with high SES.

Irene considered the controversies she has seen over sexually oriented businesses in her career as a public employee and told me that while no neighborhood wants to have a sexually oriented business, many different types of neighborhoods will resist them. She said:

How much people are willing to fight, I think it's always surprising. That sex store [we discussed] was maybe six years ago, 10 years ago-it [the neighborhood] was still working-class, not fancy. But even then they fought like heck. They did everything to try to stop the store from coming and then did the foot patrol. They even fought after that. They just did not want that. That other store was in ... a working-class neighborhood. I don't think that it always has to do with money. Just as much working class families will fight for their kids' safety and the perceived safety than rich people will-they just may have more resources to talk about lawyers and stuff, but the impetus to try and fight is still there. In [the case of the first sex store] it was a pretty mixed diverse neighborhood, more so than others. 
As a second example, Nelson, another public employee, described controversy over a new club I call Queeny's in the lower-SES neighborhood that Everett called "forgotten":

It's something they [neighbors] felt passionate about. They [club owners] wanted a strip club in a bad area that already had problems and they [neighbors] were willing to put some time and effort into saying, "No, we don't agree with this. We've got vulnerable populations with limited skills in dealing with stuff." There's no benefit to the greater society to having that type of establishment—-that was their opinion, I agree with it—next to populations that are already being taken advantage [of], that are already vulnerable and have multiple different challenges. And then literally 200 feet away you have the school for [a special needs population].

In this case, the sense of saturation had spurred the neighborhood response, which ultimately was successful in preventing the business from opening.

The demographics of the neighborhood-separate from income, occupation, and race-also influenced the level of conflict, in that the presence of children or older adults increased the likelihood of resistance. Liana, a seasoned public employee who had worked all over the city, suggested that the presence of children was an important ingredient: "One of the things that gets people more engaged in what's going on is anything that they feel endangers their children. An area that might have a low youth population, like the Pearl [District], might not have that." Similarly, she saw the influence of older adults and residential stability on the campaign against Queeny's: 
A lot of the families in the good part of [the neighborhood] are very established, have been there for a long time. They're older, White, retired people who have a little more time on their hands. They don't want to see the riffraff and they fight for the poor families that are trying to make a difference.

The experience of living in a low-SES neighborhood also may galvanize a reaction. Many of the concerns voiced about strip clubs revolved around the belief that clubs are part of a process of neighborhood blight, and low-SES neighborhoods are often in the most precarious situation in this regard. A co-chair of a neighborhood association made this connection in a statement supporting Measure 31:

Many of the [Portland] outer southeast neighborhoods are economically fragile and ripe for undesirable businesses taking advantage of lower commercial costs. Adult oriented businesses promote negative imagery and gender roles to children and adults. They have TREMENDOUS DESTRUCTIVE POTENTIAL FOR NEIGHBORHOODS on the brink of deterioration.

In this case, the neighborhood resisted strip clubs specifically because residents felt that its precarious socioeconomic status made the community vulnerable to further decline.

\section{Site-specific factors.}

Community perceptions of strip clubs are further influenced by what I term site-specific factors. The age of the club, its physical appearance, and how its staff 
interact with neighbors are important influences on clubs' relationships with their neighbors. Clubs that integrate with the spatial and social order of their surroundings are often well tolerated, but those that stand out through physical or social incivilities (Taylor, 1988) may foment conflict. Clubs can actively manage the extent of incivilities through choices about site design and club management. While being invisible may help prevent the emergence of problems, having managers who are visible and accessible to the community is important for resolving problems do arise.

\section{Being discreet.}

Clubs forestall conflict by being discreet in both appearance and activities occurring outside of their club. These characteristics allow neighbors to treat clubs in an "out of sight, out of mind" manner. Because many of the concerns about strip clubs relate to undesirable changes clubs might cause to the neighborhood, discreet clubs are more able to avoid being scapegoats for neighbors' fears. Merchants and neighborhood leaders with experience in neighborhoods with clubs suggested that when it is not possible to see inside the business from the street, minors are kept out of the club, and dancers' skimpy attire stays inside the club, clubs present no problem for the neighbors. As dancer Fiona put it, because Portland's clubs are "not in-your-face," they are not an overwhelming presence. If owners keep their properties neat and well-groomed, minimizing threats to aesthetic order, such as graffiti and litter-which also suggest a lack of informal social control—conflict is less likely. For example, interviews with businesses neighboring one discreet club 
revealed that some people who worked nearby were unaware that the bar even offered nude entertainment. Not surprisingly, they also reported no problems resulting from the club's presence.

At the individual property level, most clubs are designed in ways that make them discreet but also unfriendly spaces, which can disrupt the sociospatial order, particularly in residential areas. Although lack of windows prevents passersby from seeing what goes on inside, this also prevents the natural surveillance provided by "eyes on the street" (Jacobs, 2002/1961), and can present a monolithic, fortified face that is unattractive. There are also other, less rosy, interpretations of club owners' reasons for keeping a low profile. Neighborhood leaders, public employees, and dancers described to me how some of the more notorious clubs in Portland used tight systems of internal control to avoid conflict with neighbors, presumably to conceal extensive illicit activities occurring inside the clubs. Interviewees explained that if more mundane problems, like noise or serving alcohol to underage patrons, brought government agencies into the club, profitable illicit activities like prostitution and money laundering might be exposed. Barbara told me about a wide variety of illegal and dangerous activities that took place at Babydolls, where she started working as a teenager, and described one of the strategies for protecting the management's cash flow through avoiding government intrusion: a blanket policy that anyone who called 911 would be fired on the spot.

However, a few clubs managed to be both discreet and inviting. For example, dancer Whitney considered The Lagoon "a cornerstone, a keystone business" in its neighborhood because of the way it looks. She explained to me, "It's elegant, it's 
nicely done, it's never ramshackle. The lights are always working. It's good for [the neighborhood] to have that. The owners obviously care about it, the people who work there take pride in it."

As we spoke in the corner of the kitchen of Diamond Dust that served as his office, strip club manager Darren described to me how being having a well-kept appearance is part of establishing a "gentleman's club" atmosphere. He told me, Our signs aren't offensive. They [concerned neighbors] thought we were gonna have naked girls on it, XXX, Girls! Girls! Girls! As long as it didn't show nudity, we could put anything we wanted to. But we don't because we want to be a good neighbor.

He continued,

We patrol the parking lot, we keep it clean, we make sure that we don't have any disturbances.... We never overserve, we cut people off if they're visibly intoxicated. We always offer cabs, we have a tow truck tow your car. We do what we can to make sure that what happens in here doesn't spill out to there. Legally and morally, we have an obligation to make sure it doesn't happen. We really haven't had a lot of problems.

Ostensibly, a gentlemen's club would be less troublesome to neighbors because it is not a sleazy establishment that threatens the neighborhood's identity as the domain of middle-class families.

Diana, whose dislike of strip clubs has already been mentioned, had a much more fraught relationship with the strip club near her workplace because she perceived it as a major disruption to the social order. She told me in our interview, 
It stresses me. Every time I go out and I see any of it I get angry. For a while we were constantly having little papers tacked on the telephone poles advertising different things and so I'm forever going out and taking 'em down. I want my area clean. It does create more work, more hassle. I don't want my grandchildren going outside-I don't know if they're going to get pricked with a needle from somebody shooting up. I hate it that I know these terms. I don't want to know this stuff.

While Diana mentioned fears of physical harm to her grandchildren, she offered no evidence that she had actually seen used syringes in the neighborhood. The most concrete complaints I could elicit in our interview were ways that the club resulted in a sense of disorder-flyers posted, litter in the street, sexually explicit magazines and video packaging left in dumpsters-and the intrusion of different people's experiences and behaviors into her mental and physical world.

Darren, a club manager who has tried to work with neighbors, felt that residents' concerns were genuine but often misplaced:

They think that if a strip club goes up next to the [convenience store] all of a sudden there's pedophiles walking around trying to take their kids away. We all know that pedophiles would not come into a strip club. They would go to a library, where there's children. I've never heard of regulations put on those places.

To him, the fear of what might happen at clubs was a far greater problem than what actually did happen at clubs. Whitney, a dancer, also questioned the notion that strip clubs are a threat to children. In our interview, she asked rhetorically, "Is it 
bad taste to have [a club] next to a church, or next to a school? To me churches are more creepy than anything right now, with molestation. And schools are like little prisons." Many of the people who worked in strip clubs shared the perspective that communities faced far more serious threats than strip clubs, which they viewed as harmless or even beneficial to the surrounding community.

\section{Cultivating relationships.}

Beyond physical appearance, how open a club's management is to contact with neighbors has a strong influence on how residents and merchants perceive the business - and the degree of conflict over club activities. When people know a club's employees or have had a positive interaction with the management or the property, they are far less concerned that its presence will damage their neighborhood or their business.

While the neighborhood association program and good neighbor agreements (GNAs) provide a formal system for clubs to interact with neighbors, trust can also be cultivated informally. Timothy, whose club thusfar had not needed a GNA, explained informal ways he had built relationships with neighbors:

There's a house that's directly behind the [club] and it's kind of a college house. So we're pretty stoked on that because it's always young people that are living in the house and they'll come over to the bar. Anytime anybody parks in front of their house or drops off any garbage, I'm always there to help.

From his perspective, this constitutes good business practices. He continued: 
I'm always really really sincere about anybody that has any complaints about the bar. And I always try to solve whatever issue that they're having because that's the last thing you want, is your neighbors not wanting you there or a disgruntled neighbor. Any time that anybody starts to have a problem with you, and depending on how much free time they have on their hands, they can make it a real issue for your business.

Reciprocity between clubs and their commercial neighbors also helps establish the club as a respected participant in community life. Susanna, who managed a food service establishment near The Lagoon, enjoyed having the employees of nearby sexually oriented businesses as customers because they were regulars who tipped well. She told me about several club employees whom she considered "sweethearts," and commented that she could see no reason to object to their presence in the neighborhood since the dancers "covered up" when they were in the restaurant and were came around after children had gone to bed anyway.

She noted that the strip club workers were friendlier than many of her other customers, and more reliable sources of income. Louis, whose business was next door to the same club, spoke of the well-mannered manager and the orders for merchandise he had placed with Louis' business. Harold, a recent migrant to Portland who opened a business catering to the city's "creative class," reported that the staff of the neighboring strip club came over to meet him and to check out his business when he was getting settled in. Their visit created a feeling of collegiality and a sense of reciprocity. 
Just as he actively worked to address residential neighborhood concerns, Timothy intentionally built relationships with businesses near The Lagoon. He told me,

We're definitely very friendly with all the businesses that are around there.. . I went around and introduced myself to all the other neighbors and actually became really good friends with the [business] that's next door. And she ended up becoming a regular, and then she comes over and cooks [a holiday meal] for all the bar staff. And once a year, she lets us use her parking lot and we do a benefit... I think it makes everybody feel good. I guess that's our little small contribution to the neighborhood.

Clubs with less forthcoming management did not fare nearly so well with their neighbors. Liana described neighborhood meetings with the management of Glitter as an example. She told me, "Everyone wanted to believe that, when they came to the table and said, 'We want to have this country-western business.'” But when residents learned that one of the license applicants worked at another Portland strip club and had had legal problems while running a bar in another state, they pressed for more information and were rebuffed by the applicant. He resisted dialog and negotiation, and then off-handedly mentioned at a later meeting, "If we can't make this a success with this business, we may just make it a strip club" (as paraphrased by Liana), shocking the neighbors. Liana saw that moment as a major turning point:

People could have fallen off their seats. From that point on, things changed. Neighbors had been willing, then they didn't want to meet with the neighbors 
anymore because they said terrible things about them. The whole sense of trust was lost.

Other public employees agreed that strip club problems were worst where owners and neighbors could not find common ground. As I sat in their office listening to their war stories, public employees Billy and Norbert told me about club owners who felt picked on by their neighbors and who also realized that GNAs have no enforcement mechanism. Since some owners feel that neighbors will be dissatisfied no matter what they do, they make no effort to resolve problems and sometimes taunt neighbors by doing things like having scantily clad women "advertising" the business in their parking lots. "Those are the worst!" Billy and Norbert groaned in agreement.

They went on to describe a situation that is an extreme example of this phenomenon. Neighbors of Silk Stockings had advocated with the city to restrict the size of one of the businesses parking lots. This restriction had the unanticipated effect of causing club customers to park in front of nearby houses, which the neighbors then complained about. The fed-up owner felt he had tried to address neighbors' concerns, but that the only thing that would satisfy the neighbors would be to close the club. Viewing the situation as hopeless, he became less conciliatory. Billy and Norbert reported that this situation was not unusual: since neighbors will not be happy regardless of what the owner does, the owner gives up efforts to be a good neighbor. To paraphrase what Billy and Norbert told me, some club owners start out never caring but others get that way after frustrating interactions with neighbors. Club owners may also resist bowing to neighbors' wishes because the 
high visibility of the industry in Portland gives them a sense of clout. Throughout the ballot measures and court cases related to the obscenity standard, club owners promoted themselves as business people whose work is unfairly encumbered by city governments, which unjustly try to block their businesses out of prudishness.

In some cases, the professionalization of the industry has produced owners who engage in proactive negotiations with neighbors. A city employee described the opening of a strip club called Delilah's in a commercial district:

Their security was very proactive and actually, they started patrolling the area and really improved safety because before they were there in the nighttime there were a lot of issues because of [a facility in the neighborhood] - you saw a pickup in the drug trade too. So when the strip club showed up it actually made that little corner safer.

Clubs that serve (or are perceived to serve) neighborhood residents gain credibility with residents, making conflict less likely to erupt. Again, Timothy described The Lagoon's role in the neighborhood to me: "We get a lot of the neighborhood that comes in. On snow days we're packed because there's nothing else to do around there." From his perspective, the establishment is a cherished local bar; having strippers is almost secondary. Mara, a neighborhood leader, explained how this influenced her opinion of The Lagoon. She was not bothered by its presence near her house because the people that go there... probably live in the neighborhood. It's not a place where people are traveling from the other side of town to come there. I don't 
know if I would feel differently if it were a regional draw. I think the distinction is 'our' strip club is a neighborhood place.

She recognized that the dancers might be her neighbors, commenting that she would not be surprised if they lived nearby. She also noted that her neighborhood club hosted activities beyond striptease, such as live music, which made it welcoming to a broader audience. By contrast, she was less enamored of a nearby gambling parlor that drew its clients from throughout the region.

\section{Temporal effects.}

Time is another element affecting neighborhoods' perception of strip clubs. Local opposition is most common when clubs first open, but usually wanes if few disruptions to neighborhood life occur. Nelson, a public employee, explained that while there is often conflict over the initial siting process, "Once you're established, it's not gonna change. People turn a blind eye to it unless the clubs change management and do something different in their format to draw attention to themselves." Most of the problems that do surface are typical of nightlife businesses: complaints about loud music and rowdy patrons bothering neighbors. Well-established strip clubs report few problems with neighbors.

Club owners who are aware of this process may use it strategically. Timothy and his partners used incremental changes to establish their club. They took over a property that had been a bar for decades, and as he told me:

It was a very very easy gradual process of turning it into a strip club. I think it was to ease people into the fact that it wasn't their local dive bar anymore. 
It's their local dive strip bar. I think there was a lot of regulars, and I think if it just switched right away they would have been maybe turned off. This was a conscious effort to avoid making waves in the neighborhood.

However, clubs that manage to ride out the challenging opening phase are not guaranteed indefinite peaceful coexistence with their neighbors. New opposition may emerge if there is a high-profile event in the community, such as a crime on club property. In one case, a club was subject to sudden scrutiny because of opposition to another club's application to move in down the street. As Tina, a public employee who worked with liquor licensees, put it: “The Roadhouse [didn't] seem to be on anybody's radar, but now that Velour is going in, the neighborhood's saying that the Roadhouse has all sorts of problems."

Because location can be an important asset to a club, club owners may be genuinely concerned about their club's surroundings. According to dancer Wendy, "I think a lot of the clubs that have been around for a long time have more of a stake in their community, so they feel like a shareholder in their community in that level." In this way, longevity at a site can also change the way a club responds to its neighbors.

\section{Research Question 3: Dancer Experience}

The third research question of this study was, what affects the work experience of female exotic dancers? The size, diversity, and spatial extent of Portland's strip club industry confer several benefits on dancers, but they do not fully mitigate the hazards of the job. In this section, I describe working conditions in 
the city's strip clubs and then examine the role of various influences on these conditions. I begin with the effect of state-level factors and continue through successively more local levels of analysis.

\section{Working conditions.}

Virtually all of the dancers I interviewed had many positive things to say about working as a dancer (some of these experiences are detailed below). However, not just dancers but club owners, public employees, and even neighbors I interviewed commented on the hazards of the job, the most prominent of which are connected to the instability and unpredictability of the workplace. There are additional challenges outside the workplace: though the stigma of the strip club as a place is not as great in Portland as elsewhere, the stigma of working as an exotic dancer is still borne by Portland dancers.

Much of dancers' experience of constraint came from the actions of club owners or managers. Carly described the effect of different management styles on dancers' work experience:

Some of the places treat the girls like they're kind of indisposible [sic].

There's so many dancers. You just hear a lot of not taking account of girls' schedules and being a little harder on the girls because there's so many other girls. I think that's why the girls like this place so much, because [the owner]'s very fair ... Some clubs they'll just all of a sudden take somebody off the schedule or switch their schedule around. That's messing with somebody's money.... If you wanna get shifts there [at the Roadhouse], you 
have to pay your shift fees and not protest anything. In the winter time, they have a woodstove that heats the whole downstairs and it's freezing and you're trying to dance around naked. You'd think the girls would protest. Well they don't, because they need the shifts. And for every girl that chooses not to work, there's two or three other girls willing to work. And The Roadhouse has a reputation for making good money, so the girls put up with it and there's no recourse.

Dancers accept these inconveniences and risks of the workplace because those risks, in their calculus, are outweighed by the benefits of the money to be earned. Dancers endure injuries, sexual harassment, physical violence, and radical fluctuation in income because there is always the potential that they will earn hundreds of dollars in a few hours-though those experiences are less common than the long, boring shifts in which dancers barely break even.

Even during busy shifts, dancers cannot count on receiving their money or being safe at work, partly because of lack of legal protection. A law enforcement officer I interviewed recounted visiting a strip club in response to a call about a customer who had refused to pay for a lap dance. She laughed as she told me the story, saying that she did not know what the dancer wanted her to do because the customer hadn't "stolen" anything. Another public employee recounted an instance when a police officer did nothing to assist a stripper who had been locked in a hotel room closet by an angry customer who called the police because she would not have sex with him. These responses make it clear that even when sex work is legal and socially tolerated, the labor is not valued and the workers are not protected. 
Dancers also experience discrimination outside of the workplace. Fiona described the challenges of parlaying strip club experience into another job, or using strip club income to support a lease application: "Some people will turn their nose at you if you want to apply somewhere. You're automatically categorized as a whore or somebody dirty. As many strip clubs as we have, it's still shocking for people to hear that." Barbara described how she succeeded in finding housing because the building manager was a former dancer willing to take on dancers as tenants when other landlords wouldn't. A public employee confirmed that when women who have worked as exotic dancers experience assault or rape, district attorneys decline to prosecute because dancers are not "believable" victims since they perform sex work.

\section{State level.}

The State of Oregon influences dancers mainly by its absence. As discussed in sections above, there are no state regulations specifically addressing working or pay conditions for exotic dancers. This lack of regulations removes encumbrances to dancing, such as the rules in other states requiring dancers to obtain permits, cover certain body parts, etc.; however, the lack of state involvement also fails to protect people working as exotic dancers. Because exotic dancers are not considered employees, they are not subject to the oversight of either the state Occupational Safety and Health Division (OSHD) or to the Bureau of Labor and Industries (BOLI). The former regulates the physical condition of workplaces and the latter deals with hour and wage issues. Both Oregon OSHD and BOLI respond to 
complaints from workers, but neither has taken any visible stance on exotic dancers, whose working environments routinely violate standard workplace practices.

To avoid the additional costs and liabilities of paying wages and benefits, clubs do whatever they can to classify dancers as independent contractors. Some use booking agents to create an intermediary between club management and dancers, so that they can claim that the booking service is setting hours and fees rather than the club. Club owners and managers exert significant control over dancers' work, creating an employer/employee relationship regardless of the dancers' ostensible status as independent contractors. These relationships contravene many of the criteria that BOLI uses to define independent contractors, such as where work is performed and whether the work is central to the function of the business-clearly, most exotic dancers do their work at strip clubs, and strip clubs would not exist were strippers not present. Three BOLI cases or lawsuits on behalf of exotic dancers seeking wages found that dancers were working as employees and awarded them back wages (BOLI hearing on Geoffroy in 1996, State Roberts v. Acropolis McLoughlin in 1997, and State ex rel Roberts v. Bomareto Ent., Inc. in 1988). In a fourth case, a Multnomah County Circuit court found against a dancer who sued for back wages because she was an independent contractor and did not meet the standards for being an employee (Pitkin, 2010).

Darren explained that his club took pains to avoid using the term independent contractor because they knew it did not accurately describe the strip club industry's workforce. His club's strategy was to say that dancers were leasing 
performance space from the club. He gave me the club's perspective on the difference:

You would consider an entertainer like a hairdresser: they lease a space and they keep all their money for the services that they render. They're not independent contractors like people like to call them because they don't meet the test of an independent contractor. Other clubs use the independent contractor model, which is probably going to get them in trouble. Independent contractors set their own schedule, bring their own tools, have their own stuff. Some clubs in town will tell you you need to be here at 10 o'clock and wear this and this and this. If you're leasing the space from me, I can say, "Hey, we need you here between these times, this is when we're open." I can't have you cutting hair at 2 o'clock in the morning. And I need you to make sure that you have clients bringing business in. Because if you're not I'm going to bring someone else in to have this chair because this chair is money. You have a little bit more control when they're leasing. If they don't show up, we don't have to let them work. You don't get fired, we just have someone else replace them. It's like the electrician who shows up an hour late: the general contractor's gonna go, "I just got someone else, I don't need you anymore."

Exotic dance has far less regulation and other interaction with the state than do the other professions listed by Darren. For better and for worse, the state of Oregon is basically absent from exotic dancers' work experience, outside of its role controlling the service of alcohol in the locations where many dancers work. 


\section{City level.}

The prevalence, diversity, and tolerance of strip clubs in Portland create an environment conducive to working as an exotic dancer. Dancers have a wide variety of clubs to choose from, and their profession is less stigmatized and sometimes even celebrated in Portland. This is due to the interplay between the city's culture and its built environment, one feature of which is the neighborhood strip club. This peculiar institution is well represented in Portland and provides unique work environments for dancers.

Xena told me that Portland is "an amazing place to be a dancer," and other dancer interviewees agreed. Several told me that they could not imagine dancing anywhere else, or that they never would have gotten started in a different city. Carly reflected on her decades working in Portland strip clubs and told me about how stripping has been normalized:

It's become a lot more mainstream. The education level is a little higher, at least here. I did this survey of the girls we had working and there was 12 girls that were currently in college, 5 already had their bachelor's degrees, 2 had their master's, only 6 were moms, 9 were musicians, and there was one published author. So the dynamic was a lot different than the stereotype. I think it's a little different here. Maybe it's just Portland because there's so many clubs that it's more socially acceptable, it's not this big taboo thing, or as bad as some places. 
Dancers praised Portland for the variety of strip clubs, the athletic and artistic talent of dancers, the social acceptability of strip clubs, the diversity of their clientele, and the "low-key" dynamic at most Portland clubs. Because there are so many strip clubs in Portland, dancers may end up performing in one or many niches. As Xena put it in our interview, "You get a broad spectrum of options." Dancers described trying out different clubs until they found one where they fit, or made distinctions between different clubs' styles. For example, Fiona described her favorite club, Casablanca, as, "more like pretty girls that are gentle," in comparison to The Lagoon, where "pounding your pelvis" to rock music was more typical.

Dancers expressed strong preferences for certain types of clubs and club locations. Terra, noting spatial, racial, and cultural variation between clubs, described club selection a matter of lifestyle. She expressed disdain for the suburbs and their denizens, seeing Portland's clubs as the counterpoint to a landscape dominated by big box stores and strip clubs populated by dancers who are all overly tanned, with breast implants and big, blonde hair. As a multiracial woman, she felt at home working in Southeast Portland's strip clubs. From her perspective, patrons in this bohemian part of town better appreciated her aesthetic (both physical appearance and personal style) than did people in other parts of the city. To elaborate, she explained that she rarely made much money when working in North Portland clubs, where African American women were popular, or in working-class White neighborhoods, where clubs were more "like biker bars." Meghan also had strong place associations, telling me, "I obviously would never work up at one of those clubs up on like $92^{\text {nd }}$ or $122^{\text {nd }}$, like by [Interstate] 205 . Very different clientele. 
It just seems like there's worse clubs up there." Mindy told me that she decided to stay with clubs close to her home after trying out clubs all over town because she liked the sleepier character of her neighborhood.

Having a variety of places to work helps dancers compensate for the instability of job tenure and income. Because clubs' systems for discipline, conflict resolution, and seniority are unpredictable, the main recourse dancers have regarding any concern in the workplace is to leave and go to work at a different club. For example, if dancers have a conflict with a coworker, they stop showing up for work. Sometimes this is not by choice: if a dancer displeases a club manager, her name stops appearing on the schedule. The large number of clubs also provides the chance to boost income by periodically switching to a new club, since being "the new girl" helps a dancer to garner extra tips.

The fact that some clubs are located in neighborhood commercial districts confers a level of legitimacy on them. Proximity to other local businesses and services, such as restaurants and retail stores, not only suggests that a strip club is providing a similarly valuable service, but also lets the club's workers conduct their personal business close to their workplace. Likewise, when residents regularly see or pass by clubs, the sites become normalized, even if they are disliked. As Fiona, a dancer, told me, "I'm still amazed that we have the most strip clubs per capita. I kinda don't see it that much, it's not in your face every block you go on there's a strip club on the corner."

Comparing her experiences working in Las Vegas and Portland, Terra commented that the Las Vegas clubs are segregated to an industrial area of town, 
despite the fact that they are probably as integral to the city's reputation as are the casinos on The Strip. She was galled by this arrangement, seeing it as a slight to dancers. From her perspective, dancing demands a complement of physical, social, and psychological capabilities, and relegating it to the sidelines of the city shows a lack of respect for the performers.

By contrast, Portland dancers felt respected by the city at large. Many Portlanders consider being an exotic dancer a perfectly acceptable, and for some, even a coveted, job. Xena told me, "It's so normal here. You say you're a dancer here and people barely bat an eye. You go anywhere else and people are like, 'Oh, wow, crazy whore!' It's a big deal somewhere else." In fact, some dancers are local celebrities. Katrina told me that for some dancers, the "notoriety" is the best part of the job, including the proximity to high profile dancers, because "people know who they are, which is kind of fun to go out with them and everyone's super-nice to you." This type of attention is especially powerful for younger dancers.

\section{Neighborhood level.}

The neighborhood where a club was located and the amenities available there affected dancers by shaping their journey to work, their relationships with patrons, and their sense of safety. The type of club site-whether peripheral, commercial, or residential-also affected dancers' relationships with their patrons, with clubs in residential neighborhoods fostering ongoing relationships and a sense of camaraderie with other dancers. While location was not the strongest influence reported by dancers, interviews made it clear that mixed-use residential 
neighborhoods provided opportunities for convenience, safety, and social interaction that improved dancers' experience.

Dancers enjoyed working at strip clubs that were centrally located or in vibrant, mixed-use neighborhoods. This was because, like other workers, they prized short commutes, low transportation costs, and access to nearby services and amenities. Portland's close-in neighborhoods-walkable communities with a wellconnected street network and relatively dense concentration of housing and commercial development-offer advantages to dancers who work there. When strip clubs are located in dense urban neighborhoods, it is easier for dancers to get to work. Portland's public transit system provides better service to the Central Business District and neighborhood main streets than it does to auto-oriented development in industrial and peripheral areas, and some dancers are transitdependent. Several dancers I interviewed reported not owning a car during at least part of their dancing career, often because they could not afford one. For Mindy, public transportation was a lifeline when her license was suspended for driving under the influence. Without access to bus service, her only way to get to work would have been a very expensive taxi ride. Since many dancers drink alcohol or use drugs while working, being in an area with a variety of transit options may also reduce the incidence of driving under the influence.

Dancers I interviewed had actively sought to work, or simply benefited from working in, Portland neighborhoods known for their walkability, bicycling infrastructure, and transit service. Dancer Katrina enthusiastically told me about a period when she lived down the block from the club where she worked, and how 
much she enjoyed being able to roll out of bed and head to work a few minutes before her shift started. Several other dancer interviewees also reported walking or biking to work, a practice that appears infrequently in the published literature on stripping, and which I believe can be attributed to the fact that few other cities have as many strip clubs located in or near residential areas (as well as to Portland's high-quality active transportation infrastructure).

Amenities near a club were another benefit for dancers. Terra regaled me with stories of her time dancing at a club in Portland's Central East Side, at the edge of a peripheral industrial area, recalling the exhilaration of quitting time, when dancers streamed out of the club into the fresh night air, hopping on their bicycles to head to post-work adventures. The club's location in a lively neighborhood put it in close proximity to a variety of bars and other late-night destinations, making it a desirable place to work.

Dancers also felt safer working in clubs closer to residential areas. When there are other businesses and residences nearby, there is more potential that streets will have pedestrian and bicycle traffic as well as cars, and that these "eyes on the street" (Jacobs, 2002/1961) will provide a sense of surveillance. The design of these areas is also on a more human scale, providing comfort and a refuge from threats. Xena and Mindy's descriptions of their experiences working at different kinds of clubs provided a perspective on the way dancers experience these spatial differences. Xena told me, "I think neighborhood strip clubs tend to be more safe [sic] than other ones." Mara told me about a bad experience working at Fantasy, which is in an industrial area, and then elaborated on how she experienced place: 
There's quite a few clubs I would never work at because of the neighborhood they're in. Like Fantasy for example. I worked there for a day several years ago and there were no customers in there, there were only people that wanted to pimp me out. And then there were shootings in the neighborhood and knifings. I try to stay in the areas that are a little more safe [sic]. I want to know that I'm safe, that I'm protected in some way-whether it's a place to go hide, or a lot of places I'll find at least one bouncer [with whom] I build a pretty decent connection.

Thus, selecting a neighborhood in which to work is one strategy dancers use to ensure their safety.

The level of neighborhood conflict over a club did not seem to affect dancers' well-being. None of the dancers I interviewed could recall being affected by any neighborhood protests or complaints. This was true even for those who worked at sites with acrimonious relationships between club owners and neighbors. Dancers described both benefiting from interactions in the neighborhood and making a contribution to the neighborhood. The sense of belonging and reciprocity helped dancers feel grounded and respected. These attachments were especially strong for dancers at smaller neighborhood strip clubs.

For example, Xena was a long-time resident of the neighborhood where she had worked at a strip club for several years (at the time of our interview, she had moved on to another club). She had greatly enjoyed living and working in the same neighborhood. She had built friendships with customers and was entertained by incidents like encountering club customers in the local grocery store. Because the 
club where she worked catered to the neighborhood, she encountered regulars outside of the club and continued relationships with them outside the club, even after she started dancing elsewhere.

Dancers also felt that they were making a contribution to the neighborhood. They were proud not only of the economic contribution their clubs made to the neighborhood but also of the social benefits, which many of them enumerated in our interviews. They described strip clubs as a safe venue for responsible alcohol consumption, sexual expression, and social interaction. Xena told me in our interview:

Sometimes it provides a healthy environment for someone who just needs to get away from their everyday life who wants to have a little bit of fun ... It's a healthy way to do that if you do it right. I think that a good neighborhood strip club could really do it well. Some people they have perfectly healthy marriages, they have wonderful families and all they want is just a little bit of excitement on the side.

Dancers expressed pride at serving a wide spectrum of the community. Interviewees took pains to emphasize that their clientele included couples, senior citizens, local business people, and veterans. Mindy described with satisfaction the various roles she had played in her job as an exotic dancer, including health educator, therapist, and life coach. She reminded customers not to drink and drive, offered them a shoulder to cry on, and gave them pep talks about staying sober. These kinds of interactions connect dancers to their customers and the larger community, fostering place attachment while also mitigating burnout and the 
stigma of sex work, which is rooted in a belief that exotic dancers are "unskilled" laborers.

People who own and work at smaller strip clubs that serve a local audience were proud to be the neighborhood watering hole. Not only were closer relationships built, but since these clubs were not the region's most luxurious, they also provided affordable entertainment in a city with a weak economy and high unemployment rate. Darren emphasized this to me in our interview, and pointed out regulars who had come to his bar to watch a sports game as evidence.

\section{Site level.}

The physical configuration of individual club sites varied between different types of neighborhoods. Clubs in residential areas differ from those in other types of locations in two major ways: they tend to be smaller and to be more spatially integrated into the communities that surround them. By contrast, clubs in commercial areas tend to have few residential neighbors, and clubs in peripheral areas often have a larger square footage and are surrounded by large parking lots. While there were certainly other influences on the work experience-most notably the club's management style - the small size and spatial integration of neighborhood clubs were generally positive influences on dancers' experiences.

As small storefronts in neighborhood commercial districts, neighborhood strip clubs are relatively well integrated into Portland's urban fabric. Dancers who worked in such clubs connected to the neighborhood through socializing with residents in and out of the club, patronizing local businesses, and spending time 
traveling to and from work. Clubs that were spatially integrated into more urban neighborhoods offered an emphasis on performance and camaraderie in the workplace.

Neighborhood clubs tend to be "stage" clubs, where dancers spend most of their shift onstage, rather than circulating through the crowd, as is the practice at "hustle" clubs (see Bradley-Engen, 2009 for a discussion of club types). This is because the small footprint of the clubs does not allow much space for multiple stages or private rooms. With only two or three dancers working at a time, dancers in neighborhood clubs spend a large proportion of their shift performing onstage, accumulating tips left by audience members. Larger clubs may have scores of dancers working at once, so opportunities to be on stage are limited, and dancers must solicit customers to purchase lap dances, performed at individual customers' seats for a fee.

Dancers at Portland's stage clubs took pride in earning money for their stage performances, which they carefully choreographed and costumed. This feeling of artistic expression was central to the job satisfaction of several interviewees. In our interview, Meghan described her coworkers' creativity as an inspiration: "Everybody here is creative. That's why I stuck around."

The stage was also viewed as a bulwark against unwanted contact with customers. Meghan described the search for the right place to work in these terms:

The place where I was cocktailing, to be a dancer was incredibly difficult because you had to really really be engaged with everyone. You had to hustle 
yourself in a way that I didn't really feel comfortable doing, I didn't know how. It was this interaction with people that was exhausting.

The stage, in other words, provided a protected space in which to perform without requiring as much direct interaction (or sales work) with patrons.

Show clubs often foster more a more collaborative attitude toward earning money and building performance skills and among dancers. Xena explained:

The smaller neighborhood clubs I think are really great because the girls look at it together. We'll all want everybody to make money. Work in a small club like that and everyone's like, “Yeah, hey, check out her. Isn't she cute? Isn't she great on the pole? Why don't you spend a few dollars on her and then you can come back and talk to me again?" But if you get out of those small little neighborhood clubs then it's gonna be so much more cutthroat. At the smaller club, Xena saw herself as working with the other dancers to create a positive and lucrative environment for all of them. Hustle clubs work very differently: “I've worked in bigger clubs and I don't even know the girls' names I'm working with," Xena said. "They're all just a bunch of random bitches when it comes down to it." Smaller clubs often lack VIP areas or private rooms for one-on-one performances, so the dancers are also sharing one performance space with each other.

Strong personal relationships enhance dancers' sense of safety within the club. In our interview, dancer Fiona used familial terms to describe the neighborhood club where she loved working. She described the manager as 
Somebody who wants to get to know you as a person and care about you. While I was in school it was, "How's school? What are you guys studying right now?" Just a close family relationship. And if you have any problems, you can go talk to them about a problem and not be afraid that you're gonna get fired.

This feeling extended to the events happening on the club floor: "Everybody feels like they're your older brother there. They've always got eyes on the back of their heads. They're always making sure you're okay."

Neighborhood clubs have low turnover, which further strengthens the relationships. As Xena explained, "Working at a club where you're with the same girls all the time, you get to know them and you get to know what makes them tick and you get to care about them." She explicitly tied this to the size of the club. When asked what makes a good workplace from the dancer's perspective, she replied, "Having a place that's small enough and companionable enough." Carly described similar dynamics based on years of working at Club Rio: "A lot of us have worked together for a really long time so it's not a competitive atmosphere as far as the girls with each other. It's just more like a neighborhood bar but it just happens to have dancers." Conversations I had with dancers and customers at Club Rio's bar emphasized its differences from clubs with high turnover, where unscrupulous managers take advantage of new dancers, especially those who are young. Meghan, who danced there, described the relationship among the dancers there in familial terms: 
I was gone for two and a half years. I had my own business and I decided to come back because I just need that extra cash. Most of the girls here, they leave, they do their thing, they travel, they have their own business adventures they go on, and then they come back. It's just one of those clubs you can come home to. There's a different family feel here than any club. The owner, when I called her and said I wanted a shift, she didn't hesitate. She was like, "I'm happy you're back." She really cares about us.

During my visits to conduct some of my interviews in this club and owner, staff, and patrons were indeed very warm to each other.

\section{Summary of Findings}

My study found that there is variation in conflict and working conditions and that this variation is influenced by processes at multiple spatial scales. Some clubs are despised by their neighbors, a few are warily embraced, and most are ignored or grudgingly tolerated by the people who live and work around them. However, few Portlanders actively embrace living next-door to strip clubs, and my research found many examples of passive and active opposition to strip clubs.

Although a few people expressed outrage about the presence of a strip club near their home or business, most neighbor interviewees recognized the right of the business to operate or admitted that they could not conclusively say that the club caused problems. The most typical response was indifference, either because individuals were unconcerned about strip clubs or were resigned to the fact that there is no way to close or regulate them. Some clubs had amicable relationships 
with their neighbors. Neighbors were more likely to tolerate (or even embrace) clubs when they were well established, had subtle signage and appearance, were responsive to neighborhood concerns, and supported neighboring businesses.

Generally speaking, the more urban a neighborhood is, the less conflict there will be over a strip club. Socioeconomic status has a more complicated connection to neighborhood response: while I found some stereotypical responses to strip clubs, such as wealthy neighborhoods angrily resisting these land uses and poorer neighborhoods lacking the political capital to mobilize such a response, there were also examples of powerful mobilization in areas of lower socioeconomic status.

Oregon's liquor licensing system fuels conflict over strip clubs, most of which serve alcohol, through its liberal issuance of licenses and unwillingness or inability to restrict alcohol at sites that have had conflicts with their neighbors. The City of Portland attempts to manage the negative impacts of licensed premises through its municipal liquor licensing office and two ordinances that include sanctions for nuisance properties, but these strategies have only limited effectiveness at resolving conflicts that do arise at strip club sites. However, the less formal neighborhood association program has demonstrated some success at preventing and resolving conflicts.

My research also confirmed that these policies have limited effect on exotic dancers' experiences in Portland, and that dancers encounter a wide variety of hazards in the workplace even when they enjoy their job. Conditions both in and outside of strip clubs can influence the character of dancers' performances and the dancers' experience of their work. Not surprisingly, the feature of club location that 
most influences dancers' experience is the type of neighborhood (residential, commercial, peripheral) in which the club is located, because this affects their journey to work. Location can also affect the type of dance they perform: one very interesting finding of the present study is that Portland's peculiar institution of the neighborhood strip club offers a distinct performance experience for dancers. While dancers remain a vulnerable workforce, smaller club size and club locations within mainstream business districts foster dancers' sense of camaraderie, safety, and investment in the community surrounding the club. 


\section{Chapter 6: Discussion and Conclusions}

The discourses I saw and stories I heard in media coverage, public documents, and the in-depth interviews I conducted exposed me to myriad perspectives on my research questions. In many cases the narratives I saw in my data contradicted each other or posed more questions than they answered. This chapter of the dissertation presents the themes that emerged as I integrated this information with the theories from scholarly literature and my own perspectives on urban planning and health issues. It also discusses the implications of these findings for practice, both by practitioners in land use planning and community health, but also for people working in the sex industry and even for people with limited contact with these industries. The chapter then identifies trajectories for future research that build on my findings and concludes with a summation of the dissertation project.

The present study's findings are novel because they identify place influences on land use conflict and on working conditions in strip clubs. While the literature on land use conflict does identify social characteristics of communities that influence opposition to LULUs, there has been little discussion of how these processes operate in specific relation to sexually oriented businesses-most likely because the literature treats them as categorically noxious. The study not only identifies variation between sites, but also offers insights into how public policy and programs may exacerbate or quell these conflicts across settings. Based on these findings, I propose future research on the spaces of sex work and on the connections 
between sex workers and other contingent workers outside the sex industry, such as freelancers.

\section{Discussion}

The findings of this study are in dialog with two streams of literature: the call for research on the cultural context of sex work (Agustín, 2005) and discussions of sexually oriented businesses and locally unwanted land uses in urban studies and planning. To the literature on strip clubs, much of which has focused on the individual experience of dancers (2011), the present study contributes information about the role strip clubs play in neighborhoods and specifically how place affects strip clubs and vice versa. In the realm of urban studies, the findings provide more a nuanced picture of when and why strip clubs may function as LULUs, building on research exploring the proliferation and stratification of the sex industry (Coulmont \& Hubbard, 2010; Maginn \& Steinmetz, 2011) and community relationships to sexually oriented businesses (Edwards, 2010). My work in Portland suggests that increased visibility of strip clubs heightens tolerance of the sites, and that intermediary organizations can effectively resolve conflicts between groups over the space. However, the study also shows that increased tolerance of sexual commerce does not necessarily improve dancers' working conditions.

Revisiting my conceptual framework, I found clear evidence that the siting of strip clubs in Portland influenced land use conflict, and that place factors influenced the type of strip club found at a given location. These relationships are illustrated with black lines in Figure 7 below, which is a schematic illustration of my findings 
and conceptual framework. I also found that place characteristics and the spatial configuration of Portland's strip clubs had some influence on worker experience, but were not a dominant feature of exotic dancers' description of their experience. This murkier relationship is illustrated with a dashed black line. For the most part, my findings support the findings of previous scholarly literature, illustrated in the schematic with grey lines.

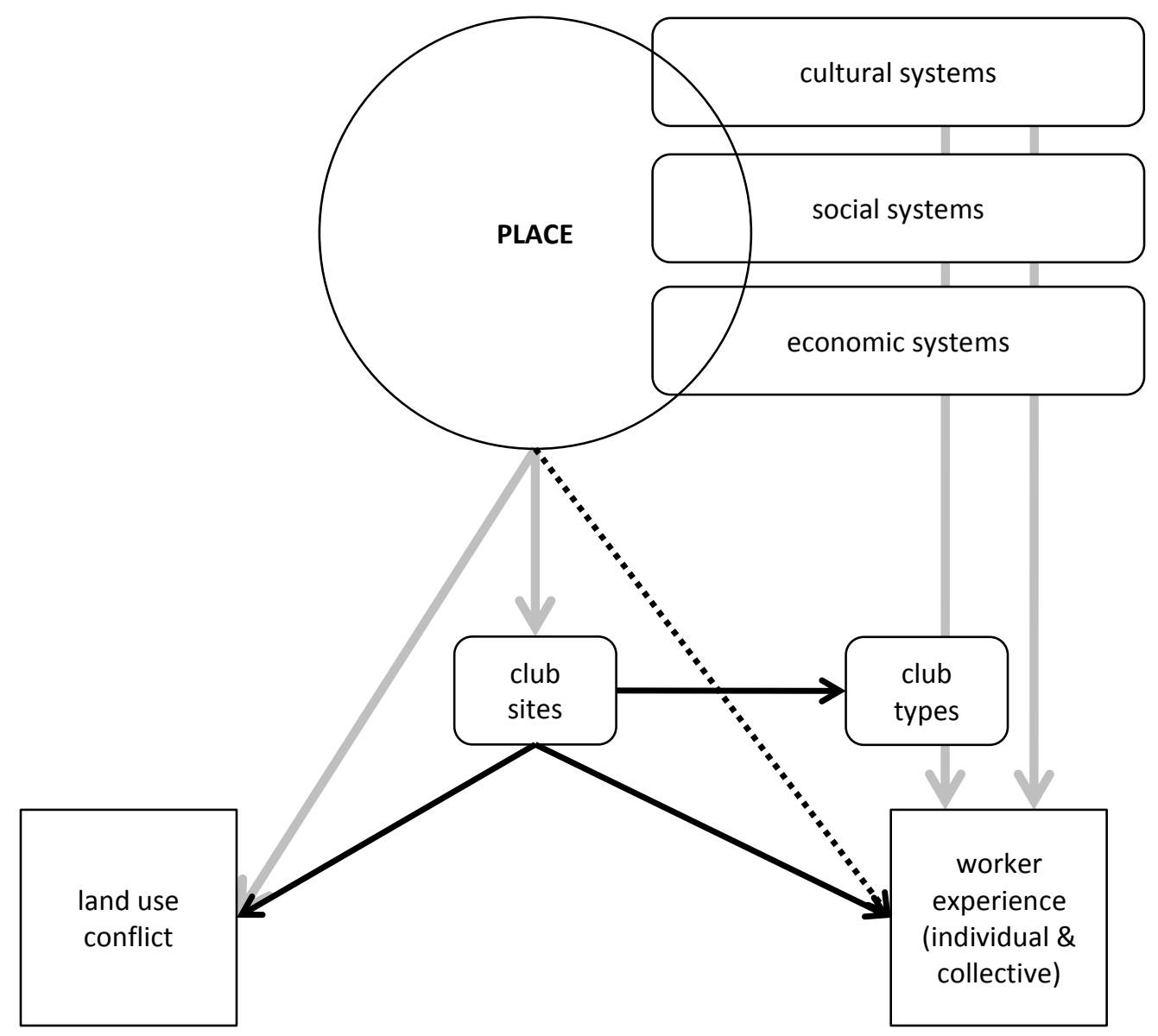

Figure 7. Schematic of findings. 
Further discussion of how I saw these relationships operating in relation to each of my research questions is presented below.

\section{Location Processes}

In response to my question about where strip clubs locate in the absence of zoning controls, I found processes operating at multiple spatial scales (discussed in greater detail below). I also found that actors in the situation maintained a strong association between city life and sexuality, despite an evolving body of scholarship that questions this assumed connection. Similarly, there was a strong connection between the family - tacitly understood as a heterosexual couple and their offspring—and less urban built environments. Opportunities for interaction between sexual commerce and this idealized family unit, through occurrences such as a strip club opening near a school, were thus seen as an interruption of a sociospatial order and resulted in perceived or real conflict. Ultimately, however, there was little political will to change the spatial arrangement of strip clubs, not only because of constitutional challenges but also because resistance to regulating strip clubs is at the nexus of liberal ideas about protecting individuality, expression, and public debate and libertarian ideas about living free of intrusive regulation. Both of these ideologies are very powerful in Portland's civic culture.

Looking across the scales in the situation, I found a range of formal and informal influences operating at each level. At the state level, the Oregon Constitution and liquor control statutes preempted restrictions on strip clubs that entities at other scales wanted to enact. At the neighborhood scale, official 
neighborhood boundaries defined by the city determined what resources would be available to resolve problems (in the form of city staff). Other scales were less clearly delimited, functioning as social rather than administrative worlds. For example, though my study parameters defined Portland using its city limits, discussion of the city's image in the public imagination does not necessarily hew to the boundaries of the incorporated territory. For example, as people talked to me about "what Portland is like," they sometimes considered "Portland" to encompass the entire metropolitan area whereas other times their description drew on a much smaller geographic area, as was the case with interviewees who told me "how Portland is" based on a life where the person had only experienced one small part of the city. Likewise, two neighbors' conceptions of "the neighborhood" could be very different based upon who they socialize with and which institutions they visit, despite the fact that the City of Portland has established very concrete neighborhood boundaries.

Though these scales are nested (i.e., neighborhoods are subdivisions of the city and each strip club lies definitively within one neighborhood), their relevance to strip clubs is not necessarily hierarchical. For example, while the Oregon Constitution establishes the legal conditions that have enabled the locational diversity of strip clubs, a neighbor who is troubled by a club next door may be more concerned by the events at that specific site than the statewide legal context. However, such a resident may become more interested in city or state policy if they are unable to resolve a conflict at the specific club site; this was the case for study participant India, who sought to organize people who lived near clubs in other 
neighborhoods to pressure city staff to address unresolved concerns about the club near her house. Conflicts that have drawn citywide attention may also result in new opposition at sites with no site-specific trigger to the conflict. These situations provide examples of the way that scale interacts with other axes of organization, such as networks, mobility, place, and positionality (Leitner, Sheppard, \& Sziarto, 2008). The notion of scale is controversial in geography, with some scholars arguing that imposing ideas of scale on social systems is inherently hierarchical, reifying social structures and impairing our ability to discern processes (Marston, Jones, \& Woodward, 2005). Others acknowledge these dangers but contend that when applied carefully, scale is still a useful organizing principle for understanding social arenas (Jonas, 2006). Using scale in this study as a heuristic device to discern processes helped me better identify the elements of the situation and proved especially valuable when reflecting on implications for practice, which are discussed later in this chapter.

One scale at which my findings do not integrate well with the literature is the global, or the discussion of globalization and the reconfiguration of the sex industry. The emergence and spatial configuration of Portland's sex industry do not seem to follow either of the two trajectories suggested by this literature: that a city may attain or retain world city statuseither through developing a sex industry that facilitates contact between members of the business elite (Hubbard, 2011a; Maginn \& Steinmetz, 2012) or by removing sexual commerce from high value spaces in the city (Johnston \& Longhurst, 2010; Papayanis, 2000). 
Portland has a large sex industry, but it is not a global city. While some dancers who have worked in Downtown Portland listed businesspeople as their clients, most of Portland's clubs are outside of the Central Business District and convention center area. Portland's neighborhood strip clubs draw neighbors, as opposed to people doing business together. Business activities may be more common at the larger, more expensive "gentlemen's clubs" in the suburbs, but evidence of this did not arise in my study. Hubbard (2011a) contends that "there are many cities whose importance as centres of sexual commerce is disproportionate to their significance as centres of finance" (para. 9), such as Atlanta and Las Vegas, where robust tourism and convention industries provide a steady flow of male customers for the sex industry but finance is relatively unimportant to the local economy. Sexual commerce thrives in areas where men are separated from their regular partners, such as these locations of business travel, or in areas of seasonal work or military conflict. While Portland is a city where the sex industry is more visible than the financial services industry, I found no evidence that this situation was fueled by any other part of the local economy that increased the presence of unpartnered men.

A powerful narrative in my findings was the association of strip clubs, and sexual expression in general, with urbanicity. Portland's strip clubs function as an integral part of city life-they were described not only as inevitable, but also as a key point of distinction between city and hinterland. Cities have long been understood as venues for women's liberation (Johnston \& Longhurst, 2010) and for 
sexual expression for people of all genders and proclivities. Explains Hubbard (2012):

Put simply, cities have long been recognized as spaces of sexual encounter, as sites where bodies come together, mix and mingle. They are known as sites of sexual experimentation, radicalism, and freedom, as spaces where individuals can pursue or purchase a rich diversity of sexual pleasures (p. xiii).

Scholars generally attributed this to the perceived anonymity of urban life and loosening of rigid rural kinship structures. The data I collected were highly resonant with this conception.

However, my findings about the myriad influences on club location, neighborhood conflict, and dancer experience also suggest that cities are not a freefor-all but rather an intricate system that teeters and lurches toward an equilibrium that balances the imperatives of the actors and actants in the situation. Not only does sexuality blossom in the city but also it is quashed, through processes of stigmatization or exploitation of sex workers and other sexual dissidents.

Theorists have criticized "metronormative" conceptions of sexuality for erasing the reality of queer lives in the hinterland (Halberstam, 2005), and it is essential to acknowledge in my discussion that scholarly research and the lives of many Americans testify to the fact that sexual expression and sexual commerce take place in all manner of communities. However, the discourses employed by my study's participants very clearly reinforced the idea that (overt) sexuality is an urban phenomenon. In most cases, this was closely connected to ideas about spaces 
for families. Family was generally understood to mean married heterosexual couples living with children in single-family homes, a household type associated with the suburban landscape. Strip clubs were viewed as out of place in less urban settings because these spaces were designated for families, whereas increased urbanicity suggested the presence of more diversity of all types. Urban areas supported expressions of sexuality that had the potential to threaten the sanctity of the suburban family lifestyle.

Though the bulk of strip club performances center around heterosexual imagery (at least on the surface), my findings of people's discomfort and displeasure with strip clubs are an example of how “some heterosexualities are 'queerer' or more dissident than others and can themselves pose a challenge to established heteronormative power relations" (Browne et al., 2007, p. 10). The discomfort or anger that some study participants expressed with seeing women who worked in strip clubs affirms the idea that the presence of women's sexuality in the public realm can be seen as a threat to the social order. Hubbard (2012) offers an illustration of these dynamics in his description of Victorian-era depiction of sex workers:

[B]y sexualizing and feminizing the public realm, the prostitute was an "inconvenient figure" who demonstrated to male authority that its control of the city was not as complete as it would have liked others to have believed; cut loose from the bounds of monogamy, productive labor and religious asceticism, she escaped from the bounds of moralized space (p. 41). 
Applying this analysis to contemporary strip club performances suggests that while strip clubs traffic in images of heterosexual desire, they also threaten heterosexuality because the sexual expression is removed from the controlled environment of the heterosexual family unit. The powerful trope of the heterosexual family unit undergirded many of my conversations with study participants and was especially salient in editorial pages and ballot measure pro and con statements. Notably, participants who worked in strip clubs also drew on the image of the family to justify their work or critique people who opposed strip clubs. Examples include Xena's description of the potential for neighborhood strip clubs to support healthy marriages and Whitney and Darren's comments about redirecting attention to institutions where children are actually harmed.

The heterosexual dynamics that are the fodder for the sexual fantasy sold at strip clubs are mainstream and socially acceptable; however, capitalizing on this interaction for profit is often seen as deviant. A given image of human bodies can be perceived as moral or deviant based on the context in which it is displayed; in describing this phenomenon, Johnston and Longhurst (2010) cite the example of a woman in New Zealand who was filmed delivering a child with the footage intended for use in pornographic film. While the footage documented an essential moment of heterosexual reproduction, it provoked outrage because of the suggestion that it would be used for purposes of profit and sexual gratification outside of the heterosexual family unit. These processes of labeling bodies require scrutiny because "the construction of heterosexuality is central to the construction of all 
forms of alterity and difference" (Browne et al., 2007, p. 11), given the primacy of the heterosexual family unit.

I consider the heterosexual family unit to be what Hanna (2013) terms an "imaginary spectator": a "fantastical audience" that does not go to strip clubs and does not know what happens inside strip clubs, yet on whose behalf clubs are regulated. These imaginary spectators fear that strip clubs threaten the sanctity of the heterosexual family unit (Hanna, 2013) by destabilizing gender and economic norms. Examples of this destabilization include that dancers' attentions could threaten married men's attachment to their wives or their financial independence could threatens men's sense of superiority (Hanna, 2013). In an in-depth case study of opposition to street sex work, Hubbard (1998a) identified a related discourse, that conspicuous female sexuality was a form of moral pollution from which women and children must be protected.

While public policy ostensibly operates in a manner that does not discriminate on the basis of household type, U.S. urban planning has a long history of endorsing or enforcing certain family types-often couching regulations in a purported health or safety rationale. As Forsyth (2011) explains,

In the US, zoning has a preoccupation with families-housing types that in other countries would have such labels as detached housing or apartments, are labeled single family and multi-family in the US with families defined within the local zoning codes. This shows a widespread cultural interest in the social character of the inhabitants rather than the physical character of the buildings (p. 38). 
However, these systems grow less and less tenable as American households diversify in their configurations. And in a post-Civil Rights Era society, citizen demands for regulation are less likely to be successful if they invoke moralistic discourses. Hence, the debate over whether and how sexually oriented businesses should be controlled revolves around the question of secondary effects-that is, ancillary crime or other harms attributable to strip clubs. Using crime and nuisance activities as a rationale for controlling sexually oriented businesses accords with the purported neutrality of the state action.

In my study, I found that in the dynamic real world setting of actual communities it is difficult to definitively conclude which problems are directly caused by a strip club. For example, if a strip club and a bar without performers are located next to each other and the area has high rates of auto theft, is it due to patrons of the strip club, or the other bar? My findings suggest that the crime and nuisance activities associated with strip clubs are connected to alcohol service rather than to sexual commerce per se: the most common complaints about strip clubs were about nuisance activities such noise and littering, which are typical issues for nightlife establishments. Further, neighbors' perceptions of disorder and crime were more important than the quantifiable occurrence of secondary effects, which accords with the dynamics observed in a study of the legal sex industry in Sydney, Australia (Prior, Boydell, \& Hubbard, 2012). Hence, the battle over secondary effects may be a proxy for debates that are truly about sexual expression, family structure, and urban space. Yet because the courts have established secondary effects as the prerogative for state regulation of sexually oriented 
businesses, municipalities that want to control these businesses have a vested interest in proving the existence of secondary effects. Secondary effects are assumed to exist (Tucker, 1997), yet some scholars contend that there is little empirical evidence of their existence (Hanna, 2003; Linz et al., 2004; Linz, Paul, \& Yao, 2006; Paul \& Linz, 2001) , though others have conducted studies and drawn the opposite conclusion (McCleary \& Weinstein, 2009). Debates over secondary effects are likely to continue, yet they often function as a smokescreen preventing fair and meaningful resolution of community concerns.

\section{Neighbor Response}

With regard to my second research question, I found that there is variation in neighbors' perceptions and responses to strip clubs, and that strip clubs are not categorically incompatible with either residential or commercial land uses. To my surprise, I also found ways in which locating strip clubs in primarily residential areas can decrease problems associated with clubs and speed the resolution of problems that do arise at club sites. These findings suggest that "sexually oriented business" is not a coherent land use classification and that community programs can help resolve conflicts over these land uses. To date, the understanding of how strip clubs affect neighborhoods, and vice versa, has been limited because the presence and/or location of these businesses is restricted in most U.S. cities. As a result, scholars and practitioners have presumed that sexually oriented businesses such as strip clubs will function as LULUs (Hubbard, Boydell, Crofts, Prior, \& Searle, 2013; Kelly \& Cooper, 2000; Owens, 1998). My research suggests a that there is greater 
complexity in the relationships between clubs and their surroundings, and that clubs may not always .

Though I did not find neighborhoods that sought the presence of a strip club, I did find that many strip clubs were tolerated by neighbors and some clubs that were even embraced gingerly. Portlanders are accustomed to encountering strip clubs in the cityscape and many are proud of living in an open-minded city that tolerates the sex industry among other activities frowned upon in other places (such as wearing jeans and a polar fleece pullover to a fine dining establishment).

Furthermore, I found that both club management and neighborhood residents can take action to heighten or quell conflict, and that there are non-human factorssuch as the physical proximity of the club to highly symbolic land uses and the design of the club property - that influence the extent of the conflict. Additionally, conflict can change over time. This contrasts with the literature, which suggests that the social characteristics of the surrounding neighborhood are the most important influence: that socially powerful neighborhoods (those with high property values, predominantly White residents, and/or a high proportion of owner/occupied properties) will resist most strongly.

While the purported "classiness" of a sexually oriented business (Hubbard et al., 2009) has been described as an important influence, my research also found other site-specific processes that had effects distinct from the club's (perceived) clientele and price point. For example, concern flared when clubs were located near schools or other child-oriented facilities, when residents felt a sense of saturation due to a perceived concentration of sexually oriented businesses in their area, or 
when club design or signage revealed what was going on inside (or, more likely, provoked people's imagination of what was going on inside). I take from this that SES is an enduring aspect of community life that influences community response but is not its sole determining factor. SES seems to influence how a community responds rather than whether it responds. For example, the high-SES neighborhood near Glitter sought media attention and pursued legal action, while the lower-SES area near Queeny's worked with city staff to negotiate with the business owners. While higher-SES areas may have more resources to enable a response, lower-SES areas may have strong responses and deep grass roots because a strip club may be "the last straw" for a neighborhood that feels under siege, or the community fears that problems associated with the strip club will threaten hard-won community development successes. Thus, the relative importance of SES to a given response is likely influenced by many other factors, such as community cohesion, residential stability, and age distribution within the neighborhood's population.

My findings also suggest that the influence of SES on neighbor response may be less prominent in Portland because neighborhood mobilization is facilitated by the city's crime prevention program. Though socioeconomic differences between neighborhoods were often referenced in my discussions with participants about where strip clubs were most controversial, these same interviews also suggested that the Office of Neighborhood Involvement created a more level playing field among neighborhoods by providing a comparable level of assistance in navigating the regulatory landscape to residents of all parts of the city. This indicates that 
trends identified in a study of neighborhood association activities in the late 1980s (Adler \& Blake, 1990) hold true today.

My findings about the potential of neighborhood associations and responsive and proactive club owners comport well with O'Neill et al.'s (2008) study of English neighborhoods where street sex work took place. Although O'Neill et al. studied a type of sex work that occurred in more public spaces than exotic dance does, they found that there was less conflict over sex work in the neighborhood when sex workers and their customers were known and when sex workers and neighbors communicated. The study also found that these communications were particularly effective when staff members of support agencies played mediator and advocate roles.

Indeed, strip clubs may actually make positive contributions to the neighborhoods in which they locate. My participants described the important role of clubs in regular customers' lives and how strip clubs contributed to the larger community through charity efforts. The assertion made by some of my participants that strip club management could quell crime in their vicinity accords with Edwards' (2010) research comparing of different types of sexually oriented businesses, which discusses the fact that sexually oriented businesses may not directly cause social disorganization and that crime in their vicinity might actually be lower than at other sites due to increased scrutiny by law enforcement. Overall, my study of strip clubs in Portland suggests that the quantity of strip clubs, their diffusion throughout the city, and their integration into neighborhood commercial districts has resulted in a normalization of strip clubs, which is likely further 
enabled by broader national and global trends normalizing sexually explicit materials and sexual commerce (Bernstein, 2007; Padilla, Hirsch, Muñoz-Laboy, Sember, \& Parker, 2007; Weitzer, 2000b). When residents regularly see or pass by clubs, the sites become normalized, even if they are disliked. The ability of strip clubs to exist without conflict establishes the status of the club on par with other nightlife establishments or performance venues. I discuss this eroding spatial stigma further in the following section, where I also address the implications for stigma related to performing at a sexually oriented business.

\section{Dancer Experience}

The majority of research on strip clubs has focused on the individual experience and on the power relationships between dancers and customers (Wahab et al., 2011), whereas mine looks at the power of place: how the organization of work within the city, neighborhood, and club affects exotic dancers' work experience. The unique spatial configuration in Portland allowed me to see how both metropolitan- and club-level conditions affect dancers' experiences in the workplace. Though place was not in the foreground of how dancers described their work to me, I saw several ways in which place affected their work experience. Perhaps most notably, I found that strip clubs located in residential areas may have better working conditions, in part due to the physical constraints of lots and buildings in this setting but also due to dancers' journey to and from work. However, I also found that larger structures of gender systems and labor markets 
create hazardous workplace conditions even though many dancers reported being happy with their jobs.

Though much of the literature on exotic dancers has suggested that separating work and personal life is an important coping mechanism (Barton, 2006; Maticka-Tyndale et al., 2000; Sanders, 2005), my study revealed that when exotic dancers have the opportunity to work in a neighborhood that includes residences and other types of businesses, they can develop a strong sense of place attachment. Dancers described both benefiting from interactions in the neighborhood and making a contribution to the neighborhood. The sense of belonging and reciprocity helped dancers feel grounded and respected. These attachments were especially strong for dancers at smaller neighborhood strip clubs.

Place was not identified as a major influence by dancers, probably because their work experience is dominated by interpersonal interactions in the workplace. However, these interpersonal interactions are structured by the larger social context of their work, and place is a part of this context. These place processes affect the worker in two ways. First, when clubs are located in mainstream business districts, it reduces the stigma associated with the place. Because this place stigma contributes to the person stigma associated with dancers, normalizing strip club locations makes dancers' work more socially acceptable, thereby mitigating some of their vulnerability to exploitation or discrimination. The physical site of the club also creates design constraints, which in turn affect workers' experience. In well established, densely developed areas, the built environment is characterized by small parcels of developed and developable land, meaning that strip clubs may be as 
small as several hundred square feet. The exigencies of a compact physical plant create a safer work environment, as discussed in the Findings chapter.

To an extent, the geography of Portland's strip clubs disrupts the process of spatial marginalization whereby governments and informal social processes relegate sex work to "circumscribed areas of the city, and then 'see' those areas through stereotypical images of red-light districts as dangerous and tantalizing places" (Domosh, 1999, p. 431). Most scholarly discussion of this phenomenon focuses on negative identities (Hubbard, 1998a, 1998b), but Portland suggests that these processes can also foster positive meanings for sex workers and spaces of sexual commerce. Being located in "respectable" neighborhoods confers a level of legitimacy to Portland strip clubs and, consequently, the people who work in them.

However, stories of dancers' satisfaction and neighbors' acceptance of strip clubs mask structural barriers to economic empowerment and artistic expression for Portland's exotic dancers. Even at the "best" of Portland clubs-where neighbors support the club and at which dancers enjoy working-exotic dancing is part of a system of constrained labor opportunities for women. This environment of constraint leads them to choose informal workplaces that lack both occupational health oversight and a career ladder.

Women in the sex industry continue to expose themselves to great risk because "the sexist and classist structure of non-sex industry jobs makes it difficult for women-particularly less educated and skilled women—to leave the industry" (Kay, 2000, p. 49). These marginalized population of workers will continue to be concentrated in urban areas because the frisson of sexual commerce is valuable to 
the convention and tourism sector and is poorly tolerated in suburban areas (Sharp, 2004). Cities present the opportunity to connect exotic dancers' talents and expressive impulses to larger arts communities, but this potential is preempted by labor practices that delegitimate their work. Xena clamors for this sort of opportunity, explaining, "The naked human body is a beautiful thing; it should be exalted and respected. There should be more burlesque and more real performances." However, even at Portland's most innovative strip clubs, the "realness" of performance is compromised by the threats to performer well-being, which include economic and interpersonal volatility as well as political invisibility. The pragmatics of exotic dance-e.g., the fact that it occurs in bars and requires personal interaction with the spectator-prevent it from developing the same training system and elite organization that occurs with ballet and other types of dance (Hanna, 1998). Thus, while the exotic dance is increasingly mainstream, it is not taken seriously as an art form because of the venue in which it occurs and where those venues are located. Hubbard (2011b) further argues that the current regulatory regime exacerbate this problem because it by effectively criminalizing many forms of sex work, fails to acknowledge the fundamental right of adults to buy and sell sex, and hence forecloses opportunities for sex workers, business owners and advocates to make effective claims to space .... privileg[ing] the rights of residential property owners over the rights of sex workers, placing commercial sex in areas where it is neither safe nor profitable (Hubbard, 2011b, p. 83). 
This contributes to dancers being treated as unskilled workers, easily fired and instantly replaced, despite the fact their work employs a distinct repertoire of skills that develop over time through practice and experience in the workplace.

Many of the dancers I interviewed bristled at the idea that their occupation was the product of an exploitative gender system, emphasizing instead the personal choice they exercised and the flexibility afforded by their work arrangement. I struggled to reconcile my belief that these dancers are the experts on their own lives and the strong evidence for the "performative power of sexualized labor" (Hubbard, 2012, p. 37) with my nagging suspicion that if there were more choices available many dancers might choose different work that provides a steadier income stream, more stable work environment, and fringe benefits.

I found perspective on this notion of flexibility in Halberstam's (2005) work. She contends that flexibility in gender, body, and identity are portrayed as empowering aspects of contemporary life, but that this flexibility serves to bolster the normative order (she focuses especially on heteronormativity) as people embrace individualism instead of resistance. She cites Duggan's (2003) description of "a new neoliberal sexual politics" and reminds the reader that,

Increased flexibility, as we now know, leads to increased opportunities for the exploitation by transnational corporations of cheap labor markets in Third World nations and in immigrant communities in the First World. The local and intersubjective forms of flexibility may be said to contribute to what Anna Tsing calls the 'charisma of globalization' by incorporating a 
seemingly radical ethic of flexibility into understandings of selfhood (Halberstam, 2005, p. 19).

This analysis helped me understand why dancers I spoke with shrugged off incidents of what sounded to me like harassment by coworkers and employers, proposing that they were untroubled by the event because they simply switched workplaces. These kinds of events were generally described amorphously as "drama" and attributed to the age, gender, and personalities of dancers rather than any aspect of the industry or workplace.

Colosi's $(2010,2011)$ work on exotic dance highlights how the occupational culture of strip clubs includes many practices and symbols-for example, substance use and loud music-generally associated with leisure time, enabling the fiction that stripping is not "real work." She contends that dancers use fun as a form of resistance in the workplace, but also as way to regulate conduct and establish a pecking order, enforcing a workplace discourse that stripping is "anti-work" (Colosi, 2011) rather than a serious job. While there is a value to the companionship and collective resistance that Colosi describes in her conception of anti-work, I believe that the anti-work paradigm also facilitates the economic exploitation of strippers. In analyses of labor issues in the sex industry, Gall $(2007,2010)$ found that a major barrier to collective organizing was the failure to adopt the "sex work discourse"that is, the idea that sex work is work and that workers who engage in it have shared interests. Thus, the anti-work discourse decreases the likelihood that dancers will advocate for improved conditions in the workplace. 
While the flexibility of the job does indeed serve dancers, it even better serves club owners and investors who as a result have extremely low staff costs, since dancers are not paid and managers are unencumbered by most of the employee management tasks conducted in most workplaces. This dynamic can be understood through the "technologies of sexiness" frame proposed by Evans, Riley, and Shankar (2010b), who contend that actions construed as empowering individual choices—such as Brazilian bikini waxes—-must be understood as choices structured by larger social structures that dictate normative expressions of gender and sexuality. Strip clubs' capitalize on dancers' adoption of technologies of sexiness, making money off dancers' "choices" to increase club earnings through body modifications and displays of their sexuality. Since the 2008 economic crash in particular, the proliferation of strip clubs has relied on a "devaluing" and "deskilling" of the labor force (Sanders \& Hardy, 2012) rather than increased consumer demand. The shift from stage performances to lap dances or "hustling" is seen as the key example of deskilling in the strip club workforce. This shifts the costs of "producing" sexual services to performers while keeping profits in owners' hands. Changing mores and a softening labor market have led to significantly lowered earnings due to an influx of underemployed women and eroded social barriers to nude dancing (Kay, 2000). These changes bring adverse consequences for dancers' well-being, especially for those dancers who are poor and/or women of color (Bradley, 2008; Brents \& Hausbeck, 2010; S. Brooks, 2010a; Sanchez, 1997). This increased vulnerability of performers simultaneous to the increasing appeal and palatability of the sex industry to the middle class (Coulmont \& Hubbard, 2010) 
suggests that occupational health issues will be both more severe and more widespread. This worker vulnerability combined with the increased community conflict that is likely as the new clubs open demonstrates a need for both additional research and policy action.

\section{Implications for Practice}

The results of this study suggest that locations and perceptions of, and working conditions within, strip clubs are dynamic processes subject to the influence of a wide variety of factors. While many of the factors I identified are intertwined in complex social and cultural systems, several are also subject to the influence of professional and citizen actions. My findings indicate that land use mix, conflict resolution programs, and normalization of strip clubs can reduce anxiety and conflict related to clubs (and likely other types of sexually oriented businesses). Addressing the other key problem discussed in this dissertation-poor working conditions in strip clubs—seems a more complex proposition. Reducing conflicts between clubs and neighbors may indirectly benefit exotic dancers by reducing the place stigma of strip clubs and, by association, some of the person stigma experienced by dancers. Shifting the public's understanding of exotic dancers' work and forging some untraditional alliances may be able to make some additional impact. However, the enduring political economy of gender remains an overarching structure for the workplace experience. This section of the dissertation discusses the potential for making changes within the domains of urban planning and public health practice. 


\section{Urban planning practice.}

As a profession, urban planning needs to develop a more sophisticated understanding of spaces of sexuality in the city. While planning has presumed that sexually oriented businesses are unwanted and noxious and thus relegated them to the margins, strip clubs and other sexually oriented businesses clearly have staying power. Planning for sexually oriented businesses is more than a chore for planners, it is also an important part of respecting civil rights and assuring cultural diversity.

The first step of planning for sexually oriented businesses is not to plan for businesses based on the substance of their transactions. Despite recognition of sex work as a formal land use, planning and licensing processes rarely regard sexually oriented businesses as equivalent to other commercial or retail businesses, and often treat these as noxious or undesirable land uses (Hubbard, 2012, p. 56). A guidance document produced by the American Planning Association (Kelly \& Cooper, 2000) directs planners that "regulations should focus on the land use activities and impacts of sex businesses, not the content," yet this proposition seems motivated by a desire to avoid litigation rather than out of acceptance of the role of sexually oriented businesses in communities. I would restate Kelly and Cooper's sentence with the word "sex" removed. Because there is so much diversity in the sex industry, and because the effects on neighbors vary more based on characteristics of the individual business rather than the type of business it is, crafting regulations specific to sexually oriented businesses (if such regulations are locally permissible) seems unlikely to achieve planning goals. Since sexually oriented businesses present many of the same problems and opportunities as other 
businesses, they should not be designated as a specific land use classification. If, in the process of being built or doing their business, sexually oriented businesses have negative effects on their neighbors, the problems should be addressed immediately, under the same statutes used to deal with noisy bars, abandoned houses, and violations of the building code. Doing otherwise heightens the fear and stigma associated with sexually oriented businesses (Crofts, 2007).

Furthermore, while most of the planning debate surrounds where strip clubs are allowed to open, this overlooks what happens after they do open. My research found that relationships between clubs and neighbors change over time, based on the conduct of both club management and neighbors. From a planning perspective, what happens after a club opens may be far more important than stopping the club from opening. Because nuisances may not rise to the level of illegality and because nuisance proceedings may be expensive and time-consuming, communities benefit from structured but non-statutory ways to resolve conflicts. While relying too heavily on neighborhood associations to do this work can result in configurations of citizenship and public space that trample civil rights (England, 2008), conflict resolution programs like Portland's Neighborhood Involvement program help stakeholders with different levels of power have more successful negotiations. Mediation and leveling the playing field are especially useful for businesses like strip clubs, which may be excluded from informal governance processes. Because residents may have limited experience with these businesses or may be uncomfortable approaching the business, the professional intermediary is an especially valuable resource. These mediators set the stage for more successful 
negotiation because they steer neighbors to use techniques that are appropriate to managing the businesses' impacts and at the same time assert the businesses' right to exist. Ultimately, I am proposing that planners plan to foster communication rather than to control sexuality.

Trying to restrict sexually oriented businesses is on increasingly tenuous legal and moral ground, as changing mores allow for a much broader acceptance of sexual diversity, including sexual commerce. Furthermore, a historical perspective on spatial controls of sexuality reveals that they have generally resulted in oppression rather than improved public safety (2010). This oppression has high costs, in the form of quashing meaningful forms of community. Halberstam (2005) speaks eloquently to the need to nurture and preserve these counterpublicsspaces that operate in contravention of social norms. Conventional planning practice can run roughshod over these systems, such as those described in Delany's (1999) study of the vibrant sexual cultures of Times Square in New York. As Halberstam (2005) puts it, "The unimaginably precious meaning of these systems are of no consequence to the city planner who sees only ugliness and filth where Delany sees a distillation of the promise of radical democracy" (p. 186). She makes a poignant case of the importance of preserving counterpublics for minority groups, particularly lesbian and other female sexual subcultures. Berlant and Warner (1998) expand on the implications for queer citizens of controls on spaces of sexuality:

Because the heteronormative culture of intimacy leaves queer culture especially dependent on ephemeral elaborations in urban space and print 
culture, queer publics are also peculiarly vulnerable to initiatives such as Mayor Rudolph Giuliani's new zoning law (p. 556).

Thus, spatial controls on sexual commerce have the potential to harm communities as much they may help to address other concerns. Planning for a pluralistic society requires understanding the diverse expressions of sexual citizenship, even if the politics of planning ultimately result in the privileging of certain expressions over others (Doan, 2011).

\section{Public health practice.}

While planners can play a role in elevating the status and regularity of strip clubs, the public health profession has a special responsibility to address strip clubs as work environments, given the field's mandate to prevent disease and injury, promote healthy behavior, and protect people from hazards (National Association of County \& City Health Officials, 2011). Like any job, being an exotic dancer entails health hazards. However, the political economy of the sex industry and the larger service sector makes it very difficult to suggest ways to effectively address these health hazards because the legal and social position of the exotic dancers keep them out of the purview of the systems used to assure safety in most workplaces. Based on the findings of this study, however, I believe that the dancer experience could be improved in three key ways: adoption of the sex work discourse by people outside the industry, building solidarity within the industry, and altering the risk environment for dancers through enforcement and policymaking that are sensitive to dancers' needs. Though these strategies are interrelated, each focuses on a different domain of action: social change outside the industry, change of 
professional culture within the industry, and action in the policymaking sphere. Sherman, Lilleston, and Reuben's (2011) work on Baltimore strip clubs offers a helpful way of thinking about the challenges faced by exotic dancers through using a framework (Rhodes, Singer, Bourgois, Friedman, \& Strathdee, 2005) proposing that risk is produced in four types of environments - physical, economic, social, and policy-each of which operate on micro, meso, and macro levels. These levels align with the scales discussed throughout the study: individual dancers and clubs, neighborhoods and cities, and states and countries, respectively.

First, exotic dancing must be taken seriously and treated as the work that it is. Though the barriers to entry to the occupational milieu are low, succeeding as an exotic dancer requires skills that are developed through practicing and building relationships. Calling exotic dance unskilled work is a mischaracterization. Furthermore, while many exotic dance performances rely on well-worn clichés, creative artistry is a hallmark of both successful and happy dancers. Affording professional status to dancers would it harder dismiss their problems as the inevitable result of working in a marginal job or location or to blame the situation on "psychosocial factors"-i.e., the dancer's personality or life experience. While the sex wars debate suggests that activities like exotic dancing must be either empowerment or exploitation, postmodernist feminism allows for a more complex understanding that a given act may be both empowering and exploitative at the same time. This is a gift to those, like me, who struggle to reconcile dancers' satisfaction with the clearly patriarchal and disempowering strip club milieu. Accepting that stripping is a job does not mean ignoring critical analyses of the work 
environment. But suggesting that exotic dancers who like their work are brainwashed or have a false consciousness only serves to minimize the agency that dancers do have. Dancers' work is described as antisocial (Scoular, Pitcher, Campbell, Hubbard, \& O'Brien, 2007), which allows for their exclusion from community life, and public disavowal of responsibility for dancers' welfare.

Public agencies that are responsible for protecting public safety, health, and welfare must employ high levels of scrutiny when working on issues related to exotic dancers. Because of their status as informal workers, dancers may encounter police bureaus, the Bureau of Labor and Industry, and the state Occupational Safety and Health Administration in some of the many of the gray areas where jurisdiction to address a problem is unclear. My interviews suggest that that these agencies, and criminal justice entities in particular, generally err on the side of not intervening unless there is a complaint filed with a definitive body of evidence. Though it may seem like an efficient use of public resources to pursue only the most egregious cases, this is not socially just stewardship of these resources because informal workers by definition will have less documentation and higher vulnerability to violations of their rights. Dancers clearly experience crime, labor violations, and health hazards in the workplace; leaders and frontline staff of public agencies must exercise leadership to creatively address these problems even if they do not fit easily with their programs' traditional activities.

Dancers are vulnerable as a result of their working conditions, but many of these vulnerabilities are also present in other occupational contexts they would be in. As these vulnerabilities are interwoven to almost every aspect of society, 
recommending to change them is a rather quixotic suggestion. Thus, my recommendation is best understood as a suggestion to change vulnerabilities rather than to fixate on those who are vulnerable. That is, don't try to change or "rescue" dancers, because they are for the most part making decisions that are sensible under the conditions they're in. As Brooks (2010a) puts it, "Working in the exotic dance industry is in and of itself not a problem, contrary to the position of antiporn feminists, but rather lack of decent wages, customer harassment, and overall safety are the issues most important to exotic dancers of color" (p. 79). These same issues are prevalent in the service sector in general and for contingent or informal workers in particular. Though there are shortcomings in the data on this labor force, it is estimated that about a third of the American workforce works in a nontraditional structure, whether on contact or as a freelancer or independent contractor (Horowitz, Calhoun, Erickson, \& Wuolo, 2011). A survey by the advocacy organization Freelancers Union found that this group of workers has fared very poorly during the recent recession, with $81 \%$ facing underemployment or joblessness without access to unemployment insurance, 39\% cutting back or eliminating health coverage because of high costs, $37 \%$ relying on credit cards to cover basic expenses, and $12 \%$ relying on government assistance to make ends meet (Horowitz, Erickson, \& Wuolo, 2011). The economic forces behind this recession are bringing even more people into the informal sector, including to the increasingly visible sex work sector (Kingston \& Sanders, 2011). Efforts to address the needs of this workforce, through policy change and though programming of nonprofit organizations like Freelancers Union, should include outreach to exotic dancers. 
Not only would policy change itself provide better opportunities for dancers, but being aligned with higher-prestige independent workers like graphic designers and lawyers could help decrease the stigma associated with working as an exotic dancers.

Improving working conditions within strip clubs is not an easy proposition. The recent history of sex worker activism in the U.S. reveals many pyrrhic victories. For example, after strip club workers in San Francisco successfully sued to be paid wages, the plaintiffs filed for bankruptcy to avoid having to pay the judgment (S. Brooks, 2001). As a response to the judgment, other clubs dramatically increased the stage fees dancer paid to work, making some dancers feel that they had to resort to prostitution to break even (Romney, 2004). After a later suit barred clubs from taking a cut of dancers' tips, clubs instituted new procedures where tips were collected differently and clubs kept even larger percentage of them (Romney, 2004) or a "piece-rate" system that set a quota of dances to be performed in a shift (Aimee, 2012b). In many cases, dancers are opposed to unionization because the core principles of collective bargaining—equality among workers and standard procedures for how work is conducted-run counter to the imperative that dancers have "to make as much money in as little time as possible" (Aimee, 2012a), which often entails competition with colleagues. Another area of debate has been private rooms, which many contend decrease dancers' safety because they are removed from scrutiny; eliminating them could make dancers safer, but would also eliminate the opportunity for high earnings that come from performing private shows (Romney, 2004). 
Acknowledgment of stripping as work by people outside the field could play a part in building solidarity within the field. Given the fragility of the sex work discourse among dancers, individuals and organizations concerned with dancers' well-being should focus their resources on empowering dancers through dancer-led activities. This strategy is essential because many well-meaning policy change efforts propose divisive strategies-such as licensing programs-that provoke discord among this fragmented workforce rather than bringing workers together. Examples of such dancer-led activities include Portland's Sex Worker Outreach Coalition, New York's We Are Dancers project, San Francisco's Lusty Lady cooperatively-owned peepshow, the Tits and Sass weblog, and now-defunct projects like Portland's Danzine and New York's \$pread magazine. Outside organizations can support these efforts with fuding technical assistance, logistical and administrative support-as Multnomah County's needle exchange program did with Danzine's health outreach program. Club owners who support solidarity among dancers through their management practices should also be acknowledged as positive influences on dancers. Dancers' sense of empowerment and investment could be improved if they were included in conversations with neighbors, such as the negotiation of good neighbor agreements.

Changes to the social perception of exotic dancers may be the most important way to improve dancers' experience, since so much of the risk they face is produced by social conditions. However, the physical, economic, and policy aspects of the risk environment can also be changed. Some of these changes can be made at the individual level, such as an individual club owner providing a cleaner, better-lit 
stage. But others may be policy strategies that affect a wide variety of workers, such as changing federal or state policies to increase the benefits available to contingent workers. Notably, the bulk of these changes have little to do with sex work per se.

\section{Implications for Research}

While my study adds to knowledge about what goes on in strip clubs and how neighbors perceive them, it also generates several new questions about these topics. These questions fall into three rough categories: people, places, and time. Certain groups of people, or social worlds in the situational analysis terminology, are powerful influences strip club location and working conditions, yet little is known about their motivations, decisions, and experiences. With regard to place, the preliminary ideas generated by my dissertation could benefit from further exploration. Finally, I identified temporal effects on the situation that indicate future longitudinal research.

Of the social worlds involved in exotic dance, there is little literature about club owners and managers despite the fact that they are described by my participants as important influences on dancer experience and neighborhood relations. While the literature on dancers is voluminous and researchers have studied customers (Egan, 2005; Frank, 2005; Wosick-Correa \& Joseph, 2008), and even bouncers (DeMichele \& Tewksbury, 2004), club owners have not been studied as a group. Because owners and managers set the tone for what goes on in a club and because they have the power to address or aggravate neighbor concerns, learning more about their motivations, challenges, and values is important. This 
knowledge is especially important in the current historical moment when the sex industry is becoming increasingly corporatized (Brents \& Sanders, 2010; Hubbard et al., 2009), because understanding these influential actors may help predict how the current problems in the industry may shift or how owners can play a part in resolving these problems. Another emerging population that was only mentioned peripherally by my participants is the strip club booking agent. As a way to assure that dancers cannot be legally classified as employees (which would require clubs to pay a wage and follow labor laws), this third-party group has emerged as an intermediary between clubs as dancers. Like club owners, booking agents may be an important influence on the dancer experience because they serve as a dancer's entrée to the club, part of their socialization process to the industry, and an entity that controls or limits dancers' access to earnings or club owners' ability to have desirable dancers perform at their clubs.

My findings about the importance of place suggest further exploration of place processes and strip clubs. As one example, my findings that Portland seems to be atypical in the discussion of sexual cities and world cities suggests that these ideas need further development. This research trajectory might entail refining the typologies of sexual cities, perhaps along the lines of proposed by Maginn and Steinmetz (2012), and testing how it applies to specific cities. Further, my findings about place should also be validated through in-depth studies at specific sites, to assess how field observations accord with neighbors' and workers reports of incivilities and conflicts. Studies at suburban and rural sites seem particularly important, given the association of sexuality with the city and its metronormative 
function despite the fact that sexuality exists in every community and sex work is expanding to become a presence in a wider variety of communities. Because urbanicity is just one influence on conflict at strip club sites, studies in non-urban settings could provide more insight into how neighbor and owner actions/attitudes spur or resolve conflict. Comparative studies across places could also help elucidate how racial and class systems affect club location and dancer experience; despite their importance in the literature, these connections were difficult for me to tease out due to my study design and the limited racial diversity of Portland.

Like most things, strip clubs are changing over time-or, at least, everyone thinks they are. My findings showed that attitudes about strip clubs and relationships between clubs and neighbors have changed over time, and a voluminous literature references restructuring of the sex industry. Yet not only my study but also most of the literature looks at just a small slice of time; this indicates a need for empirical investigation of change over time. I finish this study wondering about how many aspects of the industry have changed: average earnings, average number of dancers per club, extent of sexual content in performances, degree of conflict at land use sites, age and race of the dancer population, and more. There is a clear need for historical and longitudinal research about strip clubs.

\section{Conclusion}

My study found that strip clubs have a lot in common with other businesses and that working as an exotic dancer is not unlike many other jobs done by young women-yet these people and businesses are treated very differently by neighbors, 
policymakers, and government agencies, among others. In states other than Oregon, they are also treated differently by land use regulations. The study also found many problems associated with strip clubs in Portland neighborhoods, such as noise, litter, neighbor discomfort, and poor working conditions. However, very few of these stem directly from the fact that sexual commerce is conducting in the club. In many cases strip clubs are a relatively benign presence in a neighborhood, and the problems that do crop up may be resolved through existing programs created to support community development. More enduring, however, are the challenges of working as an exotic dancer.

Social changes are lessening the stigma associated with being an exotic dancer, and the social and spatial aspects of Portland's industry make the stigma even less powerful locally. Yet, exotic dancers still endure poor working conditions and many of them face limited occupational opportunities. In this context, demands that strip clubs be spatially segregated in order to protect families seem disingenuous at best—especially given the fact that many women are drawn to exotic dancing out of a desire to support their families. While popular culture and some research on strip clubs has pathologized dancers (Wahab et al., 2011), I hope that my work will be understood as pathologizing the system under which they work. Exotic dancers are exploited, but not because they are selling sexual fantasy or sexual services, but rather because they are women and contract workers.

While land use regulations on strip clubs have been used to maintain social norms and preserve property values-under the rubric of protecting the public from the purported secondary effects of strip clubs-these tools could alternatively 
be used to make strip clubs safer for people who work in them. My findings in Portland suggest that zoning codes that treat sexually oriented businesses like "regular" businesses can result in clubs that are safer because they are integrated into neighborhoods and subject to the same types of informal surveillance as other businesses. The sense of being watched, being accountable to neighbors, and being in a "respectable" area can change how people feel about working at a strip club or living or working near the club.

However, these changes would have limited impact on the underlying political economy that shapes working conditions. As we discussed these challenges in our interview, business owner Thomas described these limitations:

If their business is located in a particular place is one thing, how they treat their employees is a separate issue. That is extremely important but it's not part of the location or neighborhood impact. A lot of businesses hire their employees as contractors and whether they should or not is controlled by BOLI. Then there's the next layer of whether the people are in a position where they have a choice. Work at $\$ 6$ an hour at McDonald's or $\$ 100$ a night doing this. What are their choices there? It's a huge issue but it's not something you can fix with the zoning code.

Ultimately, the location issue is likely easier to resolve than the working conditions issue, which requires reframing the moral questions surrounding strip clubs. As the sex industry expands and becomes entrenched mainstream, the assertion that sexual commerce is categorically immoral grows increasingly tenuous. However, another moral question grows more pressing: why is it acceptable to deny the 
members of this growing workforce of their civil rights? Depriving workers of their rights, even if they choose to work under such conditions, is especially concerning given the fact that the workers are disproportionately young and female and therefore at economic and political disadvantage.

Over ten years ago on an $\mathrm{ABC}$ newsmagazine program about the rapidly expanding sex industry, former Surgeon General C. Everett Koop expressed puzzlement about how sex workers are treated. He told the interviewer, "We have an industry that is making billions of dollars a year, is spreading to cable television and to the Internet, and yet their employees are considered to be throwaway people" (ABC News, 2003), expressing outrage that those profiting from the industry had little concern for the harms workers were experiencing. Koop's own deeply conservative beliefs likely put sex work in conflict with his personal values, yet as a public health professional he recognized the importance of addressing the occupational health problems and economic fairness issues. Public health professionals must take up this mantle, but it also incumbent on the patrons of the industry. As more and more Americans become consumers of sexual services, more of us must question the labor arrangements of the industry. The failure to do so is especially striking in Portland, where consumers pay a premium for artisan products and food items certified "fair trade" on the basis of working conditions halfway around the world. It is tempting to conclude that Portlanders are more concerned about the beans in their caffè lattes than about the well-being of their neighbors. A more generous interpretation would be that exotic dancers are just less visible to Portlanders. For example, local concerns about worker well-being 
and community health drove the City of Portland's recent adoption of an ordinance requiring that business provide paid sick leave for employees, making it the fifth U.S. jurisdiction to mandate this important worker benefit. Unfortunately, exotic dancers will not benefit from this law, since they are not considered employees. Strip City owes strippers better. 


\section{References}

ABC News (Writer). (2003). Young women, porn, and profits: Corporate America's secret affair [Television], Primetime. U.S.: American Broadcast Corportation.

Ackman, D. (2001). How big is porn? Forbes. http://www.forbes.com/2001/05/25/0524porn.html

ACLU of Oregon. (n.d.). City of Nyssa v. Dufloth, State v. Ciancanelli. Retrieved May 7, 2013, from http://www.aclu-or.org/content/city-nyssa-v-dufloth-state-vciancanelli

Adler, S., \& Blake, G. F. (1990). The effects of a formal citizen participation program on involvement in the planning process: A case study of Portland, Oregon. State \& Local Government Review, 22(1), 37-43. doi: 10.2307/4354975

Agustín, L. M. (2005). New research directions: The cultural study of commercial sex. Sexualities, 8(5), 618-631. doi: 10.1177/1363460705058400

Aimee, R. (2012a). In search of stripper solidarity. In These Times, (May 7). http://www.inthesetimes.com/article/13089/in search of stripper solidari ty/

Aimee, R. (2012b). License to pimp: A conversation with Hima B. Retrieved from http://titsandsass.com/license-to-pimp-a-conversation-with-filmmakerhima-b-draft/

Argyle, M. (1981). The experimental study of the basic features of the situation. In D. Magnusson (Ed.), Toward a psychology of situations: An interactional perspective. Hillsdale, NJ: Lawrence Erlbaum Associates. 
Associated Press. (2011, March 18). Strip clubs: Regulations vs. rights in Oregon. Retrieved June 26, 2011, from http://www.kpic.com/news/local/118249359.html

Austin, T. (2007). American eden. Travel + Leisure, 37(8), 204+. http://www.travelandleisure.com/articles/american-eden

Barker, R. G. (1968). Ecological psychology. Palo Alto: Stanford University Press.

Barton, B. (2002). Dancing on the Möbius strip: Challenging the sex war paradigm. Gender \& Society, 16(5), 585-602. doi: 10.1177/089124302236987

Barton, B. (2006). Stripped: Inside the lives of exotic dancers. New York: New York University Press.

Barton, B. (2007). Managing the toll of stripping: Boundary setting among exotic dancers. Journal of Contemporary Ethnography, 36(5), 571-596. doi: $10.1177 / 0891241607301971$

Barton, B., \& Hardesty, C. L. (2010). Spirituality and stripping: Exotic dancers narrate the body ekstasis. Symbolic Interaction, 33(2), 280-296. doi: $10.1525 /$ si.2010.33.2.280

Bates, T. (1995a, March 20). Bill aims to keep nudity to a bare minimum, Oregonian, p. B01.

Bates, T. (1995b, May 7). Nude dancing: For some it's a living, for others a 'living death', Oregonian, p. D04.

Bates, T. (1995c, May 7). Oregon XXX-rated, Oregonian, p. D01.

Bates, T. (1996, October 18). Adult businesses fight Measure 31, Oregonian, p. A23. 
Bell, H., Sloan, L., \& Strickling, C. (1998). Exploiter or exploited: Topless dancers reflect on their experiences. Affilia, 13(3), 352-368. doi:

$10.1177 / 088610999801300306$

Bella, R. (1989, January 9). Nude-dancing businesses proliferate in Portland area, Oregonian.

Berlant, L., \& Warner, M. (1998). Sex in public. Critical Inquiry, 24(2), 547-566. doi: $10.1086 / 448884$

Bernstein, E. (2007). Sex work for the middle classes. Sexualities, 10(4), 473-488. doi: $10.1177 / 1363460707080984$

Blumer, H. (1954). What is wrong with social theory? American Sociological Review, 19(1), 3-10. doi: $10.2307 / 2088165$

Boris, E., Gilmore, S., \& Parreñas, R. (2010). Sexual labors: Interdisciplinary perspectives toward sex as work. Sexualities, 13, 131-137.

Bott, E. (2006). Pole position: Migrant British women producing selves through lap dancing work. Feminist Review, 83(1), 23-41. doi: 10.1057/palgrave.fr.9400279

Bradley, M. S. (2008). Stripping in the new millennium: Thinking about trends in exotic dance and dancers' lives. Sociology Compass, 2(2), 503-518. doi: 10.1111/j.1751-9020.2007.00083.x

Bradley-Engen, M. S. (2009). Naked lives: Inside the worlds of erotic dance. Albany: State University of New York Press. 
Bradley-Engen, M. S., \& Ulmer, J. T. (2009). Social worlds of stripping: The processual orders of exotic dance. Sociological Quarterly, 50(1), 29-60. doi: $10.1111 / \mathrm{j} .1533-8525.2008 .01132 . x$

Brents, B. G., \& Hausbeck, K. (2005). Violence and legalized brothel prostitution in Nevada: Examining safety, risk, and prostitution policy. Journal of Interpersonal Violence, 20(3), 270-295. doi: 10.1177/0886260504270333

Brents, B. G., \& Hausbeck, K. (2010). Sex work now: What the blurring of boundaries around the sex industry means for sex work, research, and activism. In M. H. Ditmore, A. Levy \& A. Willman (Eds.), Sex work matters: Exploring money, power, and intimacy in the sex industry (pp. 9-22). New York: Zed Books.

Brents, B. G., \& Sanders, T. (2010). Mainstreaming the sex industry: Economic inclusion and social ambivalence. Journal of Law and Society, 37(1), 40-60. doi: $10.1111 / \mathrm{j} \cdot 1467-6478.2010 .00494 . \mathrm{x}$

Brooks, S. (2001). Exotic dancing and unionizing: The challenges of feminist and antiracist organizing at the Lusty Lady Theater. In F. W. Twine \& K. M. Blee (Eds.), Feminism and antiracism: International struggles for justice (pp. 5970). New York: New York University Press.

Brooks, S. (2010a). Hypersexualization and the dark body: Race and inequality among Black and Latina women in the exotic dance industry. Sexuality Research and Social Policy, 7(2), 70-80. doi: 10.1007/s13178-010-0010-5 Brooks, S. (2010b). Unequal desires: Race and erotic capital in the stripping industry. Albany: State University of New York Press. 
Brooks, T. J. (2008). 'In Da Club': An econometric analysis of strip club patrons. Paper presented at the American Economics Association, New Orleans.

Browne, K., Lim, J., \& Brown, G. (2007). Introduction, or why have a book on geographies of sexualities? In K. Browne, J. Lim \& G. Brown (Eds.), Geographies of sexualities: Theory, practices and politics (pp. 1-18). Burlington, VT: Ashgate.

Bruckert, C. (2002). Taking it off, putting it on: Women in the strip trade. Toronto: Women's Press.

Brunner, J. (2006, November 20). When it comes to strip clubs, Portland has nothing to hide, Seattle Times.

Bryman, A. (2003). Triangulation. In M. S. Lewis-Beck, A. Bryman \& T. F. Liao (Eds.), The Sage encyclopedia of social science research methods (pp. 1142-1143). Thousand Oaks, CA: Sage.

Bureau of Labor Statistics. (2013). Occupational outlook handbook, 2012-13 edition: Dancers and choreographers. Retrieved January 20, 2013, from http://www.bls.gov/ooh/Entertainment-and-Sports/Dancers-andchoreographers.htm

Busse, P. (2003). Stripping the strippers? Portland Mercury, (May 22). http://www.portlandmercury.com/portland/stripping-thestrippers $/$ Content?oid $=29046$

Butler, J. (1993). Bodies that matter: On the discursive limits of "sex". New York: Routledge. 
Butler, J. (1997). Excitable speech: A politics of the performative. New York: Routledge.

Cameron, S. (2004). Space, risk and opportunity: The evolution of paid sex markets. Urban Studies, 41(9), 1643-1657. doi: 10.1080/0042098042000243084

Chapkis, W. (1997). Live sex acts: Women performing erotic labor. New York: Routledge.

Chapkis, W. (2000). Power and control in the commercial sex trade. In R. Weitzer (Ed.), Sex for sale: Prostitution, pornography, and the sex industry (pp. 181201). New York: Routledge.

Charmaz, K. (2005). Grounded theory in the 21st century: Applications for advancing social justice studies. In N. K. Denzin \& Y. S. Lincoln (Eds.), Handbook of Qualitative Research (3rd ed., pp. 507-537). Thousand Oaks, CA: Sage Publications.

Chaskin, R. J. (2003). Fostering neighborhood democracy: Legitimacy and accountability within loosely coupled systems. Nonprofit and Voluntary Sector Quarterly, 32(2), 161-189. doi: 10.1177/0899764003032002001 Chiotti, Q. P., \& Joseph, A. E. (1995). Casey House: Interpreting the location of a Toronto AIDS hospice. Social Science \& Medicine, 41(1). doi: 10.1016/02779536(94)00304-C

City Club of Portland Research Committee. (2000). State of Oregon Ballot Measure 87: Zoning sexually-oriented businesses. City Club of Portland Bulletin, 82(19). 
Clarke, A. E. (2003). Situational analyses: Grounded theory mapping after the postmodern turn. Symbolic Interaction, 26(4), 553-576. doi: $10.1525 /$ si.2003.26.4.553

Clarke, A. E. (2005). Situational analysis: Grounded theory after the postmodern turn. Thousand Oaks, CA: Sage Publications.

Clarke, A. E. (2007a). Feminisms, grounded theory, and situational analysis. In S. N. Hesse-Biber (Ed.), Handbook of Feminist Research Methods: Theory and Praxis (pp. 345-370). Thousand Oaks, CA: Sage Publications.

Clarke, A. E. (2007b). Grounded theory: Critiques, debates, and situational analysis. In W. Outhwaite \& S. P. Turner (Eds.), The Sage handbook of social science methodology (pp. 423-442). Los Angeles: Sage Publications.

Cohan, D. L., Lutnick, A., Davidson, P., Cloniger, C., Herlyn, A., Breyer, J. (2006). Sex worker health, San Francisco style. Sexually Transmitted Infections, 82(5), 418-422. doi: 10.1136/sti.2006.020628

Colosi, R. (2010). A return to the Chicago school? From the 'subculture' of taxi dancers to the contemporary lap dancer. Journal of Youth Studies, 13(1), 1-16. doi: $10.1080 / 13676260903214183$

Colosi, R. (2011). "Just get pissed and enjoy yourself": Understanding lap-dancing as "anti-work". In K. Hardy, S. Kingston \& T. Sanders (Eds.), New Sociologies of Sex Work (pp. 181-196). Farnham, England: Ashgate.

Cortright, J. (1999). Understanding the two Oregons: Myths, realities, and confronting change. Portland, OR: Impresa Consulting. 
Coulmont, B. J., \& Hubbard, P. J. (2010). Consuming sex: Socio-legal shifts in the space and place of sex shops. Journal of Law and Society, 37(1), 189-209. doi: 10.1111/j.1467-6478.2010.00501.x

Cresswell, J. W. (2003). Research design: Qualitative, quantitative, and mixed methods approaches (2nd ed.). Thousand Oaks, CA: Sage.

Crofts, P. (2007). Brothels and disorderly acts. Public Space: The Journal of Law and Social Justice, 1, 1-39. http://epress.lib.uts.edu.au/journals/index.php/publicspace/article/view/5 $\underline{38}$

Dahly, D. L., \& Adair, L. S. (2007). Quantifying the urban environment: A scale measure of urbanicity outperforms the urban-rural dichotomy. Social Science \& Medicine, 64(7), 1407-1419. doi: 10.1016/j.socscimed.2006.11.019

Dando, C. E. (2009). "Whore-friendly people": Heritage tourism, the media and the place of sex work in Butte, Montana. Gender, Place \& Culture, 16(5), 587-607. doi: $10.1080 / 09663690903148440$

Dear, M. J., \& Wolch, J. (1992). Landscapes of despair: From deinstitutionalization to homelessness Princeton, NJ: Princeton University Press.

Delany, S. R. (1999). Times Square red, Times Square blue. New York: New York University Press.

DeMichele, M. T., \& Tewksbury, R. (2004). Sociological explorations in site-specific social control: The role of the strip club bouncer. Deviant Behavior, 25(6), 537-558. doi: 10.1080/01639620490484068 
Deng, F. F. (2003). The rebound of private zoning: Property rights and local governance in urban land use. Environment and Planning A, 35, 133-149. doi: $10.1068 / \mathrm{a} 35123$

Denzin, N. K. (1970). The research act: A theoretical introduction to sociological methods. Chicago: Aldine Publishing Company.

Deshotels, T. H., \& Forsyth, C. J. (2006). Strategic flirting and the emotional tab of exotic dancing. Deviant Behavior, 27(2), 223-241. doi:

$10.1080 / 01639620500468600$

Deshotels, T. H., \& Forsyth, C. J. (2008). Sex rules: The edicts of income in exotic dancing. Deviant Behavior, 29(5), 484-500. doi:

$10.1080 / 01639620701673081$

Doan, P. L. (2011). Why question planning assumptions and practices about queer spaces. In P. L. Doan (Ed.), Queerying planning: Challenging heteronormative assumptions and reframing planning practice (pp. 1-18). Burlington, VT.: Ashgate.

Domosh, M. (1999). Sexing feminist geography. Progress in Human Geography, 23(3), 429-436. doi: 10.1177/030913259902300306

Don't zone out rights. (1996, October 5). Oregonian, p. D06+.

Donaldson James, S. (2008). Strip club teases small Oregon city. Retrieved February 23, 2010, from http://abcnews.go.com/TheLaw/story?id=6088041

Duggan, L. (2003). The twilight of equality?: Neoliberalism, cultural politics, and the attack on democracy. Boston: Beacon Press. 
Dunn, K. (2002). Look, but don't touch. Portland Mercury. http://www.portlandmercury.com/portland/look-but-donttouch/Content?oid=27188

Edwards, M. L. (2010). Gender, social disorganization theory, and the locations of sexually oriented businesses. Deviant Behavior, 31(2), 135-158. doi: $10.1080 / 01639620902854852$

Egan, R. D. (2005). Emotional consumption: Mapping love and masochism in an exotic dance club. Body \& Society, 11(4), 87-108. doi:

$10.1177 / 1357034 \times 05058021$

Egan, R. D. (2006). Resistance under the black light: Exploring the use of music in two exotic dance clubs. Journal of Contemporary Ethnography, 35(2), 201219.

Ellis, G. (2004). Discourses of objection: Towards and understanding of third-party rights in planning. Environment and Planning A, 36(9), 1549-1570. doi: $10.1068 / \mathrm{a} 36176$

Emerson, R. M., Fretz, R. I., \& Shaw, L. L. (1995). Writing ethnographic field notes. Chicago: University of Chicago Press.

England, M. (2008). Stay out of drug areas: Drugs, othering and regulation of public space in Seattle, Washington. Space and Polity, 12(2), 197-213. doi: $10.1080 / 13562570802173281$

ESRI. (2010). ArcGIS (Version 10.1). Redlands, CA: ESRI. 
Evans, A., Riley, S., \& Shankar, A. (2010a). Postfeminist heterotopias: Negotiating 'safe' and 'seedy' in the British sex shop space European Journal of Women's Studies, 17(3), 211-229. doi: 10.1177/1350506810368817

Evans, A., Riley, S., \& Shankar, A. (2010b). Technologies of sexiness: Theorizing women's engagement in the sexualization of culture. Feminism \& Psychology, 20(1), 114-131. doi: 10.1177/0959353509351854

Farrell, P. (2000, April 8). Katz decides not to seek escort rules, Oregonian, p. E08. Feulner, N. (2011, May 27). Proposed strip club on McLoughlin Boulevard faces opposition from Milwaukie, Portland neighbors, Oregonian. Retrieved from http://www.oregonlive.com/milwaukie/index.ssf/2011/05/proposed strip club on mcloughlin boulevard faces opposition from milwaukie portland $\mathrm{n}$ eighbors.html

Florida, R. L. (2002). The rise of the creative class: And how it's transforming work, leisure, community and everyday life. New York: Basic Books.

Forsyth, A. A. (2011). Queerying planning practice: Understanding non-conformist populations. In P. L. Doan (Ed.), Queerying planning: Challenging heteronormative assumptions and reframing planning practice (pp. 21-51). Burlington, VT: Ashgate.

Forsyth, C. J., \& Deshotels, T. H. (1997). The occupational milieu of the nude dancer. Deviant Behavior, 18(2), 125-142. doi: 10.1080/01639625.1997.9968049

Foucault, M. (1986). Of other spaces. Diacritics, 16, 22-27. doi: 10.2307/464648

Frank, K. (2005). Exploring the motivations and fantasies of strip club customers in relation to legal regulations. Archives of Sexual Behavior, 34(5), 487-504. 
Frank, K. (2007). Thinking critically about strip club research. Sexualities, 10(4), 501-517. doi: $10.1177 / 1363460707080989$

Frenken, G. M. N., \& Sifaneck, S. J. (1998). Sexworkers and dope: An ethnography of heroin using lap dancers in New York City. Addiction Research, 6(4), 341-370. doi: $10.3109 / 16066359808993311$

Gall, G. (2007). Sex worker unionisation: An exploratory study of emerging collective organisation Industrial Relations Journal, 38(1), 70-88. doi: $10.1111 / \mathrm{j} .1468-2338.2007 .00436 . x$

Gall, G. (2010). Sex worker collective organization: Between advocacy group and labour union? Equality, Diversity and Inclusion: An International Journal, 29(3), 289-304. doi: 10.1108/02610151011028877

Glaser, B. G., \& Strauss, A. L. (1967). The discovery of grounded theory: Strategies for qualitative research. New York: Aldine de Gruyter.

Glasscock, J. (2003). Striptease: From gaslight to spotlight. New York: H.N. Abrams. Goffman, E. (1974). Frame analysis. Cambridge, MA: Harvard University Press. Gould, J. (2005). The best strip clubs in America: With a client, a friend, or alone. Men's Fitness, 21(7), 62+. http://www.mensfitness.com/lifestyle/entertainment/10-best-strip-clubs$\underline{\text { america }}$

Green, A. S. (2002a, October 31). Nude dancing ruling touches on free speech, Oregonian, p. A01.

Green, A. S. (2002b, May 6). Ruling challenges Oregon's unique speech protections, Oregonian, p. A01. 
Green, J., \& Thorogood, N. (2004). Qualitative methods for health research. Thousand Oaks, CA.: Sage Publications.

Green-Rennis, L. L., Hernandez-Cordero, L. J., Schmitz, K., \& Fullilove, M. T. (in press). "We have a situation here!": Using situation analysis for health and social research. In R. A. Miller (Ed.), Qualitative Research Methods for Social Work Research. New York: Columbia University Press.

Gross, M. (2009, May 10). Frugal Portland, New York Times, p. TR1. Retrieved from http://travel.nytimes.com/2009/05/10/travel/10Portland.html

Guba, E. G., \& Lincoln, Y. A. (1994). Competing paradigms in qualitative research. In N. K. Denzin \& Y. S. Lincoln (Eds.), Handbook of qualitative research (1st ed., pp. 105-117). Thousand Oaks, CA: Sage Publications.

Halberstam, J. (2005). In a queer time and place: Transgender bodies, subcultural lives. New York: New York University Press.

Hanna, J. L. (1998). Undressing the First Amendment and corsetting the striptease dancer. TDR: Drama Review, 42(2), 38-69. doi: 10.1162/dram.1998.42.2.38

Hanna, J. L. (2003). Exotic dance adult entertainment: Ethnography challenges false mythology. City \& Society, 15(2), 165-193. doi: 10.1525/city.2003.15.2.165

Hanna, J. L. (2005). Exotic dance adult entertainment: A guide for planners and policy makers. Journal of Planning Literature, 20(2), 116-134. doi: $10.1177 / 0885412205277071$

Hanna, J. L. (2010). Dance and sexuality: Many moves. Journal of Sex Research, 47(23), 212-241. doi: 10.1080/00224491003599744 
Hanna, J. L. (2013). Striptease spectators: Live and imaginary. Sexuality \& Culture, 17(1), 67-82. doi: 10.1007/s12119-012-9139-0

Hochschild, A. R. (1983). The managed heart: Commercialization of human feeling. Berkeley: University of California Press.

Hogan, D. (1985, September 15). City, club owners await outcome of nude dancing controversy, Oregonian, p. C1.

Horowitz, S., Calhoun, H., Erickson, A., \& Wuolo, G. (2011). American's uncounted independent workforce. Brooklyn: Freelancers Union.

Horowitz, S., Erickson, A., \& Wuolo, G. (2011). Independent, innovative, and unprotected: How the old safety net is failing America's new workforce. Brooklyn: Freelancers Union.

Hubbard, P. J. (1998a). Community action and the displacement of street prostitution: Evidence from British cities. Geoforum, 29(3), 269-286. doi: 10.1016/S0016-7185(98)00014-1

Hubbard, P. J. (1998b). Sexuality, immorality and the city: Red-light districts and the marginalisation of female street prostitutes. Gender, Place \& Culture, 5(1), 5576. doi: $10.1080 / 09663699825322$

Hubbard, P. J. (1999). Researching female sex work: Reflections on geographical exclusion, critical methodologies and 'useful' knowledge. Area, 31(3), 229237. doi: $10.1111 / \mathrm{j} .1475-4762.1999 . t b 00087 . x$

Hubbard, P. J. (2001). Sex zones: Intimacy, citizenship and public space. Sexualities, 4(1), 51-71. doi: $10.1177 / 136346001004001003$ 
Hubbard, P. J. (2002). Maintaining family values? Cleansing the streets of sex advertising. Area, 34(4), 353-360. doi: 10.1111/1475-4762.00092

Hubbard, P. J. (2004). Cleansing the metropolis: Sex work and the politics of zero tolerance. Urban Studies, 41(9), 1687-1702. doi:

$10.1080 / 0042098042000243101$

Hubbard, P. J. (2008). Encouraging sexual exploitation? Regulating striptease and 'adult entertainment' in the UK. Paper presented at the Globalization, Media and Adult/Sexual Content: Challenges to Regulation and Research meeting, Athens. https://dspace.lboro.ac.uk/dspace-jspui/handle/2134/3777

Hubbard, P. J. (2009). Opposing striptopia: The embattled spaces of adult entertainment. Sexualities, 12(6), 721-745. doi: $10.1177 / 1363460709346111$

Hubbard, P. J. (2011a). Gender, power \& sex in the world city network. L'espace politique, (13). http://espacepolitique.revues.org/index1815.html doi:10.4000/espacepolitique.1815

Hubbard, P. J. (2011b). Planning for sex/work. In P. L. Doan (Ed.), Queerying planning: Challenging heteronormative assumptions and reframing planning practice (pp. 169-184). Burlington, VT.: Ashgate.

Hubbard, P. J. (2012). Cities and sexualities. New York, NY: Routledge.

Hubbard, P. J., Boydell, S., Crofts, P., Prior, J., \& Searle, G. (2013). Noxious neighbours? Interrogating the impacts of sex premises in residential areas. Environment \& Planning A, 45(1), 126-141. doi: 10.1068/a4574 
Hubbard, P. J., Matthews, R., \& Scoular, J. (2009). Legal geographies--Controlling sexually oriented businesses: Law, licensing, and the geographies of a controversial land use. Urban Geography, 30(2), 185-205. doi:10.2747/02723638.30.2.185

Hubbard, P. J., Matthews, R., Scoular, J., \& Agustín, L. (2008). Away from prying eyes? The urban geographies of 'adult entertainment'. Progress in Human Geography, 32(3), 363-381. doi: 10.1177/0309132508089095

Hubbard, P. J., \& Sanders, T. (2003). Making space for sex work: Female street prostitution and the production of urban space. International Journal of Urban and Regional Research, 27(1), 75-89. doi: 10.1111/1468-2427.00432

Jacobs, J. (2002/1961). The death and life of great American cities (2002 ed.). New York: Random House.

Jeffrey, L. A., \& MacDonald, G. (2006). "It's the money, honey": The economy of sex work in the Maritimes. Canadian Review of Sociology and Anthropology-Révue Canadienne de Sociologie et d'Anthropologie, 43(3), 313-327. doi: 10.1111/j.1755-618X.2006.tb02227.x

Jeffreys, S. (2008). Keeping women down and out: The strip club boom and the reinforcement of male dominance. Signs, 34(1), 151-173. doi: $10.1086 / 588501$

Johnson, M. L. (2006). Stripper bashing: An autovideography of violence against strippers. In R. D. Egan, K. Frank \& M. L. Johnson (Eds.), Flesh for fantasy: Producing and consuming exotic dance (pp. 159-188). New York: Thunder's Mouth Press. 
Johnson, S. R. (2004). The myth and reality of Portland's engaged citizenry and process-oriented government. In C. P. Ozawa (Ed.), The Portland edge: Challenges and successes in growing communities. Washington, DC: Island Press.

Johnston, L., \& Longhurst, R. (2010). Space, place, and sex: Geographies of sexualities. Lanham, MD: Rowman \& Littlefield.

Jonas, A. E. G. (2006). Pro scale: Further reflections on the 'scale debate' in human geography. Transactions of the Institute of British Geographers, 31(3), 399406. doi: 10.1111/j.1475-5661.2006.00210.x

Jones-Smith, J., \& Popkin, B. M. (2009). Economic development, urbanicity and adult health changes in China. Paper presented at the Population Association of America, Detroit, MI. http://paa2009.princeton.edu/papers/90757

Juma, M., Askew, I., \& Ferguson, A. (2007). Situation analysis of the sexual and reproductive health and HIV risks and prevention needs of older orphaned and vulnerable children in Nyanza Province, Kenya. Nairobi: Department of Children's Services, Government of Kenya.

Jurjevich, J., \& Schrock, G. (2012). Is Portland really the place where young people go to retire? Migration patterns of Portland's young and college--educated, 1980--2010. Portland, OR: Portland State University.

Kay, K. (2000). Naked but unseen: Sex and labor conflict in San Francisco's adult entertainment theaters. Sexuality and Culture, 3(3), 39-67.

Kelly, E. D., \& Cooper, C. B. (2000). Everything you always wanted to know about regulating sex businesses. Chicago, IL: American Planning Association. 
Kerkin, K. (2004). Discourse, representation and urban planning: How a critical approach to discourse helps reveal the spatial re-ordering of street sex work. Australian Geographer, 35(2), 185-192. doi:

$10.1080 / 0004918042000249494$

Killian, D. (1995, July 25). Legislature making another try at censorship, Oregonian, p. B07.

Kingston, S., \& Sanders, T. (2011). Introduction: New sociologies of sex work in perspective. In K. Hardy, S. Kingston \& T. Sanders (Eds.), New Sociologies of Sex Work (pp. 1-8). Farnham, England: Ashgate.

Kirk, J., \& Miller, M. L. (1986). Reliability and validity in qualitative research. Thousand Oaks, CA: Sage Publications.

Knopp, L. M., Jr. (1995). Sexuality and urban space: A framework for analysis. In D. Bell \& G. Valentine (Eds.), Mapping desire: Geographies of sexualities (pp. 149161). New York: Routledge.

Krause, J. D. (1992). The effects of prison siting practices on community status arrangements: A framework applied to the siting of California state prisons Crime \& Delinquency, 38(1), 27-55. doi: dx.doi.org/10.1177/0011128792038001003

Las Vegas, V. (2009). Magic gardens (or, the starry-eyed saviors of the western night). Portland, OR: Dame Rocket Press.

Lasker, S. (2002). Sex and the city: Zoning "pornography peddlers and live nude shows". UCLA Law Review, 49(4), 1139-1185. 
Lee, R. M., \& Renzetti, C. M. (1993). Overview and introduction. In R. M. Lee \& C. M. Renzetti (Eds.), Researching Sensitive Topics (pp. 3-14). Newbury Park, CA: Sage Publications.

Lefebvre, H. (1991). The production of space (D. Nicholson-Smith, Trans.). Cambridge, MA: Blackwell.

Leitner, H., Sheppard, E., \& Sziarto, K. M. (2008). The spatialities of contentious politics. Transactions of the Institute of British Geographers, 33(2), 157-172. doi: 10.1111/j.1475-5661.2008.00293.x

Levy, A. (2005). Female chauvinist pigs: Women and the rise of raunch culture. New York: Free Press.

Lewis, J. (1998). Learning to strip: The socialization experiences of exotic dancers. Canadian Journal of Human Sexuality, 7(1), 51-66.

Lewis, J. (2006). "I'll scratch your back if you'll scratch mine": The role of reciprocity, power and autonomy in the strip club. Canadian Review of Sociology and Anthropology-Révue Canadienne de Sociologie et d'Anthropologie, 43(3), 297-311. doi: 10.1111/j.1755-618X.2006.tb02226.x

Liepe-Levinson, K. (2002). Strip show: Performances of gender and desire. New York: Routledge.

Lilleston, P., Reuben, J., \& Sherman, S. G. (2012). "This is our sanctuary": Perceptions of safety among exotic dancers in Baltimore, Maryland. Health \& Place, 18(3), 561-567. doi: 10.1016/j.healthplace.2012.01.009

Lincoln, Y. S., \& Guba, E. G. (1985). Naturalistic inquiry. Beverly Hills, CA: Sage Publications. 
Linz, D., Land, K. C., Williams, J. R., Paul, B., \& Ezell, M. E. (2004). An examination of the assumption that adult businesses are associated with crime in surrounding areas: A secondary effects study in Charlotte, North Carolina. Law \& Society Review, 38(1), 69-104. doi: 10.1111/j.00239216.2004.03801003.x

Linz, D., Paul, B., \& Yao, M. Z. (2006). Peep show establishments, police activity, public place, and time: A study of secondary effects in San Diego, California. Journal of Sex Research, 43(2), 182-193. doi: 10.1080/00224490609552313

Lofland, J., \& Lofland, L. H. (1995). Analyzing social settings: A guide to qualitative observation and analysis (3rd ed.). Belmont, CA: Wadsworth Publishing.

Macdonald, C. L., \& Sirianni, C. (1996). The service society and the changing experience of work. In C. L. Macdonald \& C. Sirianni (Eds.), Working in the service society (pp. 1-26). Philadelphia: Temple University Press.

Maginn, P. J., \& Steinmetz, C. A. (2011). Sex in the city: The changing face of adult retailing. The Conversation, (September 5). http://theconversation.edu.au/sex-in-the-city-the-changing-face-of-adultretailing-3083

Maginn, P. J., \& Steinmetz, C. A. (2012). Erotic Sydney: The sexual economy, global city status and urban cosmopolitanism. Paper presented at the Association of American Geographers Annual Meeting, New York.

Marshall, C., \& Rossman, G. B. (1999). Designing qualitative research (3rd ed.). Thousand Oaks, CA: Sage. 
Marston, S. A., Jones, J. P., \& Woodward, K. (2005). Human geography without scale. Transactions of the Institute of British Geographers, 30(4), 416-432. doi: 10.1111/j.1475-5661.2005.00180.x

Mason, M. (2010). Sample size and saturation in PhD studies using qualitative interviews. Forum: Qualitative Social Research, 11(3).

Maticka-Tyndale, E., Lewis, J., Clark, J. P., Zubick, J., \& Young, S. (1999). Social and cultural vulnerability to sexually transmitted infection: The work of exotic dancers. Canadian Journal of Public Health-Revue Canadienne De Sante Publique, 90(1), 19-22.

Maticka-Tyndale, E., Lewis, J., Clark, J. P., Zubick, J., \& Young, S. (2000). Exotic dancing and health. Women \& Health, 31(1), 87-108. doi: 10.1300/J013v31n01_06

Maticka-Tyndale, E., Lewis, J., \& Street, M. (2005). Making a place for escort work: A case study. Journal of Sex Research, 42(1), 46-53. doi:10.1080/00224490509552256

Maxwell, J. A. (2005). Qualitative research design: An interactive approach (2nd ed. Vol. 41). Thousand Oaks, CA: Sage.

McBee, J. (2012). IBISWorld Industry Report OD4409: Strip clubs in the U.S. Santa Monica, CA.: IBISWorld.

McCleary, R., \& Weinstein, A. C. (2009). Do "off-site" adult businesses have secondary effects? Legal doctrine, social theory, and empirical evidence. Law \& Policy, 31(2), 217-235. doi: 10.1111/j.1467-9930.2009.00295.x 
McGrath, M. M. (2009). Sketchy in the city: Strip club street-blocks and women's wellbeing in Portland, Oregon. Paper presented at the American Public Health Association 137th Annual Meeting, Philadelphia.

McGrath, M. M., Fullilove, R. E., III, Kaufman, M. R., Wallace, R. M., \& Fullilove, M. T. (2009). The limits of collaboration: A qualitative study of community ethical review of environmental health research. American Journal of Public Health, 99(8), 1510-1514. doi: 10.2105/ajph.2008.149310

McNair, B. (2002). Striptease culture: Sex, media and the democratization of desire. London; New York: Routledge.

Metro Data Resource Center. (2012). Regional Land Use Information System (RLIS) (November ed.). Portland, OR: Metro regional government.

Miles, M. B., \& Huberman, A. M. (1994). Qualitative data analysis: An expanded sourcebook (2nd ed.). Thousand Oaks, CA: Sage Publications.

Miss Mary Ann. (2006). Labor organizing in the skin trade: Tales of a peep show prole. In R. D. Egan, K. Frank \& M. L. Johnson (Eds.), Flesh for fantasy: Producing and consuming exotic dance (pp. 214-224). New York: Thunder's Mouth Press.

Mitchell, J. C. (1983). Case and situation analysis. Sociological Review, 31(2), $187-$ 211. doi: $10.4135 / 9780857024367 . d 12$

Moore, A. C. (1998). The powers of preservation: New life for urban historic places. New York: McGraw-Hill.

Moore, A. S. (2005, March 9). Bump and grind, Portland Mercury. Retrieved from http://wweek.com/story.php?story=6093 
Muhr, T. (2007). ATLAS.ti (Version 5.2). Berlin: ATLAS.ti GmbH.

Nally, C. (2009). Grrrly hurly burly: Neo-burlesque and the performance of gender. Textual Practice, 23(4), 621-643. doi: 10.1080/09502360903000554

National Association of County \& City Health Officials. (2011). Describing the local public health workforce: Workers who prevent, promote, and protect the nation's health. Washington, DC: National Association of County \& City Health Officials.

O'Neill, M., Campbell, R., Hubbard, P. J., Pitcher, J., \& Scoular, J. (2008). Living with the Other: Street sex work, contingent communities and degrees of tolerance. Crime, Media, Culture, 4(1), 73-93. doi: 10.1177/1741659007087274

O'Reilly, M., \& Parker, N. (2012). "Unsatisfactory saturation": A critical exploration of the notion of saturated sample sizes in qualitative research. Qualitative Research. doi: 10.1177/1468794112446106

Owens, D. W. (1998). Recent developments regarding local regulation of sexually oriented businesses. Planning and Zoning Bulletin(10), 1-13.

Padilla, M. B., Hirsch, J. S., Muñoz-Laboy, M., Sember, R., \& Parker, R. G. (Eds.). (2007). Love and globalization: Transformations of intimacy in the contemporary world. Nashville, TN: Vanderbilt University Press.

Papayanis, M. A. (2000). Sex and the revanchist city: Zoning out pornography in New York. Environment and Planning D-Society \& Space, 18(3), 341-353. doi: $10.1068 / \mathrm{d} 10 \mathrm{~s}$

Pasko, L. (2002). Naked power: The practice of stripping as a confidence game. Sexualities, 5(1), 49-66. doi: 10.1177/1363460702005001003 
Paul, B., \& Linz, D. (2001). Government regulation of "adult" businesses through zoning and anti-nudity ordinances: Debunking the legal myth of negative secondary effects. Communication Law and Policy, 6(2), 355-391. doi: /10.1207/S15326926CLP0602_4

Pitkin, J. (2010, July 1). Stripper loses lawsuit for hourly wages. Retrieved from http://www.wweek.com/portland/blog-1337stripper loses lawsuit for hourly wages.html

Popper, F. J. (1981). Siting LULU's. Planning, 47(4), 12-15.

Prior, J., Boydell, S., \& Hubbard, P. J. (2012). Nocturnal rights to the city: Property, propriety and sex premises in Inner Sydney. Urban Studies, 49(8), 18371852. doi: $10.1177 / 0042098011417019$

Redden, J. (2002, March 22). Constitution throws up a roadblock, The Portland Tribune. Retrieved from http://thevig.portlandtribune.com/news/print story.php?story id=10378 Rhodes, T., Singer, M., Bourgois, P., Friedman, S. R., \& Strathdee, S. A. (2005). The social structural production of HIV risk among injecting drug users. Social Science \& Medicine, 61(5), 1026-1044. doi: http://dx.doi.org/10.1016/i.socscimed.2004.12.024

Rick's Cabaret International Inc. (2009). Annual report persuant to Section 13 or 15(d) of the Securities Exchange Act of 1934 for the fiscal year ended December 31, 2009. Retrieved March 17, 2013, from http://www.sec.gov/Archives/edgar/data/935419/000114036109029530/ form $10 \mathrm{k} \cdot \mathrm{htm}$ 
Rick's Cabaret International Inc. (2012). Annual report persuant to Section 13 or 15(d) of the Securities Exchange Act of 1934 for the fiscal year ended December 31, 2012. Retrieved March 17, 2013, from http://www.sec.gov/Archives/edgar/data/935419/000114420412068015/ v328527 10k.htm

Roberts, M. (1999, April 7). Hot topics: House panel hears testimony on allowing sex shop zoning, Oregonian, p. E06.

Romney, L. (2004). In S.F., weighing strippers' rights, Los Angeles Times. Retrieved from http://articles.latimes.com/2004/dec/19/local/me-stripper19

Ronai, C. R. (1989). Turn-ons for money: Interactional strategies of the table dancer. Journal of Contemporary Ethnography, 18(3), 271-198. doi: $10.1177 / 089124189018003002$

Rossman, G. B., \& Rallis, S. F. (1998). Learning in the field: An introduction to qualitative research. Thousand Oaks, CA: Sage Publications.

Rutman, M. (1999). Exotic dancers' employment law regulations. Temple Political \& Civil Rights Law Review, 8, 515-573.

Sanchez, L. E. (1997). Boundaries of legitimacy: Sex, violence, citizenship, and community in a local sexual economy. Law and Social Inquiry: Journal of the American Bar Foundation, 22(3), 543-580. doi: 10.1111/j.17474469.1997.tb01081.x

Sanders, T. (2004). A continuum of risk? The management of health, physical and emotional risks by female sex workers. Sociology of Health \& Illness, 26(5), 557-574. doi: 10.1111/j.0141-9889.2004.00405.x 
Sanders, T. (2005). It's just acting: Sex workers' strategies for capitalising on sexuality. Gender, Work, and Organization, 14(4), 319-342. doi: $10.1111 / \mathrm{j} .1468-0432.2005 .00276 . \mathrm{x}$

Sanders, T. (2006). Sexing up the subject: Methodological nuances in researching the female sex industry. Sexualities, 9(4), 449-468. doi: $10.1177 / 1363460706068044$

Sanders, T. (2007). Protecting the health and safety of female sex workers: The responsibility of all. BJOG: An International Journal of Obstetrics and Gynaecology, 114(7), 791-793. doi: 10.1111/j.1471-0528.2007.01378.x

Sanders, T., \& Campbell, R. (2007). Designing out vulnerability, building in respect: Violence, safety and sex work policy. British Journal of Sociology, 58(1), 1-19. doi: 10.1111/j.1468-4446.2007.00136.x

Sanders, T., \& Hardy, K. (2012). Devalued, deskilled and diversified: Explaining the proliferation of the strip industry in the UK. The British Journal of Sociology, 63(3), 513-532. doi: 10.1111/j.1468-4446.2012.01422.x

Sangera, J. (1997). In the belly of the beast: Sex trade, prostitution and globalization. Paper presented at the South Asia Regional Consultation on Prostitution, Bangkok. http://web.archive.org/web/20061208171513/http://www.hsph.harvard.e du/Organizations/healthnet/SAsia/repro2/jyoti sangera.htm

Schively, C. (2007). Understanding the NIMBY and LULU phenomena: Reassessing our knowledge based and informing future research. Journal of Planning Literature, 21(3), 257-266. doi: 10.1177/0885412206295845 
Schlanger, L., \& Choo, E. (2012). Health correlates of injuries and violence among female employees of an adult entertainment club. Paper presented at the American Public Health Association 140th Annual Meeting, San Francisco.

Schlosser, E. (1997, February 10). The business of pornography. U.S. News and World Report, 122, 42-50.

Scott, J. C. (1985). Weapons of the weak: Everyday forms of peasant resistance. New Haven: Yale University Press.

Scoular, J., Pitcher, J., Campbell, R., Hubbard, P. J., \& O'Brien, M. (2007). What's antisocial about sex work? The changing representation of prostitution's incivility. Community Safety Journal, 6(1), 11-17. doi:

$10.1108 / 17578043200700003$

Sharp, E. B. (2004). Metropolitan structure and the sex business. In R. C. Feiock (Ed.), Metropolitan governance: Conflict, competition, and cooperation. Washington, DC: Georgetown University Press.

Shaver, F. M. (2005). Sex work research: Methodological and ethical challenges. Journal of Interpersonal Violence, 20(3), 296-319. doi:

\section{$10.1177 / 0886260504274340$}

Sherman, S. G., Lilleston, P., \& Reuben, J. (2011). More than a dance: The production of sexual health risk in the exotic dance clubs in Baltimore, USA. Social Science \& Medicine, 73(3), 475-481. doi:10.1016/j.socscimed.2011.05.036

Sherman, W. (2007). The naked truth about strip clubs. New York Daily News, (July 8). http://www.nydailynews.com/news/naked-truth-strip-clubs-article- 
Shteir, R. (2004). Striptease: The untold history of the girlie show. New York: Oxford University Press.

Sides, J. (2006). Excavating the postwar sex district in San Francisco. Journal of Urban History, 32(3), 355-379. doi: 10.1177/0096144205282713

Sieber, J. E. (1993). The ethics and politics of sensitive research. In R. M. Lee \& C. M. Renzetti (Eds.), Researching sensitive topics (pp. 14-26). Newbury Park, CA: Sage Publications.

Singleton, R. A., Jr., \& Straits, B. C. (2005). Approaches to social research (4th ed.). New York: Oxford University Press.

Sloan, L., \& Wahab, S. (2000). Feminist voices on sex work: Implications for social work. Affilia-Journal of Women and Social Work, 15(4), 457-479. doi: $10.1177 / 08861090022094065$

Smith, N. (1996). The new urban frontier: Gentrification and the revanchist city. New York: Routledge.

Sottille, L. (2005). Dancing lessons. Willamette Week, (October 26). http://www.wweek.com/portland/article-4953-dancing lessons.html

Spice, W. (2007). Management of sex workers and other high-risk groups. Occupational Medicine, 57, 322-328. doi: 10.1093/occmed/kqm045

Stern, H. (2002, November 20). Portland considers nude dancing restrictions, Oregonian, p. C01.

Stern, H. (2003, May 15). City watch, Oregonian, p. C02. 
Strom, E. (2003). Cultural policy as development policy: Evidence from the United States. International Journal of Cultural Policy, 9(3), 247-263. doi: $10.1080 / 1028663032000161687$

Suit ends city's ban on nudity. (1985, June 19). Oregonian, p. B2.

Takahashi, L. M. (1998). Homelessness, AIDS, and stigmatization: The NIMBY syndrome in the United States at the end of the twentieth century. New York: Oxford University Press.

Takahashi, L. M., \& Dear, M. J. (1997). The changing dynamics of community opposition to human service facilities. Journal of the American Planning Association, 63(1), 79-93. doi: 10.1080/01944369708975725

Tani, S. (2002). Whose place is this space? Life in the street prostitution area of Helsinki. International Journal of Urban and Regional Research, 26(2), 343359. doi: $10.1111 / 1468-2427.00383$

Taylor, R. B. (1988). Human territorial functioning: An empirical, evolutionary perspective on individual and small group territorial cognitions, behaviors, and consequences. New York: Cambridge University Press.

The Ultimate Strip Club List. (2013, March 19). Worldwide strip clubs. The Ultimate Strip Club List, Vol. 20, No. 78. Retrieved March 19, 2013, from https://www.tuscl.net/r.php

Thomas, W. I., \& Thomas, D. S. (1928). The child in America. New York: Alfred A. Knopf.

Tuan, Y.-f. (1977). Space and place: The perspective of experience. Minneapolis: University of Minnesota Press. 
Tucker, D. M. (1997). Preventing the secondary effects of adult entertainment establishments: Is zoning the solution? Journal of Land Use and Environmental Law, 12(2), 383-431.

Uganda Ministry of Health. (2008). Situation analysis of newborn health in Uganda: Current status and opportunities to improve care and survival. Kampala: Government of Uganda.

Vanwesenbeeck, I. (2001). Another decade of social scientific work on sex work: A review of research 1990-2000. Annual Review of Sex Research, 12, 242-289. Vanwesenbeeck, I. (2005). Burnout among female indoor sex workers. Archives of Sexual Behavior, 34(6), 627-639.

VCG Holding Corp. (2009). Annual report persuant to Section 13 or 15(d) of the Securities Exchange Act of 1934 for the fiscal year ended December 31, 2009. Retrieved March 17, 2013, from http://www.sec.gov/Archives/edgar/data/1172852/000095012310024255 Ld71477e10vk.htm\#102

VCG Holding Corp. (2012). Annual report persuant to Section 13 or 15(d) of the Securities Exchange Act of 1934 for the fiscal year ended December 31, 2012. Retrieved March 17, 2013, from http://www.sec.gov/Archives/edgar/data/1172852/000095012311030479 /d81034e10vk.htm

Vlahov, D., \& Galea, S. (2002). Urbanization, urbanicity, and health. Journal of Urban Health: Bulletin of the New York Academy of Medicine, 79(Supplement 1), S1S12. doi: 10.1093/jurban/79.suppl_1.S1 
Wahab, S., Baker, L., Smith, J., Cooper, K., \& Lerum, K. (2011). Exotic dance research: A review of the literature from 1970 to 2008. Sexuality \& Culture, 15(1), 5679. doi: $10.1007 / \mathrm{s} 12119-010-9084-8$

Weitzer, R. (2000a). Why we need more research on sex work. In R. Weitzer (Ed.), Sex for sale: Prostitution, pornography, and the sex industry (pp. 1-13). New York: Routledge.

Weitzer, R. (Ed.). (2000b). Sex for sale: Prostitution, pornography, and the sex industry. New York: Routledge.

West, D. M., \& Orr, M. (2007). Morality and economics: Public assessments of the adult entertainment industry. Economic Development Quarterly, 21(4), 314324. doi: $10.1177 / 0891242407304168$

Wharton, A. S. (2009). The sociology of emotional labor. Annual Review of Sociology, 35, 147-165. doi: 10.1146/annurev-soc-070308-115944

Wosick-Correa, K. R., \& Joseph, L. J. (2008). Sexy ladies sexing ladies: Women as consumers in strip clubs. Journal of Sex Research, 45(3), 201-216. doi: $10.1080 / 00224490801987432$

Yin, R. K. (2003). Case study research: Design and methods (3rd ed.). Thousand Oaks, CA: Sage.

Zatz, N. D. (1997). Sex work/sex act: Law, labor, and desire in constructions of prostitution. Signs, 22(2), 277-308. doi: 10.1086/495157

Zone sex shops. (1999, January 28). Oregonian, p. B10. 
Appendix A:

\section{Human Subjects Research Review Committee Application}

\section{Project Title \& Prospectus}

Strip clubs in the neighborhood context in Portland, Oregon

This project will use situational analysis-a qualitative research methodology-to explore the role that strip clubs play in Portland neighborhoods, focusing on how neighborhood conditions affect the well-being of exotic dancers who work in the clubs. Field observations and one-on-one interviews will be conducted along with a complementary review of newspaper coverage of these issues.

The study will focus on three clubs within the Portland metropolitan area, interviewing dancers, club managers/owners, and residents of the neighborhoods that house the clubs. I will also interview representatives of city and state governments that have expertise on this topic. These people will be asked to speak about their perception of:

- the role the club plays in the neighborhood,

- any incidents that have shown conflict or cooperation between the club and area residents, and

- the health concerns faced by exotic dancers working at the club.

Portland is an important locale for this research because of the high concentration of adult entertainment establishments in the city and the unique interpretation of the State Constitution to protect nude dancing as free speech-thus prohibiting municipal regulation of club location. The informal processes that control club location may influence the extent or degree of occupational health hazards for exotic dancers, which include violence, disease, substance abuse, and depression. The project has the potential to contribute to the understanding of the ways local social, political, and geographic conditions affect the well-being of this population of workers and possibly other independent contractors as well.

II. Exemption Claim for Waiver of Review

None

III. Subject Recruitment

This project will recruit people over age 18 who fit into one or more of the following categories:

- Women who have worked as exotic dancers at one of the three study sites (sites TBD) in the past six months-up to 5 dancers per club

- Owners or managers who have worked at one of the three study sites (sites TBD) in the past six months-up to 2 per club 
- People who have in the past six months lived or worked in the neighborhoods that house the three study sites (sites TBD), with neighborhood boundaries defined by the local neighborhood association; project focus will be on neighborhood association members and owners of businesses nearest to strip clubs-up to 5 per site

- City of Portland Planning Bureau district planners and Office of Neighborhood Involvement crime prevention coordinators - up to 6 total

- Oregon Liquor Control Commission staff-up to 3 total

Participants may be of any ethnicity, race, educational, health, or economic status but must be fluent in English.

Most participants will be recruited through snowball sampling, starting with the personal social network of the researchers (i.e., asking friends of friends to participate, and then asking interviewees to propose further contacts at the end of meetings). This method is chosen to help the researcher gain entrée into the community and to bolster the researcher's credibility with participants. It also broadens the avenues for participants to reflect on their participation-if they have concerns about the study, they are free to contact Research and Sponsored Projects, the investigator, or the participant who referred them.

When a participant suggests a colleague's name as a potential participant, the investigator will ask the participant if she is willing to contact the individual and provide the investigator contact information and/or obtain permission to pass on the individual's contact information to the investigator. After a week, the investigator will follow up with the participant about the status of the referral. Upon obtaining permission from the participant to contact the referral, the investigator will telephone or e-mail the referral to express interest in having her participate in a project at Portland State University. In this initial contact, the investigator will not mention the nature of the project or the name of the participant who provided the referral, in order to protect the identity of participants and minimize the possibility of "outing" participants to others who may have access to their phone or e-mail messages.

Participants who are being interviewed in a public capacity-like government employees, neighborhood association members, and owners of strip clubs and other businesses will also be contacted by mail or phone.

After participants have expressed interest in participating, the investigator will arrange a mutually convenient time and place for conducting the interview.

The study will entail roughly 25 to 45 interviews conducted throughout 2009.

\section{Informed Consent}

The investigator will obtain informed consent from each study participant. At the outset of the interview, she will explain the study goals and also the rationale for the human subjects protection (to help make the paperwork intimidating). Participants will be provided with an information letter/coversheet as well as a separate business card with 
the investigator's name and contact information but no mention of university affiliation or other identifying details. This measure will allow participants to dispose of the information sheet-which mentions the study topic-and still retain the necessary information to contact the investigator and express concerns about their participation. This is important because of who the participants are and what the study is about: sex workers may want to avoid holding onto a document that confirms what their job is, and a participants engaged in any kind of dispute over clubs might not be comfortable with others knowing that they had discussed the issues with anyone. To facilitate rapport building with dancers, their consent will be obtained orally after discussing the material in the information sheet. The legalistic nature of the consent document can be intimidating to research participants, and dancers-who may not report all their income or who may be exposed to illegal activities on the jobsite-may be leery of signing their name to a form. Allowing dancers to provide consent orally further protects members of this sensitive population from potential exposure of their identities. The only difference between the consent form that dancers receive will be the deletion of the signature line. Their verbal agreement to participate will be documented in a separate consent log that will be stored with the other signed consent forms.

\section{First-Person Scenario}

\section{From the perspective of an exotic dancer recruited through snowball sampling:}

At work last week, a colleague mentioned that she had been interviewed by a researcher at Portland State and that the woman was looking to speak to more people. My colleague gave me the researcher's card and also asked if she could give her my number. I said okay. Later that week, I got a message on my voicemail from the researcher, asking me to call her back if I was willing to share my experiences. After a week or so, I called her and we agreed to meet; she offered to come to my house, or to arrange a room at the university. I decided it would be easiest to meet at my home. She called the day before to confirm the appointment, and then showed up at the arranged time and introduced herself and explained why she is doing the study. We talked casually for an hour. She asked me questions about my experiences working in Portland and what I thought about the neighborhood. She also wanted to know my thoughts about dancers unionizing or doing other political activity, and whether the neighbors had any problem with our club. When we wrapped up, she asked if it would be okay to contact me again in a few months to get my feedback on the things she was finding. I told her that I wasn't sure I could commit to helping, but she could call. She asked what name she should use when calling, whether calling or e-mail was better, and if it was okay to mention the topic of the study-because some dancers share phone lines with people and don't want people to know what they do for work. I told her she could call, use my real name, and mention dancing-because otherwise I might not remember who she was. A week later she called to ask if I had any other dancers to recommend and I told her that 2 of my co-workers said they were willing to participate. I gave them her e-mail addresses and said it was okay to use my name; she e-mailed them that same day, I learned at work that night.

From the perspective of a neighborhood association member recruited by phone: 
Last week I received a voicemail from a researcher at Portland State who said she wanted to talk to our neighborhood association about strip clubs. That's not an issue I'm currently working on, and I was having a busy day, so I didn't call her back. She called again today and caught me while I was in the office. She explained that she is interested in learning about how neighborhood associations work with businesses. We set up an appointment to talk at our office. She came and asked me about concerns that the neighborhood association has with businesses, and strip clubs in particular. I told her that we weren't as bothered by the strip club as the adult video places and told her the problems we had with soliciting in the parking lot and drug dealing nearby. She asked about our negotiations with the owner and whether we had succeeded in getting him to do anything about the problems. She let me know that she would be interviewing other people in our neighborhood over the next few months and gave me her contact information so I could get in touch in case I thought of anything else or wanted to ask any questions.

\section{Potential Risks and Safeguards}

There are two main risks to participants: the discomfort of discussing issues personal or sensitive issues (which is particularly important in the case of dancers who may have had negative experiences in the workplace), and the potential of having one's identity exposed. Protections to avoid disclosure of identity are described in section VIII. Participants will also be foregoing income during the time they are participating, which can be a large inconvenience for low-income people.

By focusing on professional experience and neighborhood conditions rather than life history, interviews will be somewhat less intrusive and personal, but may still bring up

difficult topics. Participants' rights to decline responding to questions and terminate participation at any point will be emphasized in the consent process and throughout the interview. The researcher will discontinue the interview if the participant appears to be distraught or disturbed and will spend time discussing social services available to assist the participant with the issue that spurred the distress (or any other issue that the participant identifies as a concern). The researcher will travel to interviews with program and contact information for resources regarding known problems in the exotic dance community: sexual and domestic violence, child welfare and custody, substance use, legal services, mental health care, and housing services. The investigator will apply her professional experience in crisis response, sexual assault support, outreach work, and one-on-one case management to complete these encounters.

It is also possible the discussing workplace conditions may encourage some dancers to advocate for improvements in their workplace, which could spur reprisal from management. There is no particular safeguard for this risk, unfortunately. However, the researcher might be able to connect participants with public interest law services if such a situation results.

VII. Potential Benefits 
Subjects will receive no direct benefit for participating. However, they may enjoy the opportunity to share their experience, to have their concerns acknowledged, and discuss the political implications of their work. This benefit may be especially great because it can lend feelings of legitimacy to people whose work is stigmatized. There is also a potential benefit of increased worker awareness of labor concerns, which could lead to activism or advocacy work with positive activism.

\section{Records \& Distribution}

The investigator will protect participants' identities by keeping all study information will be kept in password-protected computer files. A file with participants' contact information will be kept separate from a file that includes names and dates/locations of interviews to minimize the possibility of a third party being able to access the materials and identify participants.

Immediately following an interview, a pseudonym will be assigned to the participant and used in all memos, filenames, and study documents. Interviews will be audio recorded, with audio files uploaded to computer and deleted from the hardware as soon as possible following the completion of an interview summaries. When contacting participants at home, the investigator will not mention the university or exotic dancing, to minimize damage that could occur if the message were intercepted. When calling offices, the investigator will identify herself with her university affiliation.

Hard copies of materials will be kept in a locked cabinet at the Portland State University School of Urban Studies, if space is available there. Otherwise, the investigator will store the materials at her home. Materials will be maintained for a minimum of three years. At the point it is deemed no longer necessary to retain the raw data, files will be purged from computer hard drives, and versions on paper and other media will be destroyed.

\section{Appendices}

Please see:

- Appendix B - Sample Interview Guides

- Appendix C - Recruitment E-mail/Telephone Script

- Appendix D - Consent Form 
Appendix B:

\section{Sample Interview Guides}

This section presents samples of guides for semi-structured interviews. Interview content varied depending on the type of person being interviewed, hence the four different sections.

Interviews with dancers will address some of the following questions:

- How did you come to dance at this club?

- Would you say that you are typical of the people who work here? How are you different from other people who work here?

- How does this club stack up to other clubs? (Have you worked other places? What reputation does this club have? Is that a well-deserved reputation?

- What are some of the best things about working here? What are some of your least favorite things?

- How would you describe the neighborhood that this club is in?

- How much time do you spend in this neighborhood? What places do you go to besides the club? How do you get to work?

- Who do you know in this neighborhood?

- What would make this club a better place to work in? From your perspective, what would make the neighborhood a better place?

- Would you consider your club to be a good neighbor? What does the club do to be a good neighbor?

- Would you say that others in the neighborhood are good neighbors? If you had a problem, would you ask someone in this neighborhood for help? Have you had any problems in the neighborhood since you've worked here?

- Some people say that strip clubs should only be in certain parts of town. What do you think about that? (Should they be allowed to be residential neighborhoods, near schools?)

- Have you heard any objections to this club?

- What effect do you think strip clubs have on a neighborhood? How do you think the neighborhood affects this strip club?

Interviewers with club owners/managers will address some of the following questions:

- How did you come to own/manage this club?

- How did this club end up in this location?

- How would you describe the neighborhood? From your perspective, what are some of the best and worst things about this neighborhood?

- Would you say that yours is a typical club? Why and why not?

- What are some of the main challenges you face in managing this club?

- How much time do you spend in this neighborhood? What places do you go to besides the club? How do you get to work?

- Who do you know in this neighborhood?

- How do you think neighborhood residents perceive your club?

- What kinds of interactions have you had with residents? The neighborhood association? Police? How have you resolved problems/conflicts? 
- Would you consider your club to be a good neighbor? What do you do to be a good neighbor?

- Some people say that strip clubs should only be in certain parts of town. What do you think about that? (Should they be allowed to be residential neighborhoods, near schools?)

- What effect do you think strip clubs have on a neighborhood? How do you think the neighborhood affects this strip club?

Interviews with residents will address some of the following questions:

- How long have you lived/worked in this neighborhood? How would you describe the neighborhood?

- What role do you play in the neighborhood?

- As I mentioned, I am interested in knowing about the relationship between $[\mathrm{x}]$ club and the neighborhood ...

- What do you know about the club?

- What role does the club play in the neighborhood?

- What is your impression of the people who work there? Manage the club?

- Would you consider the club to be a good neighbor? What do you do to be a good neighbor?

- Are there other "adult" establishments in the neighborhood? How does this one compare to the others?

- What effect do you think strip clubs have on a neighborhood? How do you think the neighborhood affects this strip club?

- Some people say that strip clubs should only be in certain parts of town. What do you think about that? (Should they be allowed to be residential neighborhoods, near schools?)

Interviewers with government employees will address some of the following questions:

- Please tell me a little bit about your job and how long you have had it.

- How does your agency's scope of work relate to strip clubs?

- How would you describe the neighborhood where this strip club is?

- As I mentioned, I am interested in knowing about the relationship between [x] club and the neighborhood ...

- What do you know about the club?

- What role does the club play in the neighborhood?

- What is your impression of the people who work there? Manage the club?

- Would you consider the club to be a good neighbor? What do you do to be a good neighbor?

- Are there other "adult" establishments in the neighborhood? How does this one compare to the others?

- What effect do you think strip clubs have on a neighborhood? How do you think the neighborhood affects this strip club? 
- $\quad$ Some people say that strip clubs should only be in certain parts of town. What do you think about that? (Should they be allowed to be residential neighborhoods, near schools?) 
Appendix C:

\section{Recruitment E-mail/Telephone Script}

For people contacted at home/through snowball sampling:

Hello [first name],

My name is Moriah and I'm getting in touch with you because [referrer's first name] suggested that you might be willing to talk to me about a project I'm doing.

I would love to get an opportunity to tell you more about it and see if you might be willing to help.

Please feel free to contact me however is most convenient for you. My phone number is 503.235.0610 and my e-mail address is moriah@pdx.edu.

Look forward to hearing from you,

Moriah McSharry McGrath

For people contacted at the office/through public role:

Dear Mr./Ms./Dr. [last name],

I'm working on a research project at Portland State University and am hoping that you might be willing to speak with me about your work at [company/organization].

I am interested in speaking with residents of [neighborhood] about relationships between businesses and neighbors and am interested in getting your perspective about these issues.

I would welcome opportunity to tell you more about the project and see if you might be willing to help.

Please feel free to contact me however is most convenient for you. My phone number is 503.235.0610 and my e-mail address is moriah@pdx.edu.

Sincerely,

Moriah McSharry McGrath, MPH, MSUP 
Appendix D:

\section{Consent Form}

Strip clubs in the neighborhood context in Portland, Oregon

As a student in Portland State University's PhD program in Urban Studies, I am conducting a research project on the relationships between businesses and neighborhood residents in Portland. I am specifically interested in learning about how residents and sexually-oriented businesses share space. I will be talking to a variety of people about their impressions and experiences with these issues. I am asking to speak with people who have expertise on these issues because of their jobs as well as people whose expertise comes from living in certain neighborhoods.

The details of the study are explained below. I would be glad to answer any questions you have.

\section{What Will You Have To Do?}

If you decide to take part in this project, I will ask you to talk with me for about an hour. We will find a time and place that are convenient for you to do this. I will ask your permission to record the interview. The interview will focus on these topics:

- Your impression of the neighborhood and the businesses in it

- Your opinions about where sexually-oriented businesses should be within cities

- The health issues faced by people who work at sexually-oriented businesses

At the interview, you will also be asked if you would be willing to recommend anyone to be interviewed. You will also be asked if you'd be willing to be contacted again in several months, to see if you'd be interested in looking over the conclusions the researcher is drawing from the interviews. You are under no obligation to do either of these things. Whether or not you recommend anyone or comment on the research will not affect your relationship with the interviewer.

\section{Are There Any Risks?}

Talking about your personal experiences or discussing sexually-oriented businesses may be uncomfortable for you. You do not have to take part in this study. If you do agree to take part, you could feel angry, sad, guilty, scared or embarrassed because of some of the questions I ask. You don't have to answer any questions you don't want to. And if you don't want to go on, you can stop at any point. If you are upset after the interview and would like to talk with someone, I can give you a list of organizations that may be able to help you with certain problems.

Other people may be interested to know whether you are participating in this study. For example, if you work at a club, others who work there may be curious about whether you decide to speak with me. Your decision is a private matter. I will not tell anyone 
whether I asked you to speak with me. I will also not tell anyone whether or you decided to be interviewed. You are welcome to discuss this information with anyone, but I will not share any information about study participants with people who ask me for it.

\section{What Will You Get In Return?}

Your participation will be greatly appreciated. You will have the opportunity to share your opinions about your work and/or your neighborhood, and your ideas will help the researcher draw conclusions about how neighborhood conditions could be improved. You will also have the opportunity to comment on her recommendations and suggest people or organizations who should know about what the study says.

Unfortunately, there is no money available to pay you for your participation. Both you and the researcher will be providing your time for free.

\section{How Will the Researcher Protect You?}

Your privacy is very important. I will do many things to protect you:

- I won't tell anyone whether or not you decide to take part in this study.

- You will be interviewed alone. What you tell me will be kept private.

- Your name and what you tell me in the interview will be kept private to the extent allowed by law. By "kept private," I mean that the names of people who take part in the study will not be given to anyone else. And it means that I will only reveal what you say in a way that no one could ever guess or know it was you who said it. If, in the course of the interview you disclose that you are, or are intending to, harm yourself or others, I am ethically and legally required to notify the appropriate authorities. If you know specific details of examples of these or any other illegal activities, you may prefer not to share them with me.

- Only staff from the research project will know what you say. If you found out about this project at a clinic or through a social service agency, no one from the clinic or the agency will know if you participated or what you say.

- Your name and other personal information, which I need in order to keep track of who I talk to, will be kept in a locked file cabinet or in a locked file on the computer so that no-one other than the research staff will be able to see it.

- When I write or talk about what we learned in this study, I will leave out details so no one will be able to tell whom I am talking about.

You are welcome to discuss your participation in the project with other people, but I will not.

\section{Any Questions?}

If you have any questions about this study, this form, or the interview, you can call me at 503.235.0610 or send an e-mail to moriah@pdx.edu. You can also contact the 
Human Subjects Committee of Portland State University about your rights as a research participant (someone who takes part in a study). The office is located at:

$$
\begin{aligned}
& \text { Unitus Bldg., 6th floor } \\
& 2121 \text { SW 4th Avenue } \\
& \text { Portland, OR } 97201
\end{aligned}
$$

The telephone number is (503) $725-4288$, or you can call toll-free to (877) $480-4400$, or send e-mail to: hsrrc@lists.pdx.edu. Their hours are 9:00 a.m. to 5:00 p.m.

\section{If I Participate, What Does It Mean?}

If you are willing to take part in the study by talking with me in an interview, it is my job as a researcher to make sure that:

- You have read and understand what this form says.

- You know that you do not have to take part in this study. And even if you agree, you can change your mind and stop at any time.

If you found out about this study at a clinic or from a service provider, you know that taking part in this study has nothing to do with the services you receive. If you agree to take part or if you say no, they won't know and it won't matter. They will treat you the same.

Thank you for taking the time to learn about the project!

If you are willing to participate in the project, please sign below to indicate your consent.

name-PRINTED 个

signature $\uparrow$

date $\uparrow$

please check here if you consent to have your interview recorded 
Appendix E:

\section{Categories by Analytical Axis and Spatial Scale}

\begin{tabular}{|c|c|c|c|c|}
\hline & & \multicolumn{3}{|c|}{ Axes of the situation } \\
\hline & & \multicolumn{3}{|c|}{ Category types } \\
\hline & & Location processes & Conflict processes & Health processes \\
\hline \multirow{4}{*}{ 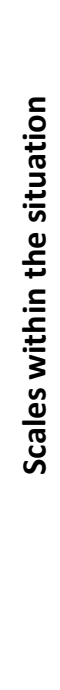 } & Club site & -- & $\begin{array}{l}\text { - Social incivilities } \\
\text { - Physical incivilities }\end{array}$ & - Job remains difficult \\
\hline & $\begin{array}{l}\text { Neighbor- } \\
\text { hood }\end{array}$ & $\begin{array}{l}\text { - Visibility/invisibility } \\
\text { - Club location } \\
\text { - Strip City }\end{array}$ & $\begin{array}{l}\text { neighborhood } \\
\text { - Neighborhood } \\
\text { socioeconomic } \\
\text { status }\end{array}$ & $\begin{array}{l}\text { - Neighborhood clubs are } \\
\text { better places to work }\end{array}$ \\
\hline & City & $\begin{array}{l}\text { - } \text { [Absence of planners] } \\
\text { - Strip City }\end{array}$ & $\begin{array}{l}\text { - Tension between } \\
\text { libertarian and } \\
\text { liberal } \\
\text { - Suburbs are more } \\
\text { resistant }\end{array}$ & $\begin{array}{l}\text { - Portland is a great place } \\
\text { to be a dancer }\end{array}$ \\
\hline & State & -- & -- & - [Absence of state] \\
\hline
\end{tabular}


Appendix F: Situational Map

\begin{tabular}{|c|c|}
\hline Individual human elements & Nonhuman elements/actants \\
\hline Concerned citizens & $\begin{array}{l}\text { Internet and availability of sexually explicit } \\
\text { material }\end{array}$ \\
\hline Politicians & Nightclubs \\
\hline Club owners & Music \\
\hline Dancers & Stripper clothes \\
\hline Collective human elements/actors & Implicated/silent actors/actants \\
\hline Association of Club Executives & Children exposed to sexual exploitation \\
\hline Neighborhood organizations & Race and class \\
\hline \multicolumn{2}{|l|}{ City of Portland incl. police } \\
\hline \multicolumn{2}{|l|}{ Orgs that propose or oppose ballot measures } \\
\hline \multicolumn{2}{|l|}{ Service organizations } \\
\hline Discursive constructions of human actors & Discursive constructions of nonhuman actants \\
\hline Family as sacred unit & Suburbs vs. city \\
\hline Representation of strippers in media & Portland as free thinking city \\
\hline Stripper as fallen woman & Downtown/city as bastion of vice \\
\hline Live and let live & $\begin{array}{l}\text { "Ghetto" neighborhoods with limited political } \\
\text { power }\end{array}$ \\
\hline Cowboy/frontier mentality & Secondary effects of strip clubs \\
\hline Artists and hippies & Oregon as smut capital \\
\hline \multicolumn{2}{|l|}{ Entrepreneurship } \\
\hline Political/economic elements & Sociocultural/symbolic elements \\
\hline Oregon state constitution & Men as consumers of sexuality \\
\hline Federal constitution & Men's sexuality as irrepressible \\
\hline Oregon court cases & All sexuality as irrepressible \\
\hline Attempted city ordinances & Suicide Girls \\
\hline Proposed ballot measures & Free speech \\
\hline \multicolumn{2}{|l|}{ High unemployment } \\
\hline \multicolumn{2}{|l|}{ Constrained labor opportunities for women } \\
\hline \multicolumn{2}{|l|}{ Lack of health insurance/safety net } \\
\hline Temporal elements & Spatial elements \\
\hline Burlesque revival & Concentration of clubs in certain neighborhoods \\
\hline Pole dance exercise trend & Clusters of adult businesses \\
\hline Increasing acceptability of tattoos and piercings & Young demographic of Portland \\
\hline \multicolumn{2}{|l|}{ Economic downturn } \\
\hline \multicolumn{2}{|l|}{ Post Sept. 11th } \\
\hline \multicolumn{2}{|l|}{ Nightlife } \\
\hline \multicolumn{2}{|l|}{ New clubs opening } \\
\hline Major issues/debates & $\begin{array}{r}\text { Related discourses } \\
\end{array}$ \\
\hline Is stripping obscene or is it art? & Sex-positive feminism \\
\hline Should state constitution be revised? & Anti-porn feminism \\
\hline Is stripping empowering or exploitative? & Girl power \\
\hline \multicolumn{2}{|l|}{ Does it disadvantage certain types of people? } \\
\hline \multicolumn{2}{|l|}{ Should strippers be paid a wage/unionize? } \\
\hline Do strip clubs hurt neighborhoods? & \\
\hline
\end{tabular}


Appendix G:

\section{Social Worlds Map}

\begin{tabular}{cl}
\hline Strip clubs \\
- $\quad$ Bartenders \\
- $\quad$ Bouncers \\
- $\quad$ Dancers \\
- Owners \\
- Bookers \\
Customers \\
$\circ \quad$ Regulars \\
$\circ \quad$ Occasional visitors \\
$\circ \quad$ Couples \\
$\circ \quad$ Girls' night out \\
$\circ \quad$ Boys' night out
\end{tabular}

\section{Sex industry}

- Owners

- $\quad$ Lingerie models

- $\quad$ Store clerks

- Bookstores

- Exotic dancers

Service industry workers

\section{Arts scene}

- Bands/musicians

- Freelancers/crafters

Government workers

- OLCC

- Planners

- Police

\section{Citizens}

- Homeowners

- Renters

- Businesses

- Involved citizens 


\section{Appendix H: Positional Map}

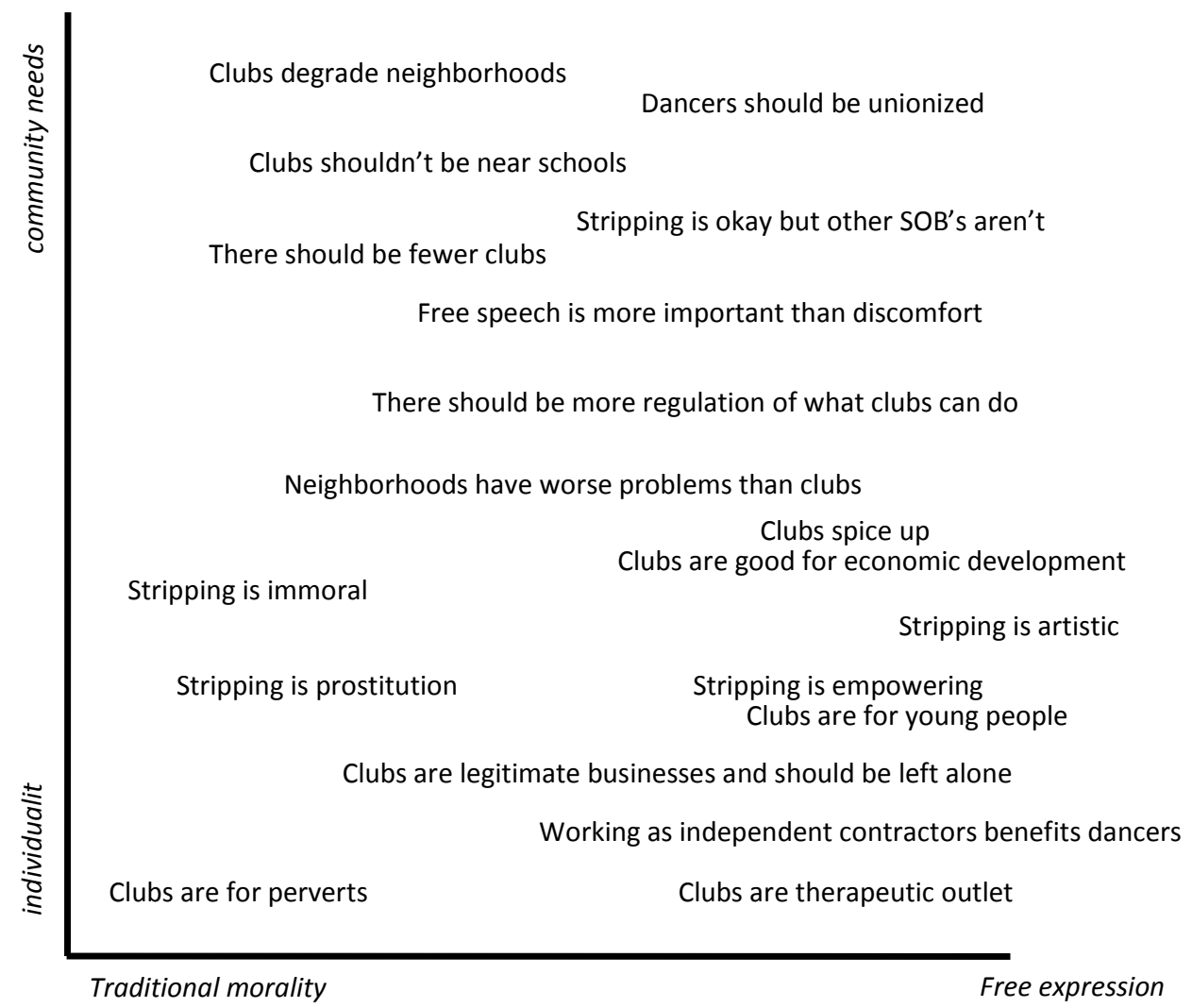

